\title{
The potential use of ultrasound-assisted bleaching in removing heavy metals and pigments from soybean oil using kinetic, thermodynamic and equilibrium modeling: Linear and nonlinear approach and error analysis
}

Elahe Abedi ( $\nabla$ elaheabedi1389@gmail.com )

Fasa University

Mohammad Javad Amiri

Fasa University

Mehran Sayadi

Fasa University of Medical Science

Research Article

Keywords: Adsorption, Modeling, Freundlich, Bentonite clay, Endothermic

Posted Date: February 23rd, 2021

DOI: https://doi.org/10.21203/rs.3.rs-160420/v1

License: (1) (i) This work is licensed under a Creative Commons Attribution 4.0 International License.

Read Full License 
1 The potential use of ultrasound-assisted bleaching in removing heavy metals and 2 pigments from soybean oil using kinetic, thermodynamic and equilibrium 3 modeling: Linear and nonlinear approach and error analysis

$5 \quad$ Elahe Abedi ${ }^{\mathrm{a}^{*}}$, Mohammad Javad Amiri $^{\mathrm{b}^{*}}$, Mehran Sayadi ${ }^{\mathrm{i}^{*}}$

6

${ }^{a}$ Department of Food Science and Technology, Faculty of Agriculture, Fasa Fasa. Iran. University, Fasa. Iran.

${ }^{b}$ Department of Water Engineering, Faculty of Agriculture, Fasa University,

14 E-mail addresses: elaheabedi1389@gmail.com; e.abedi@fasau.ac.ir; Tel.: +98 715

16 Mehran Sayadi: mehransayadi62@gmail.com 


\section{Abstract}

29 In this research, the sorption behavior (kinetic, isotherm and thermodynamic modeling) of heavy metals ( $\mathrm{Cu}$ (II) and Fe (II)) and pigments (carotenoid and

31 chlorophyll) on activated bentonite clay was investigated for soybean oil under 32 industrial (IBM) and ultrasonic bleaching method (UBM). The results indicated that a 33 nonlinear fitting approach with a higher coefficient of determination $\left(R^{2}\right)$ and lower Chi-square $\left(\chi^{2}\right)$ values was more appropriate to estimate kinetic and isotherm

列
parameters than the linear fitting approach. The adsorption of metal ions and pigments on activated bentonite clay under UBM was quite well by the pseudo-first-order model. In both bleaching methods, the equilibrium adsorption data follows the Freundlich isotherm model, presenting the sorption occurrence tends to be on a heterogeneous surface by multi-layer adsorption. The results indicated that the adsorption thermodynamics was endothermic nature and the process was spontaneous between 35 and $65{ }^{\circ} \mathrm{C}$.

Keywords Adsorption . Modeling . Freundlich . Bentonite clay . Endothermic.

\section{Introduction}

5 Soybean oil consumption rate increase consistently owing to the unique properties of its fatty acid profile mainly polyunsaturated fatty acids (PUFA $57 \%$ ), monounsaturated fatty acids (MUFA $22 \%$ ), and saturated fatty acids (SFA 15\%) (Abedi and Sahari 2014). Soybean oil is mostly consumed in main applications including, food (as salad, frying, cooking and shortening oil, as well as magerine oil), cosmetic, pharmaceutical, and biodiesel industries. According to global production of oils and fats (FAO-Trade and Markets Division, 2020), in the 2019/2020 crop year, soybeans were the important variety of oilseed in the world. That year, soybeans were 
53 produced (336.11) million metric tons, placed first grade in worldwide owing to fatty 54 acid profile, and also in vitamin E and A (Huth et al. 2015; Dai et al. 2016), followed 55 by rapeseed (68.2), sunflower oil (54.97), peanut (45.38), cotton seed (44.84), palm 56 kernel (19.85) and copra (5.86) million metric tons. In the United States, soybean oil 57 is the most consumed type of edible oil by volume. Canola oil came in second place, 58 followed by palm oil (https://www.statista.com/statistics/267271/worldwide-oilseed59 production-since-2008/). Further extraction of soybean oil from soya seeds using the 60 solvent extraction method, is purified using various series of sequential steps 61 consisting of degumming, neutralization, bleaching, and deodorization (Erickson 62 1995; More and Gogate 2018). Among all these steps, bleaching is a leading step as 63 adsorption operation with emphasis aims at removing pigments, residual soaps and 64 residual phosphatides, oxidation products and trace metals using activated clay 65 (Erickson 1995; More and Gogate 2018), in order to reduce their deleterious impact 66 on oil stability (Abedi et al. 2015).

67 The relevant pigments found in vegetable oils are the chlorophylls and carotenoids.

68 Carotenoids are yellow-red pigment, which can be categorized into carotenes and 69 xanthophylls. Meanwhile, the $\beta$ - carotene is the most predominant carotenoid in crude 70 vegetable oils. The carotenoids removal is valuable to enhance the visual appearance 71 of bleached oil for the consumer; however its permanence improves oxidative stability 72 of the oil. However, chlorophyll removal is more significant than the carotenoids, 73 which heating cause to decompose it into pheophytins, resulting oil with opaque and 74 dark color appearance. The main step in color reduction occurs in bleaching process. 75 The soybean oil bleaching process must be conducted to eliminate chlorophyll, which 76 is engaged in photosensitized oxidation, and to break down peroxides into lower 
molecular weight carbonyl compounds that are removed with deodorization (Proctor and Brooks 2005; Hussin et al. 2011; Abedi et al. 2020a, b).

Normal amount of chlorophyll in crude soybean oil are in the range of 100 to $200 \mathrm{ppb}$.

Erickson evaluated the reduction in chlorophyll in oil processing would be expected to be in the range of 10 to $20 \mathrm{ppb}$. Acceptable limit levels of chlorophyll and peroxide value should be $50 \mathrm{ppb}$ content and a zero peroxide value to maintain the optimal oxidative stability of the finished oil. Chlorophyll levels more than $50 \mathrm{ppb}$ following bleaching may lead to a green/gray color in the refined oil. This faint green tinge is hindered by yellow and red colors. The final step of deodorization may diminish the yellow and red to values low enough to permit the green/gray color to be apparent. Hence, the oil is rebleached if the green/gray color becomes problematic (Erickson 1995; More and Gogate 2018).

The occurrence of trace metals including copper $(\mathrm{Cu})$, iron $(\mathrm{Fe})$, cobalt $(\mathrm{Co})$, nickel $(\mathrm{Ni})$, manganese $(\mathrm{Mn})$, calcium $(\mathrm{Ca})$, and magnesium $(\mathrm{Mg})$ in edible oils, not only are toxic, but also can enhance the rate of oil oxidation, affecting the oil's shelf life and storage stability (Proctor and Brooks 2005).

The adsorption process comprise of attaching contaminants to the surface of activated clay in two ways: chemisorption and physisorption. The chemisorption, the contaminant is bonded on the surface of activated clay via ionic bonding or covalent bond, caused by exchange of electrons between the sorbent surface and contaminant whereas in the physisorption process was conducted by van der Waals bonding with no substantial manipulation happen in electronic structure (Didi et al. 2009).

Application of ultrasonic in oil refining process such as olive, rapeseed, soybean, , palm, and canola compared with the traditional has several advantages mainly low energy consumption, higher throughput and shorter processing time (Jahouach-Rabai 
103 Asgari et al. 2017, 2018; Icyer and Durak 2018; Roohi et al. 2019). However, few

104 surveys have reported the adsorption kinetics behavior and thermodynamic aspects

105 associated with the compounds adsorption of oils on sorbent surface. Kinetics,

106 equilibrium and thermodynamics of the bleaching step of rice bran oil (Pohndorf et al.

107 2016), soybean oil (Abedi et al. 2020a), palm oil (Silva et al. 2013; Almeida et al.

108 2019) and olive oil (Asgari et al. 2018) were investigated. To understand the

109 mechanism of heavy metals and pigments removal from edible vegetable oils under

110 commercial bleaching, the insight into the adsorption kinetic, isotherm and

111 thermodynamic models is necessary. In this regard, linear and nonlinear forms of

112 kinetic, isotherm and thermodynamic models of oil bleaching under commercial and

113 ultrasonic are used to predict model parameters. Although several kinds of research

114 have been performed on target pollutants adsorption by bleaching clays either in

115 natural or acid-activated form (Su et al. 2013; Abedi et al. 2015; Icyer and Durak

116 2018), low studies can be found in the literature to characterize adsorption mechanism

117 in terms of operating parameters (Asgari et al. 2018) (Abedi et al. 2020a).

118 Therefore, the overarching aim of this study is to evaluate the performance of

119 ultrasonic bleaching method (UBM) in refining soybean oil from heavy metals $(\mathrm{Cu}$

120 (II) and $\mathrm{Fe}$ (II)) and pigments (carotenoid and chlorophyll) by activated bentonite clay

121 in term s of ultrasonic power (25 and $40 \mathrm{kHz})$, clay content $(0.5-2 \%)$, temperature

$122\left(35-65^{\circ} \mathrm{C}\right)$, and time $(0-30 \mathrm{~min})$ as compared with industrial bleaching method

123 (IBM). The specific aims of this study are listed below: (1) compare the linear and

124 nonlinear forms of equilibrium isotherms models (Langmuir, Freundlich, and

125 Tempkin) to determine the accurate design parameters of metals and pigments

126 adsorption, (2) compare the linear and nonlinear forms of kinetic models (pseudo- 
127 first-order, pseudo-second-order, and intraparticle diffusion) to elucidate the

128 adsorption mechanism, (3) Analyze the experimental data to a better comprehend the

129 bleaching time effect on the adsorption of metals and pigments via thermodynamic

130 parameters such as standard enthalpy $\left(\Delta H^{o}\right)$, standard entropy $\left(\Delta S^{o}\right)$, and standard

131 free energy $\left(\Delta G^{o}\right)$.

132

133 Material and Methods

134 Materials

135 Neutralized soybean oil for bleaching process was purchased from Narges Oil

136 Company (Shiraz, Fars Province, Iran). All the chemicals used in this work were

137 purchased from Merck Co. (Darmstadt, Germany) and were analytical grade.

139 Bleaching process

140 Bleaching experiments were carried out by adding various amounts of activated

141 bentonite clay $(0.5,1,1.5$ and $2 \%(\mathrm{w} / \mathrm{v}))$ to $50 \mathrm{~mL}$ oil sample. The oil sample is

142 treated by ultrasonic horn. Horn ultrasonic bleaching process was carried out by the

143 ultrasonic processor UP400S Hielscher (400 W, 25, and $40 \mathrm{kHz}$ ) at amplitude 100\%

144 at a bleaching time of between 0 and $30 \mathrm{~min}$ and a bleaching temperature of $35,45,55$

145 and $65^{\circ} \mathrm{C}$ in batch conditions. An immersible probe is dipped in the liquid at the $1 \mathrm{~cm}$

146 top of the tank and emits the sound vibration into the solution via a titanium alloy rod

$14714 \mathrm{~mm}$ diameter. The reactor is a cylindrical jacket glass vessel (volume $100 \mathrm{ml}$ ).

148 After agitation, the mixture was filtered through the centrifuge at $14000 \mathrm{rpm}$ for 20

$149 \min$ and the supernatant solution was further filtered using Whatman 42 filter paper.

150 The bleaching under the mentioned condition without the ultrasonic process is

151 considered as control (IBM). All tests were performed in triplicate. 
153 Mineral measurement

154 Atomic absorption spectrophotometry (AA-680 Shimadzu, Kyoto, Japan) was

155 employed to determine the residual $\mathrm{Fe}(\mathrm{II})$ and $\mathrm{Cu}(\mathrm{II})$ concentrations in bleached oil

156 during the temperature $\left(35,45,55\right.$ and $\left.65^{\circ} \mathrm{C}\right)$ and time $(0,5,10,15,20,25$ and 30

$157 \mathrm{~min}$ ), following the AOAC official method 999.11. Briefly, $5 \mathrm{~g}$ sample was dried at

$158105{ }^{\circ} \mathrm{C}$ for $24 \mathrm{~h}$. Then, samples were ashed at $450{ }^{\circ} \mathrm{C}$ for $6 \mathrm{~h}$ under gradual increase

$159\left(<50{ }^{\circ} \mathrm{C} / \mathrm{h}\right)$. The resultant white ash was dissolved in $3 \mathrm{ml} \mathrm{HCl}$ and $\mathrm{HNO}_{3}(3 / 1$ ratio)

160 and valium were adjusted to $25 \mathrm{ml}$ using deionized water. The final solution was

161 filtered via filter paper (Whatman, Grade 1) and the concentrations of the elements (Fe

162 and $\mathrm{Cu}$ ) were measured as previously described (Vafaei et al. 2018). All assays were

163 carried out in 5 replicates and mineral contents were expressed in $\mathrm{mg} / \mathrm{kg}$.

164 The effect of ultrasonication on the reduction of particle size and cleaning of surface

165 is presented in Fig. 1.

166

167 Pigments measurement

168 The chlorophyll and carotenoid content of bleached oils were measured according to

169 the method proposed by (Abedi et al. 2015). In this regard, $7.5 \mathrm{~g}$ of oil was dissolved

170 in cyclohexane up to a final volume of $25 \mathrm{~mL}$. Then, chlorophyll and carotenoid level

171 of bleached oils was recorded by a UV-VIS Spectrophotometer (UV S-2100; Scinco,

172 Seoul, South Korea) at 670 and $470 \mathrm{~nm}$, respectively, using the following Eq (1 and 173 2):

174 chlorophyll $\left(\frac{\mu g}{\mathrm{~kg}}\right)=A 670 \times \frac{10^{9}}{613} \times 100 \times d$

175 carotenoid $\left(\frac{m g}{k g}\right)=A 470 \times \frac{10^{6}}{2000} \times 100 \times d$ 


\section{$177 \quad$ Kinetic studies}

178 In order to examine the effect of bleaching time (0-30 min) on adsorption of metal ion 179 and pigments onto activated bentonite clay under IBM and UBM, $1 \%$ of bleaching 180 clay at $65^{\circ} \mathrm{C}$ was selected. In this regard, $1 \%(\mathrm{w} / \mathrm{v})$ of activated bentonite clay was

181 added to $50 \mathrm{~mL}$ oil samples containing metals and pigments at $65^{\circ} \mathrm{C}$. The solution

182 was agitated for varying amounts of time $(5,10,15,20,25$, and $30 \mathrm{~min})$, followed by

183 filtration. Finally, the concentrations of metal ions and pigments were measured by 184 atomic absorption spectrophotometry and UV-VIS Spectrophotometer, respectively.

185 The amount of metals and pigments adsorbed at various time intervals and at 186 equilibrium time was calculated by the following equation: $q_{t}=\frac{\left(C_{o}-C_{t}\right) \times V}{m}$

$$
q_{e}=\frac{\left(C_{o}-C_{e}\right) \times V}{m}
$$

189 where $C_{t}$ is the amount of metals and pigments adsorbed at any time $(t), C_{o}$ and $C_{e}$

190 are the initial and equilibrium concentrations of metals and pigments, respectively.

191 The volume of soybean oil solution in L is represented by $(V)$ and $m$ is the amount 192 of activated bentonite clay in g. The kinetics of metal ions and pigments onto 193 activated bentonite clay can be determined with three common kinetic models. In this 194 study, the kinetic of metal ions and pigments adsorption within activated bentonite 195 clay under IBM and UBM was evaluated with the pseudo-first-order, pseudo-second196 order and the intraparticle diffusion models. For the analysis of data, the linear and 197 nonlinear forms of these models were used and the results were compared. The 198 nonlinear forms of pseudo-first-order, pseudo-second-order, and the intraparticle 199 diffusion models can be expressed by Eqs. (5) - (7), respectively (Gil et al. 2018). 
$201 \quad$ Pseudo-second-order model $: q_{t}=\frac{q_{e}{ }^{2} k_{2} t}{1+q_{e} k_{2} t}$

202 Intraparticle diffusion model $: q_{t}=k_{p} t^{0.5}+C$

203 where $q_{e}\left(\mathrm{mg} \mathrm{g}^{-1}\right)$ and $q_{t}\left(\mathrm{mg} \mathrm{g}^{-1}\right)$ are the adsorption capacities of activated bentonite 204 clay under IBM and UBM at equilibrium time and time $t$, respectively. The $k_{1}, k_{2}$ 205 and $k_{p}$ are the pseudo-first-order rate constant $\left(\mathrm{min}^{-1}\right)$, pseudo-second-order rate 206 constant $\left(\mathrm{gmg}^{-1} \mathrm{~min}^{-1}\right)$, and intraparticle diffusion model rate constant $\left(\mathrm{mgg}^{-1} \mathrm{~min}^{-0.5}\right)$, 207 respectively, $\mathrm{t}(\mathrm{min})$ is the bleaching time and $\mathrm{C}$ is the intercept of intraparticle 208 diffusion model. The linear forms of pseudo-first-order, pseudo-second-order, and the 209 intraparticle diffusion models can be calculated according to Eqs. (8) - (10), 210 respectively (Batool et al. 2018).

211 Pseudo-first-order $\bmod e l: \log \left(q_{e}-q_{t}\right)=\log q_{e}-k_{1} t$

212 Pseudo-second-order model $: \frac{t}{q_{t}}=\frac{t}{q_{e}}+\frac{1}{k_{2} q_{e}{ }^{2}}$

213 Intraparticle diffusion $\bmod e l: \log q_{t}=\log \left(k_{p} C\right)+0.5 \log t$

\section{Equilibrium studies}

216 To study the influence of bleaching clay usage on the adsorption efficiency, $50 \mathrm{~mL}$ 217 soybean oil solutions containing metal ions and pigments with various activated 218 bentonite clay dosages $(0.5,1,1.5$, and $2 \%(\mathrm{w} / \mathrm{v}))$ were agitated at $65{ }^{\circ} \mathrm{C}$ for $30 \mathrm{~min}$. 219 After filtration, the residual concentrations of metal ions and pigments were measured 220 by atomic absorption spectrophotometry and UV-VIS Spectrophotometer, 221 respectively. To distinguish the distribution of metal ions and pigments between 
222 solution and solid phase, the Langmuir, Freundlich, and Tempkin models in nonlinear

223 forms were used as Eqs. 11 to 13 (Aljeboree et al. 2017; Hashemi and Amiri 2020).

224 Langmuir model $: q_{e}=\frac{K_{L} q_{m} C_{e}}{\left(1+K_{L} C_{e}\right)}$

225 Freundlich model $: q_{e}=K_{F}\left(C_{e}^{1 / n}\right)$

226 Tempkin model $: q_{e}=\frac{R T}{b_{T}} \ln \left(A_{T} C_{e}\right)$

227 where $q_{e}$ is the amount of metals and pigments adsorbed in solid phases $\left(m g g^{-1}\right), q_{m}$

228 is the maximum adsorption capacity $\left(\mathrm{mgg}^{-1}\right), C_{e}$ is the amount of bleaching clay in

229 the solution $\left(m g L^{-1}\right), K_{F}$ is the Freundlich coefficient corresponded to the adsorption

230 capacity $\left(\left(m g g^{-1}\right)\left(\mathrm{Lmg}^{-1}\right)^{1 / n}\right), n$ is the constant corresponded to the adsorption

231 intensity, $K_{L}$ is the Langmuir coefficient corresponded to the energy of adsorption

$232\left(\mathrm{Lmg}^{-1}\right), T$ and $R$ are the absolute temperature $(K)$ and the universal constant

$233\left(8.314 \mathrm{Jmol}^{-1} \mathrm{~K}^{-1}\right)$, respectively, $A_{T}$ is the Temkin isotherm constant related to the

234 maximum binding energy $\left(\mathrm{Lmg}^{-1}\right), b_{T}$ is the Temkin constant corresponded to the

235 heat of sorption $\left(\mathrm{Jmol}^{-1}\right)$. The linear forms of the Langmuir, Freundlich, and

236 Tempkin models can be calculated according to Eqs. (14) - (16), respectively (Nassar 237 2010).

238 Langmuir model $: \frac{C_{e}}{q_{e}}=\frac{1}{K_{L} q_{m}}+\frac{C_{e}}{q_{m}}$

$239 \quad$ Freundlich model $: \ln q_{e}=\frac{1}{n} \ln C_{e}+\ln K_{F}$

$240 \quad$ Tempkin model $: q_{e}=\frac{R T}{b_{T}} \ln \left(A_{T}\right)+\frac{R T}{b_{T}} \ln C_{e}$

\section{Thermodynamic Studies}


242 In order to determine whether the adsorption process is spontaneous or not, the

243 prediction of the thermodynamic parameters such as standard enthalpy $\left(\Delta H^{o}\right)$,

244 standard entropy $\left(\Delta S^{o}\right)$, and standard free energy $\left(\Delta G^{o}\right)$ is necessary. These

245 thermodynamic parameters can be predicted from the following equations (Nassar

246 2010; Arshadi et al. 2014; Aljeboree et al. 2017; Gil et al. 2018) :

$247 \quad \ln k_{d}=\frac{\Delta S^{o}}{R}-\frac{\Delta H^{o}}{R T}$

$248 \quad k_{d}=\frac{q_{e}}{C_{e}}$

$249 \quad \frac{d \ln k_{d}}{d t}=\frac{\Delta H^{o}}{R T^{2}}$

$250 \Delta G^{o}=\Delta H^{o}-T \Delta S^{o}$

$251 \Delta G^{o}=-R T \ln k_{d}$

252 where $k_{d}$ is the equilibrium constant, $q_{e}$ is the concentrations of metal ions and 253 pigments adsorbed on activated bentonite clay at equilibrium $\left(m g L^{-1}\right), C_{e}$ is the 254 equilibrium concentration of metal ions and pigments in the solution $\left(m g L^{-1}\right), R$ is 255 the ideal gas constant $\left(8.314 \mathrm{Jmol}^{-1} \mathrm{~K}^{-1}\right), T$ is the temperature $(K)$.

Goodness of fit

258 To check the performance of kinetic and isotherm models that best describes the 259 interaction between the activated bentonite clay and metal ions as well as pigments, 260 two statistical criteria is used. The coefficient of determination $\left(R^{2}\right)$ and Chi-square 261 statistic test $\left(\chi^{2}\right)$ have been used to check model fit. These criteria are given as 262 (Hashemi and Amiri 2020): 
$264 \quad R^{2}=\frac{\sum_{i=1}^{n}\left[\left[\left(q_{e}\right)_{c a l}-\left(\overline{q_{e}}\right)_{c a l}\right]\left[\left(q_{e}\right)_{\exp }-\left(\overline{q_{e}}\right)_{\exp }\right]\right]}{\sum_{i=1}^{n}\left[\left(q_{e}\right)_{\exp }-\left(\overline{q_{e}}\right)_{\exp }\right]^{2} \sum_{i=1}^{n}\left[\left(q_{e}\right)_{c a l}-\left(\overline{q_{e}}\right)_{c a l}\right]^{2}}$

$265 \quad \chi^{2}=\sum_{i=1}^{i=N} \frac{\left(q_{e, \exp }-q_{e, c a l}\right)^{2}}{q_{e, c a l}}$

266 where $q_{e, \text { exp }}$ is the equilibrium adsorption capacity obtained from the measured data

$267\left(m g g^{-1}\right), q_{e, c a l}$ is the equilibrium adsorption capacity obtained from the models $268\left(m g g^{-1}\right),\left(\overline{q_{e}}\right)_{c a l}$ and $\left(\overline{q_{e}}\right)_{\exp }$ are the average of the calculated and observed 269 equilibrium adsorption capacity, respectively. The higher $\left(R^{2}\right)$ and lower $\left(\chi^{2}\right)$ 270 values show a better agreement between the experimental data and model predictions.

\section{Statistical analysis}

273 The statistical software package, Minitab software Version 16, was used for the 274 regression analysis of the experimental data and to obtain the regression coefficients.

275 Statistical assumptions mainly normality of data distribution and homogeneity of 276 variances were determined by Shapiro-Wilk and Levene's tests, respectively. Then, 277 oneway and two-way analysis of variance ANOVA were performed for 278 physicochemical and bleaching data (factors and products), respectively to investigate 279 the effect of bleaching methods on considered parameters. The adsorption 280 experiments were conducted as a function of four major factors namely frequency ( 25 281 and $40 \mathrm{kHz})$, time $(0,5,10,15,20,25$ and $30 \mathrm{~min})$, clay content $(0.5,1,1.5$ and $2 \%)$ 282 and temperature $\left(35,45,55\right.$ and $\left.65{ }^{\circ} \mathrm{C}\right)$. Bleaching process was full filed at 283 temperature $65^{\circ} \mathrm{C}$ with the speed of $600 \mathrm{rpm}$. The Least Significant Difference (LSD) 284 test was utilized for post -hoc analyses. 
Results and Discussion

The effect of sonication on metal ions and pigments adsorption

The concentrations of heavy metals including $\mathrm{Fe}(\mathrm{II})$ and $\mathrm{Cu}(\mathrm{II})$ ions and pigments namely carotenoids and chlorophyll in bleached oil under industrial and

290 sonication process was presented in Table 1-4. The adsorption trends of metals and 291 pigments on activated clay under ultrasonication were significantly $(\mathrm{p}<0.05)$ more than industrial condition at same temperature. Trace metals and pigments were reduced under cavitation in the suspension containing clay particle due to some reasons:

1) pyrolytic reactions and thermal decomposition inside or near the bubbles; 2) radical reactions following by mainly hydroxyl and free radicals formation during ultrasonic processing could have damaged the carotenoid and chlorophyll structure, inducing sonochemical degradation (Tiwari et al. 2008; Abedi et al. 2015).

299 Meanwhile, the concomitant consumption of clay and sonication could have promoted 300 a synergic effect on the reduction of pigment content and metals; 3) in order to 301 initiation acoustic cavitation, a surface require for generation of nuclei bubbles. This 302 surface should not be dissolved in fluid, which can include container wall, fluid 303 contamination and clay particles. Bubbles grow when exposure to the pressure lower 304 than threshold pressure. Numerous parameters can affect threshold pressure mainly, 305 applied ultrasound intensity and frequency, the presence of fine particles and gases in 306 the liquid (Niazi et al. 2014; Abedi et al. 2015, 2017). According to (Roohi et al. 307 2019), clay particles might reduce the threshold pressure and accelerate the bubbles 308 cavitation. 4) Sonication at various concentrations of solids, causing a release of 309 energy due to the collapse of the cavitation bubbles (Farmer et al. 2000). The 310 cavitation phenomenon simply produces very high-velocity particle-to-particle 
311 collisions (Farmer et al. 2000; Abedi et al. 2017) and induces high shear forces,

312 macro-turbulence and perturbation in microporous particles, and finally, causing the

313 reduction in the particle size, increasing surface area and surface cleaning effect. The

314 reduction in the particle size of the clays is one of the other application of sonication

315 which were evaluated by (Wiewióra et al. 2003; Franco et al. 2004; Pérez-Maqueda et

316 al. 2005; Pérez-Rodríguez et al. 2006; Poli et al. 2008; Sompech et al. 2012; Ali et al.

317 2014; Pradhan et al. 2016; Retamal Marín et al. 2018). Moreover, cavitation at the

318 liquid-solid interface leads to surface peeling, erosion, particle breakdown, thus,

319 ultrasonic of a suspension containing particles can constantly produce new surfaces of

320 clay ready for absorbing of impurities, increasing mass transfer of oil pigments and

321 trace metals on clay microporous surface particles (Farmer et al. 2000). Cavitation in

322 suspension containing suspended powder particles is divided into two categories: i)

323 cavitation in suspension containing large particles generates shear stress and shock

324 waves, which eventually result in their fragmentation while cavitation in suspension 325 containing tiny particles may cause particles collisions and particle abrasion 326 (Thompson and Doraiswamy 1999; Zhao et al. 2007; Abedi et al. 2015)

Effect of time and temperature of sonication on metal ions and pigments adsorption

331 Regarding to obtained results in Table 1-4, there are substantial $(\mathrm{P}<0.05)$ differences 332 among treatments (ultrasonic frequency, and treatment temperature as well as time) 333 on the reduction of metals and pigments. (Jahouach-Rabai et al. 2008) and (Abedi et 334 al. 2015) revealed that the collapse of bubbles and cavitation happen when the oil is 335 treated by sonication upon a period of time greater than $20 \mathrm{~min}$. In mentioned studies, 336 the changes in pigment were observed at range 20-30 min. Temperature has a direct 
impact on the kinetics of adsorption. In general, every $10{ }^{\circ} \mathrm{C}$ rise in temperature 338 doubles the reaction rate (the Van Hoff rule). The optimal temperature range for oil 339 bleaching is $85-120{ }^{\circ} \mathrm{C}$ depending on oil type and clay activity (i.e. residual and 340 surface acidity) (Proctor and Brooks 2005).

341 According to Table 2, the iron and cupper as well as pigments elimination in soybean 342 oil medium improved with increasing the temperature from 35 to $65^{\circ} \mathrm{C}$ under IBM 343 and UBM conditions. With increasing $10{ }^{\circ} \mathrm{C}$ in temperature range $\left(35-65{ }^{\circ} \mathrm{C}\right)$, the 344 elimination of iron and cupper in IBM, UBM-40 kHz, and UBM-25 kHz conditions 345 were about in range (3-24\% and $12.5-24 \%),(22.5-100 \%$ and $15-53 \%)$ and (42.5$346100 \%$ and $53-100 \%$ ), respectively. The percent reduction of carotenoids were 347 determined in range $(6.97-25.3),(20.7-70.5)$ and $(38.1-51.1)$ while chlorophylls was 348 recorded in range (9.2-18.3), (24.8-37.8) and (22.9-32.3) following IBM, UBM-40 $349 \mathrm{kHz}$, and UBM-25 kHz conditions, respectively. The adsorption of $\mathrm{Fe}(\mathrm{II})$ and $\mathrm{Cu}(\mathrm{II})$ 350 ions on activated clay enhanced with increasing the temperature and time of bleaching 351 process in both of industrial and ultrasonic conditions. In general, doubles the reaction 352 rate occur with $10{ }^{\circ} \mathrm{C}$ rise in temperature (the Van Hoff rule). The optimal 353 temperature for the adsorption of polar compounds such as trace metals and pigment 354 adsorption (chlorophyll and carotenoid) are around $60-80{ }^{\circ} \mathrm{C}$ and $100-120{ }^{\circ} \mathrm{C}$, 355 respectively (Proctor and Brooks 2005).

356 The most considerable effect of adsorption was observed for sonication at higher 357 temperature $\left(65^{\circ} \mathrm{C}\right)$ and time $(30 \mathrm{~min})$ due to occurrence of cavitations and facilitate 358 in particles size reduction (Ali et al. 2014). The exfoliation and delamination 359 improved due to cavitation and natural evaporation bubbles of the water at this 360 temperature (Ali et al. 2014). Temperature had contradictory effect as follow; as the 361 temperature of the solutions rises, bubbles generate and grow quickly, which acts a 
cushion which lead to reduce violence of bubbles collapse as a result of inhibit the

363 successful transfer of acoustic energy (Thompson and Doraiswamy 1999), while the

364 evaporation of water bubble in oil sample as a result of increasing temperature induce

365 to decrease inside vapour tension and accelerate the cavitation with higher the

366 violence of the collapses (Ali et al. 2014; Abedi et al. 2015, 2017). The increase in

367 temperature can decrease threshold of cavitation by reduction in the oil viscosity.

368 (Santos et al. 2005) and (Fasina and Colley 2008) illustrate viscosity variation as a

369 function of temperature. According to the Arrhenius model (Eq. 1), the viscosity of an

370 oil reduces by approximately $30 \%$ for each $10{ }^{\circ} \mathrm{C}$ rise in temperature due to a higher

371 thermal movement among molecules, reducing intermolecular forces, making flow

372 among them easier and reducing viscosity (Santos et al. 2005).

373

$\mu=A \times \exp \left[\frac{E_{a}}{R T}\right]$

374 where $\mu$ is the rate constant namely: the collision or frequency factor, $E_{a}$ is the

375 activation energy $\left(\mathrm{J} \mathrm{mol}^{-1}\right), A$ is the pre-exponential factor, $R$ is the universal gas 376 constant $\left(8.314 \mathrm{Jmol}^{-1} \mathrm{~K}^{-1}\right), T$ is the absolute temperature $(K)$.

The effect of frequency of sonication on metal ions and pigments adsorption

379 The frequency is considered as one the main parameter of the ultrasound for 380 improving cavitation bubbles. An increase in the frequency from 25 to $40 \mathrm{kHz}$ of

381 sonication remarkably decreased the reduction rate of pigment discoloration and metal 382 absorption on activated clay (Table 1-4)

383 1) Cavitation yield decline as frequency increases, thence scattering and attenuation of 384 sound waves occur. 
385 2) The formation of cavitation bubbles accelerate at the lower frequency, the formed 386 bubble size maximize to the largest size $(60-100 \mu \mathrm{m})$ and their life time minimized; 387 therefore, bubbles collapse take place very quickly, causing the formation of a 388 comparatively large amount of heat and shock wave (Priego-Capote and De Castro 389 2004; Proctor and Brooks 2005; Kulkarni and Rathod 2014; Abedi et al. 2017; Roohi 390 et al. 2019). Regarding the results from (Merouani et al. 2013) and (Brotchie et al. 391 2009) mean size along with range (mean of the distribution) of active bubble becomes 392 smaller, when the ultrasound frequency increases for all employed acoustic 393 amplitudes. 3) The generation of unstable cavitation facilitates at lower frequency, 394 leading to violent collapse of the cavitation bubbles and locally high temperatures and 395 pressures (up to $50 \mathrm{MPa}$ or even higher) that conduct more rapid agitation and mass 396 transfer, whereas moderate physical impacts, namely microstreaming, are the major 397 effects of ultrasonic waves at high frequency (Vilkhu et al. 2008; Brotchie et al. 2009; 398 Kulkarni and Rathod 2014; Abedi et al. 2015; Asgari et al. 2018). 4) The bubble 399 formation accelerates further increase acoustic frequency, producing the high number 400 of bubbles, which acts as a barrier throughout the liquid suspension. The collapse of 401 cavitation bubbles reduced owing to inhibit the successful transfer of acoustic energy 402 (Priego-Capote and De Castro 2004; Merouani et al. 2013; Abedi et al. 2017).

403 The adsorptions concentration of $\mathrm{Fe}(\mathrm{II})$ and $\mathrm{Cu}(\mathrm{II})$ elements in all temperatures and 404 times in frequency $25 \mathrm{kHz}$ were considerable $(\mathrm{p}<0.05)$ higher than $40 \mathrm{kHz}$ (Table 1 $4052)$.

\section{Kinetic results}

409 The contact time is a key parameter in the adsorption process, especially for the 410 adsorption of metal ions and pigments of soybean oil bleaching (Abedi et al. 2020a), 
411 consequently the correlations between reaction time and adsorption kinetics were 412 studied in terms of pseudo-first-order, pseudo-second-order, and intraparticle 413 diffusion models in the range of 0-30 min and the results are reported in Tables 5-8.

414 The adsorption of metal ions and pigments on activated bentonite clay under UBM 415 was rapid during the first 20 min and can be described quite well by the pseudo-first416 order model. The $\mathrm{R}^{2}$ values of the pseudo-first-order model for the adsorption of 417 heavy metals (Cu (II) and Fe (II)) and pigments (carotenoid and chlorophyll) onto the 418 activated bentonite clay under IBM and UBM were higher than those computed by 419 other models $\left(\mathrm{R}^{2}>0.93\right)$. Moreover, $\chi^{2}$ values of the pseudo-first-order model under 420 IBM and UBM were lower than those computed by other models. The good 421 agreement of pseudo-first order model with heavy metals ( $\mathrm{Cu}$ (II) and $\mathrm{Fe}$ (II)) and 422 pigments (carotenoid and chlorophyll) adsorption indicates that the adsorption is 423 physisorption (Arshadi et al. 2014; Amiri et al. 2016, 2018). It can be clearly seen that 424 the intraparticle diffusion model also played a non-negligible role in the adsorption of 425 metal ions and pigments on activated bentonite clay under IBM and UBM (see Tables 426 5-8). According to the intraparticle diffusion model, the adsorption of metal ions and 427 pigments on activated bentonite clay under IBM and UBM can be divided into three 428 main steps. In step I, the metal ions and pigments diffused to the external surface and 429 occupied some adsorption sites of activated bentonite clay quickly. In step II, the 430 metal ions and pigments were adsorbed gently due to the intraparticle diffusion and 431 reached equilibrium in the final step (Amiri et al. 2018). In all cases, a nonlinear 432 fitting approach with a higher coefficient of determination $\left(R^{2}\right)$ and lower Chi-square $433\left(\chi^{2}\right)$ values was more appropriate to estimate kinetic parameters than the linear 434 fitting approach. The rate constants of the pseudo-first-order model for the adsorption 435 of heavy metals (Cu (II) and Fe (II)) and pigments (carotenoid and chlorophyll) onto 
436 the activated bentonite clay were in the order of UBM-25 kHz $\left(0.059 \mathrm{~min}^{-1}\right.$ for Fe(II), $4370.062 \mathrm{~min}^{-1}$ for $\mathrm{Cu}(\mathrm{II}), 0.055 \mathrm{~min}^{-1}$ for carotenoid, $0.068 \mathrm{~min}^{-1}$ for chlorophyll) $>$ 438 UBM-40 kHz (0.056 $\mathrm{min}^{-1}$ for $\mathrm{Fe}(\mathrm{II}), 0.053 \mathrm{~min}^{-1}$ for $\mathrm{Cu}(\mathrm{II}), 0.05 \mathrm{~min}^{-1}$ for carotenoid, $4390.058 \mathrm{~min}^{-1}$ for chlorophyll $)>\operatorname{IBM}\left(0.053 \mathrm{~min}^{-1}\right.$ for $\mathrm{Fe}(\mathrm{II}), 0.051 \mathrm{~min}^{-1}$ for $\mathrm{Cu}(\mathrm{II})$, $440 \quad 0.043 \mathrm{~min}^{-1}$ for carotenoid, $0.056 \mathrm{~min}^{-1}$ for chlorophyll). The greater rate constant of 441 the pseudo-first-order model shows that the adsorption of heavy metals and pigments 442 onto activated bentonite clay under UBM-25 kHz is more suitable. Moreover, the 443 calculated adsorption capacities by the pseudo-first-order model for the adsorption of 444 heavy metals and pigments onto the activated bentonite clay were in the order of 445 UBM-25 kHz (0.0058 $\mathrm{mg} \mathrm{g}^{-1}$ for $\mathrm{Fe}(\mathrm{II}), 0.0023 \mathrm{mg} \mathrm{g}^{-1}$ for $\mathrm{Cu}(\mathrm{II}), 0.426 \mathrm{mg} \mathrm{g}^{-1}$ for 446 carotenoid, $29.77 \mathrm{mg} \mathrm{g}^{-1}$ for chlorophyll $)>\mathrm{UBM}-40 \mathrm{kHz}\left(0.0054 \mathrm{mg} \mathrm{g}^{-1}\right.$ for $\mathrm{Fe}(\mathrm{II})$, $4470.0022 \mathrm{mg} \mathrm{g}^{-1}$ for $\mathrm{Cu}(\mathrm{II}), 0.397 \mathrm{mg} \mathrm{g}^{-1}$ for carotenoid, $27.74 \mathrm{mg} \mathrm{g}^{-1}$ for chlorophyll) > $448 \mathrm{IBM}\left(0.0019 \mathrm{mg} \mathrm{g}^{-1}\right.$ for $\mathrm{Fe}(\mathrm{II}), 0.0007 \mathrm{mg} \mathrm{g}^{-1}$ for $\mathrm{Cu}(\mathrm{II}), 0.211 \mathrm{mg} \mathrm{g}^{-1}$ for carotenoid, $44917.45 \mathrm{mg} \mathrm{g}^{-1}$ for chlorophyll). The non-linear fitting of adsorption kinetics for the 450 adsorption of heavy metals and pigments is represented in Fig 2-5 according to the 451 pseudo-first-order, pseudo-second-order, and intraparticle diffusion models under 452 IBM (Fig 2a-5a), UBM-25 kHz (Fig 2b-5b), and UBM-40 kHz (Fig 2c-5c) for 453 soybean oil, suggesting that the pseudo-first-order is more suitable to predict the 454 adsorption kinetics characteristic. A similar result under UBM was reported in 455 previous research by Asgari et al (2018) for carotenoids removal from olive oil onto 456 activated bentonite clay, which shows the kinetics adsorption followed pseudo-first457 order model. In a previous research, Abedi et al (2020) reported that the adsorption of $458 \mathrm{Fe}(\mathrm{II}), \mathrm{Cu}(\mathrm{II})$, carotenoids and chlorophylls on activated bentonite clay under HVEF 459 follows the pseudo-first-order model. 


\section{Thermodynamic results}

462 The influence of the temperature on the adsorption of heavy metals ( $\mathrm{Cu}$ (II) and $\mathrm{Fe}$

463 (II)) and pigments (carotenoid and chlorophyll) onto the activated bentonite clay 464 under IBM and UBM was assessed. Fig 6a-d show the amounts of metals and 465 pigments adsorbed at temperatures of $35,45,55$ and $65{ }^{\circ} \mathrm{C}$. It is found that the 466 quantities of metals and pigments adsorbed onto the activated bentonite clay under 467 IBM and UBM increase in the order of IBM $<$ UBM-40 kHz $<$ UBM-25 kHz with the 468 increase of the temperature from 35 to $65^{\circ} \mathrm{C}$, representing that the adsorption is suited 469 at higher temperature. The increment in the $q_{e}$ values with increasing the temperature 470 is associated to the endothermic nature of the adsorption process (Arshadi et al. 2014; 471 Amiri et al. 2016, 2018; Gil et al. 2018; Hashemi and Amiri 2020). Plots of $\ln \left(\mathrm{K}_{\mathrm{d}}\right)$ 472 versus $1 / \mathrm{T}$ to adsorb Fe(II) (see Fig 7), $\mathrm{Cu}$ (II) (see Fig 8), carotenoid (see Fig 9), and 473 chlorophyll (see Fig 10) on activated bentonite clay under IBM and UBM are 474 represented. The calculated thermodynamic parameters $\left(\Delta \mathrm{H}^{\mathrm{o}}, \Delta \mathrm{S}^{\mathrm{o}}\right.$, and $\left.\Delta \mathrm{G}^{\mathrm{o}}\right)$ of the 475 metal ions and pigments on the activated bentonite clay are summarized in Table 9 476 and 10, respectively. The results indicate that $\Delta \mathrm{H}^{\circ}>0$ (see Table 9 and 10), denoting 477 that the adsorption process is endothermic, which is confirmed by the increase in the 478 metal ions and pigments uptake capacity with increasing the temperature. The values 479 of $\Delta \mathrm{H}^{\mathrm{o}}$ for physisorption are between 2.1 and $20.9 \mathrm{~kJ} \mathrm{~mol}^{-1}$, and for the chemical 480 adsorption are in the range of 20.9 to $418.4 \mathrm{~kJ} \mathrm{~mol}^{-1}$. The $\Delta \mathrm{H}^{\mathrm{o}}$ values acquired in the 481 present research under IBM and UBM for $\mathrm{Fe}(\mathrm{II})$ and $\mathrm{Cu}(\mathrm{II})$ ions adsorption onto the 482 activated bentonite clay are in the range of 93.49 to $203.32 \mathrm{~kJ} \mathrm{~mol}^{-1}$ and for carotenoid 483 and chlorophyll are in the range of 46.39 to $125.56 \mathrm{~kJ} \mathrm{~mol}^{-1}$. These values are higher 484 than $20.9 \mathrm{~kJ} \mathrm{~mol}^{-1}$, demonstrating that the rate limiting step in the process is 485 chemically controlled. The negative values of $\Delta \mathrm{G}^{\mathrm{o}}$ in higher temperatures under UBM 
486 show that the adsorption of metal ions and pigments is spontaneous in this 487 temperature range. In addition, the decrease in $\Delta \mathrm{G}^{\mathrm{o}}$ values with an increase of 488 temperature demonstrates that the adsorption process is thermodynamically favorable 489 at greater temperatures (see Tables 9 and 10). It is noteworthy that the adsorption 490 mechanisms are physisorption and chemisorption when $\Delta \mathrm{G}^{\mathrm{o}}$ values ranged from -20 491 and $0 \mathrm{~kJ} \mathrm{~mol}^{-1}$ and -80 to $-400 \mathrm{~kJ} \mathrm{~mol}^{-1}$, respectively (Nassar 2010; Amiri et al. 2016, 492 2018). From the results of Tables 9 and 10 , the $\Delta \mathrm{G}^{\mathrm{o}}$ values are changed up to $-20 \mathrm{~kJ}$ $493 \mathrm{~mol}^{-1}$, indicating the physisorption mechanism is involved in the uptake of the metal 494 ions and pigments by activated bentonite clay. The data indicate that $\Delta \mathrm{S}^{\mathbf{0}}>0$ (see 495 Table 9 and 10), demonstrating that an aleatory state at the adsorbent/adsorbate 496 interactions. A similar result under UBM was reported in previous research by Asgari 497 et al (2018) for carotenoids and chlorophylls elimination from olive oil onto activated 498 bentonite clay. In a previous research, Abedi et al (2020) reported that the adsorption 499 of $\mathrm{Fe}(\mathrm{II}), \mathrm{Cu}(\mathrm{II})$, carotenoids and chlorophylls on activated bentonite clay under

500 HVEF were endothermic and spontaneous.

\section{$501 \quad$ Equilibrium results}

502 The equilibrium studies are used to display the mechanism of heavy metals (Cu (II) 503 and Fe (II)) and pigments (carotenoid and chlorophyll) adsorption onto the activated 504 bentonite clay under IBM and UBM (Abedi et al. 2020a). Therefore, the linear and 505 non-linear forms of the Langmuir, Freundlich, and Tempkin models were employed to 506 study the adsorption mechanism of heavy metals and pigments onto the activated 507 bentonite clay. The equilibrium parameters are calculated and presented in Tables 11-

508 14. It can be found that the non-linear forms of isotherm models were better than 509 those of linear form models due to the higher coefficient of determination and lower 510 Chi-square values (see Tables 11-14). Among which, the Freundlich model 
511 satisfactorily described the equilibrium sorption data and was more favorable to 512 explain the adsorption process in terms of $\mathrm{R}^{2}$ and $\chi^{2}$. Therefore, the multilayer 513 adsorption of heavy metals ( $\mathrm{Cu}$ (II) and $\mathrm{Fe}$ (II)) and pigments (carotenoid and 514 chlorophyll) onto the heterogeneous surface of activated bentonite clay was occurred.

515 Similar results were reported by Asgari et al (2018) and Abedi et al. (2020). The 516 calculated adsorption capacities $\left(K_{F}\right)$ by the Freundlich model for the sorption of 517 heavy metals and pigments onto the activated bentonite clay were in the order of $518 \quad$ UBM-25 kHz $\left(0.436\left(m g g^{-1}\right)\left(L m g^{-1}\right)^{1 / n}\right.$ for Fe(II), $0.429\left(m g g^{-1}\right)\left(L m g^{-1}\right)^{1 / n}$ for $519 \mathrm{Cu}(\mathrm{II}), \quad 0.765\left(m g g^{-1}\right)\left(L m g^{-1}\right)^{1 / n}$ for carotenoid, $29.91 \quad\left(m g g^{-1}\right)\left(L m g^{-1}\right)^{1 / n}$ for 520 chlorophyll $)>$ UBM-40 kHz $\quad\left(0.412 \quad\left(m^{\prime} g^{-1}\right)\left(L^{-1} g^{-1}\right)^{1 / n}\right.$ for $\quad \mathrm{Fe}(\mathrm{II}), \quad 0.406$ $521 \quad\left(m g g^{-1}\right)\left(\mathrm{Lmg}^{-1}\right)^{1 / n}$ for $\mathrm{Cu}(\mathrm{II}), \quad 0.649 \quad\left(m g g^{-1}\right)\left(L m g^{-1}\right)^{1 / n}$ for carotenoid, 27.41 $522\left(m g g^{-1}\right)\left(L m g^{-1}\right)^{1 / n}$ for chlorophyll $)>\operatorname{IBM}\left(0.345\left(m g g^{-1}\right)\left(\mathrm{Lmg}^{-1}\right)^{1 / n}\right.$ for Fe(II), 0.338 $523\left(m g g^{-1}\right)\left(L m g^{-1}\right)^{1 / n}$ for $\mathrm{Cu}(\mathrm{II}), \quad 0.589 \quad\left(m g g^{-1}\right)\left(L m g^{-1}\right)^{1 / n}$ for carotenoid, 17.41 $524\left(m g g^{-1}\right)\left(L m g^{-1}\right)^{1 / n}$ for chlorophyll). According to the Freundlich model, the values of $5251 / n$ are in the range of $0-1$, suggesting that, the adsorption of heavy metals (Cu (II) 526 and $\mathrm{Fe}$ (II)) and pigments (carotenoid and chlorophyll) onto the activated bentonite 527 clay under IBM and UBM is suitable. Higher values of $K_{F}$ and lower values of $1 / n$ for 528 UBM specially at a frequency of $25 \mathrm{kHz}$ show that, this method can be used instead of 529 IBM for soybean oils bleaching (see Tables 11-14).

\section{Conclusion}

532 In this research, efficacy of IBM and UBM was evaluated for adsorption of heavy 533 metals $(\mathrm{Cu}$ (II) and $\mathrm{Fe}$ (II)) and pigments (carotenoid and chlorophyll) onto the 534 activated bentonite clay from soybean oil using kinetic, thermodynamic and 
equilibrium modeling. For this regard, a comparison of $R^{2}$ and $\chi^{2}$ statistical indices

536 was employed to finding the best kinetic and isotherm models using linear and non537 linear approaches. The kinetic behavior of heavy metals ( $\mathrm{Cu}$ (II) and $\mathrm{Fe}$ (II)) and 538 pigments (carotenoid and chlorophyll) was well described by pseudo-first-order 539 equation, and the isotherms followed the Freundlich model. Improved meal ions and 540 pigments elimination in oil medium can be obtained on processing activated bentonite 541 clay with the ultrasound technology. According to the results of this study, the 542 adsorption of heavy metals ( $\mathrm{Cu}$ (II) and $\mathrm{Fe}$ (II)) and pigments (carotenoid and 543 chlorophyll) on activated bentonite clay under UBM is spontaneous $\left(\Delta \mathrm{G}^{\mathrm{o}}<0\right)$, and 544 endothermic $\left(\Delta \mathrm{H}^{0}>0\right)$ with an increase of the randomness at adsorbent/adsorbate 545 interface $\left(\Delta S^{\circ}>0\right)$. It was concluded that the UBM, particularly at a frequency of 25 $546 \mathrm{kHz}$, presented greater potential adsorption of metal ions and pigments from soybean 547 oil compared with the IBM. Under the same conditions in time and temperature, the 548 effect of metal ions and pigments elimination in ultrasonication were more than 549 industrial process due to size reduction, scrubbing and cleaning effect of sonication on 550 activated bentonite. The effect of metal ions and pigments elimination in 12 and 10 551 min of sonication are about equivalent to that with industrial bleaching in $30 \mathrm{~min}$, 552 therefore, the processing time can be decreased more than about two and three times, 553 respectively. Trace elements and pigments removed under lower frequency $(25 \mathrm{kHz})$ 554 than higher frequency $(40 \mathrm{kHz})$, due to improvement in cavitation and collapse of 555 bubbles which result in collision in the particles, followed by reduce in surface area. 556 The metal ions and pigments elimination rate can be increased by $100 \%$ at lower time 557 of the ultrasonic-assisted technology combined with activated bentonite clay in 558 solution due to their synergistic effect. 
561 We verify that we have seen and have approved the submitted manuscript. Our 562 manuscript does not report on or involve the use of any animal or human data or 563 tissue.

\section{Consent for publication}

565 None.

566 Author contributions

567 All authors conceived of the presented idea. Dr. Elahe Abedi carried out the 568 experiment. Dr. Mohammad Javad Amiri developed the theory and performed the 569 computations. All authors discussed the results and contributed to the final 570 manuscript.

\section{$571 \quad$ Funding}

572 No funding has received for this work.

\section{Competing Interests}

574 The authors declare that they have no known competing financial interests or personal 575 relationships that could have appeared to influence the work reported in this paper.

\section{Availability of data and materials}

577 Data cannot be made publicly available; readers should contact the corresponding 578 author for details.

579 Acknowledgements

580 The authors would like to thank Fasa University of Medical Sciences for supporting 581 of this work. 


\section{References}

Abedi E, Amiri MJ, Sahari MA (2020a) Kinetic, isotherm and thermodynamic investigations on adsorption of trace elements and pigments from soybean oil using high voltage electric field-assisted bleaching: A comparative study. Process Biochem 91:208-222

Abedi E, Roohi R, Hashemi SMB, Torri L (2020b) Horn ultrasonic-assisted bleaching of vegetable oils with various viscosities as a green process: Computational fluid dynamics simulation of process. Ind Crops Prod 156:112845

Abedi E, Sahari MA (2014) Long-chain polyunsaturated fatty acid sources and evaluation of their nutritional and functional properties. Food Sci Nutr 2:. https://doi.org/10.1002/fsn3.121

Abedi E, Sahari MA, Barzegar M, Azizi MH (2015) Optimisation of soya bean oil bleaching by ultrasonic processing and investigate the physico-chemical properties of bleached soya bean oil. Int J Food Sci Technol 50:. https://doi.org/10.1111/ijfs.12689

Abedi E, Sahari MA, Hashemi SMB (2017) Accelerating Bleaching of Soybean Oil by Ultrasonic Horn and Bath Under Sparge of Helium, Air, Argon and Nitrogen Gas. J Food Process Preserv 41:. https://doi.org/10.1111/jfpp.12987

Ali F, Reinert L, Lévêque J-M, et al (2014) Effect of sonication conditions: solvent, time, temperature and reactor type on the preparation of micron sized vermiculite particles. Ultrason Sonochem 21:1002-1009

Aljeboree AM, Alshirifi AN, Alkaim AF (2017) Kinetics and equilibrium study for the adsorption of textile dyes on coconut shell activated carbon. Arab J Chem 10:S3381-S3393

Almeida ES, Carvalho ACB, de Souza Soares IO, et al (2019) Elucidating how two different types of bleaching earths widely used in vegetable oils industry remove carotenes from palm oil: Equilibrium, kinetics and thermodynamic parameters. Food Res Int 121:785-797

Amiri MJ, Abedi-Koupai J, Eslamian SS, Arshadi M (2016) Adsorption of Pb (II) and $\mathrm{Hg}$ (II) ions from aqueous single metal solutions by using surfactant-modified ostrich bone waste. Desalin Water Treat 57:16522-16539

Amiri MJ, Arshadi M, Giannakopoulos E, Kalavrouziotis IK (2018) Removal of mercury (II) and lead (II) from aqueous media by using a green adsorbent: kinetics, thermodynamic, and mechanism studies. J Hazardous, Toxic, Radioact Waste 22:4017026

Arshadi M, Amiri MJ, Mousavi S (2014) Kinetic, equilibrium and thermodynamic investigations of $\mathrm{Ni}$ (II), Cd (II), Cu (II) and Co (II) adsorption on barley straw ash. Water Resour Ind 6:1-17

Asgari S, Sahari MA, Barzegar M (2017) Practical modeling and optimization of ultrasound-assisted bleaching of olive oil using hybrid artificial neural networkgenetic algorithm technique. Comput Electron Agric 140:422-432

Asgari S, Sahari MA, Barzegar M (2018) Ultrasound-assisted bleaching of olive oil: Kinetics, isotherms and thermodynamics. J Food Eng 224:37-44

Batool F, Akbar J, Iqbal S, et al (2018) Study of isothermal, kinetic, and thermodynamic parameters for adsorption of cadmium: an overview of linear and nonlinear approach and error analysis. Bioinorg Chem Appl 2018:

Brotchie A, Grieser F, Ashokkumar M (2009) Effect of power and frequency on bubble-size distributions in acoustic cavitation. Phys Rev Lett 102:84302

Chandrapala J, Oliver C, Kentish S, Ashokkumar M (2012) Ultrasonics in food processing. Ultrason Sonochem 19:975-983 
Dai Y-J, Sun L-L, Li M-Y, et al (2016) Comparison of formulas based on lipid emulsions of olive oil, soybean oil, or several oils for parenteral nutrition: a systematic review and meta-analysis. Adv Nutr 7:279-286

Didi MA, Makhoukhi B, Azzouz A, Villemin D (2009) Colza oil bleaching through optimized acid activation of bentonite. A comparative study. Appl Clay Sci 42:336-344

Erickson DR (1995) Bleaching/adsorption treatment. In: Practical handbook of soybean processing and utilization. Elsevier, pp 203-217

Farmer AD, Collings AF, Jameson GJ (2000) Effect of ultrasound on surface cleaning of silica particles. Int J Miner Process 60:101-113

Fasina OO, Colley Z (2008) Viscosity and specific heat of vegetable oils as a function of temperature: $35 \mathrm{C}$ to $180 \mathrm{C}$. Int J Food Prop 11:738-746

Franco F, Pérez-Maqueda LA, Pérez-Rodriguez JL (2004) The effect of ultrasound on the particle size and structural disorder of a well-ordered kaolinite. J Colloid Interface Sci 274:107-117

Gil A, Amiri MJ, Abedi-Koupai J, Eslamian S (2018) Adsorption/reduction of Hg (II) and $\mathrm{Pb}$ (II) from aqueous solutions by using bone ash/nZVI composite: effects of aging time, Fe loading quantity and co-existing ions. Environ Sci Pollut Res 25:2814-2829

Hashemi SMB, Amiri MJ (2020) A comparative adsorption study of aflatoxin B1 and aflatoxin $\mathrm{G} 1$ in almond butter fermented by Lactobacillus fermentum and Lactobacillus delbrueckii subsp. lactis. LWT 109500

Hussin F, Aroua MK, Daud WMAW (2011) Textural characteristics, surface chemistry and activation of bleaching earth: A review. Chem Eng J 170:90-106

Huth PJ, Fulgoni III VL, Larson BT (2015) A systematic review of high-oleic vegetable oil substitutions for other fats and oils on cardiovascular disease risk factors: implications for novel high-oleic soybean oils. Adv Nutr 6:674-693

Icyer NC, Durak MZ (2018) Ultrasound-assisted bleaching of canola oil: Improve the bleaching process by central composite design. LWT 97:640-647

Jahouach-Rabai W, Trabelsi M, Van Hoed V, et al (2008) Influence of bleaching by ultrasound on fatty acids and minor compounds of olive oil. Qualitative and quantitative analysis of volatile compounds (by SPME coupled to GC/MS). Ultrason Sonochem 15:590-597

Kulkarni VM, Rathod VK (2014) Mapping of an ultrasonic bath for ultrasound assisted extraction of mangiferin from Mangifera indica leaves. Ultrason Sonochem 21:606-611

Merouani S, Hamdaoui O, Rezgui Y, Guemini M (2013) Effects of ultrasound frequency and acoustic amplitude on the size of sonochemically active bubblesTheoretical study. Ultrason Sonochem 20:815-819

More NS, Gogate PR (2018) Ultrasound assisted enzymatic degumming of crude soybean oil. Ultrason Sonochem 42:805-813

Nassar NN (2010) Rapid removal and recovery of $\mathrm{Pb}$ (II) from wastewater by magnetic nanoadsorbents. J Hazard Mater 184:538-546

Niazi S, Hashemabadi SH, Razi MM (2014) CFD simulation of acoustic cavitation in a crude oil upgrading sonoreactor and prediction of collapse temperature and pressure of a cavitation bubble. Chem Eng Res Des 92:166-173

Pérez-Maqueda LA, Duran A, Pérez-Rodríguez JL (2005) Preparation of submicron talc particles by sonication. Appl Clay Sci 28:245-255

Pérez-Rodríguez JL, Pascual J, Franco F, et al (2006) The influence of ultrasound on the thermal behaviour of clay minerals. J Eur Ceram Soc 26:747-753 
Pohndorf RS, Cadaval Jr TRS, Pinto LAA (2016) Kinetics and thermodynamics adsorption of carotenoids and chlorophylls in rice bran oil bleaching. J Food Eng 185:9-16

Poli AL, Batista T, Schmitt CC, et al (2008) Effect of sonication on the particle size of montmorillonite clays. J Colloid Interface Sci 325:386-390

Pradhan S, Hedberg J, Blomberg E, et al (2016) Effect of sonication on particle dispersion, administered dose and metal release of non-functionalized, non-inert metal nanoparticles. J nanoparticle Res 18:285

Priego-Capote F, De Castro MDL (2004) Analytical uses of ultrasound I. Sample preparation. TrAC Trends Anal Chem 23:644-653

Proctor A, Brooks DD (2005) Adsorptive separation of oils. Bailey's Ind oil fat Prod

Retamal Marín RR, Babick F, Lindner G-G, et al (2018) Effects of sample preparation on particle size distributions of different types of silica in suspensions. Nanomaterials 8:454

Roohi R, Abedi E, Hashemi SMB, et al (2019) Ultrasound-assisted bleaching: Mathematical and 3D computational fluid dynamics simulation of ultrasound parameters on microbubble formation and cavitation structures. Innov Food Sci Emerg Technol 55:66-79

Santos JCO, Santos IMG, Souza AG (2005) Effect of heating and cooling on rheological parameters of edible vegetable oils. J Food Eng 67:401-405

Silva SM, Sampaio KA, Ceriani R, et al (2013) Adsorption of carotenes and phosphorus from palm oil onto acid activated bleaching earth: Equilibrium, kinetics and thermodynamics. J Food Eng 118:341-349

Sompech S, Srion A, Nuntiya A (2012) The effect of ultrasonic treatment on the particle size and specific surface area of LaCoO3. Procedia Eng 32:1012-1018

Su D, Xiao T, Gu D, et al (2013) Ultrasonic bleaching of rapeseed oil: Effects of bleaching conditions and underlying mechanisms. J Food Eng 117:8-13

Thompson LH, Doraiswamy LK (1999) Sonochemistry: science and engineering. Ind Eng Chem Res 38:1215-1249

Tiwari BK, Muthukumarappan K, O'donnell CP, Cullen PJ (2008) Colour degradation and quality parameters of sonicated orange juice using response surface methodology. LWT-Food Sci Technol 41:1876-1883

Vafaei M, Naseri M, Imani A (2018) Long-term storage effect on some mineral elements of canned silver carp (Hypophthalmichthys molitrix) with reference to daily intake changes. J Food Compos Anal 66:116-120

Vilkhu K, Mawson R, Simons L, Bates D (2008) Applications and opportunities for ultrasound assisted extraction in the food industry-A review. Innov Food Sci Emerg Technol 9:161-169

Wiewióra A, Pérez-Rodrıguez JL, Perez-Maqueda LA, Drapała J (2003) Particle size distribution in sonicated high-and low-charge vermiculites. Appl Clay Sci 24:5158

Zhao HL, Wang DX, Cai YX, Zhang FC (2007) Removal of iron from silica sand by surface cleaning using power ultrasound. Miner Eng 20:816-818

\section{Figure Caption}

Figure 1. The effect of ultrasonication on the reduction of particle size and cleaning of surface. 
731 Figure 2. The experimental kinetic data and predicted values of Fe(II) ions on bentonite 732 clay under IBM (a), UBM-25 kHz (b) and UBM-40 kHz (c) for soybean oil.

733 Figure 3. The experimental kinetic data and predicted values of $\mathrm{Cu}$ (II) ions on

734 bentonite clay under IBM (a), UBM-25 kHz (b) and UBM-40 kHz (c) for soybean oil.

735 Figure 4. The experimental kinetic data and predicted values of Carotenoid on bentonite 736 clay under IBM (a), UBM-25 kHz (b) and UBM-40 kHz (c) for soybean oil.

737 Figure 5. The experimental kinetic data and predicted values of Chlrophyl on bentonite 738 clay under IBM (a), UBM-25 kHz (b) and UBM-40 kHz (c) for soybean oil.

739 Figure 6. The influence of temperature for the adsorption of (a) $\mathrm{Fe}(\mathrm{II})$; (b) $\mathrm{Cu}$ (II); (c)

740 carotenoid; and (d) chlorophyll onto activated bentonite clay under IBM and UBM.

741 Industrial bleaching method (IBM), Ultrasonic bleaching method (UBM).

742 Figure 7. Plot of $\ln (\mathrm{Kd})$ versus $1 / \mathrm{T}$ for the adsorption of $\mathrm{Fe}(\mathrm{II})$ on activated bentonite 743 clay under (a) IBM, (b) UBM-25 kHz, and (c) UBM-40 kHz. IBM; industrial bleaching 744 method, UBM; ultrasonic bleaching method.

745 Figure 8. Plot of $\ln (\mathrm{Kd})$ versus $1 / \mathrm{T}$ for the adsorption of $\mathrm{Cu}(\mathrm{II})$ on activated bentonite 746 clay under (a) IBM, (b) UBM-25 kHz, and (c) UBM-40 kHz. IBM; industrial bleaching 747 method, UBM; ultrasonic bleaching method.

748 Figure 9. Plot of $\ln (\mathrm{Kd})$ versus $1 / \mathrm{T}$ for the adsorption of carotenoid on activated 749 bentonite clay under (a) IBM, (b) UBM-25 kHz, and (c) UBM-40 kHz. IBM; industrial 750 bleaching method, UBM; ultrasonic bleaching method.

751 Figure 10. Plot of $\ln (\mathrm{Kd})$ versus $1 / \mathrm{T}$ for the adsorption of chlorophyll on activated 752 bentonite clay under (a) IBM, (b) UBM-25 kHz, and (c) UBM-40 kHz. IBM; industrial 753 bleaching method, UBM; ultrasonic bleaching method. 

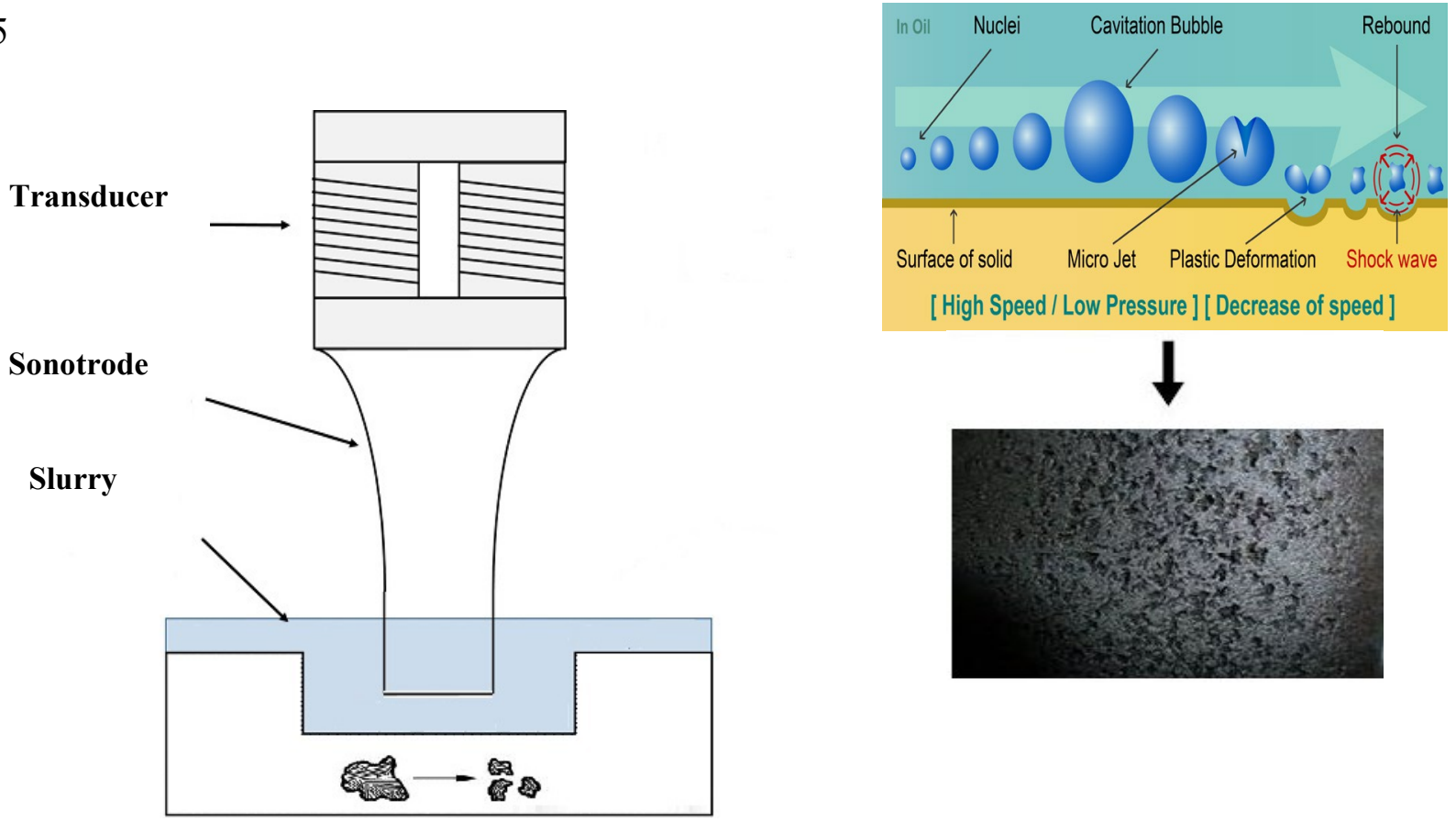

[ High Speed / Low Pressure ] [ Decrease of speed]

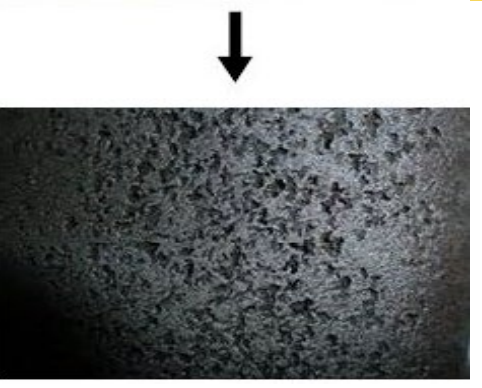

766

767

768

769

770

771

772

773

774

775

Figure 1.

776 


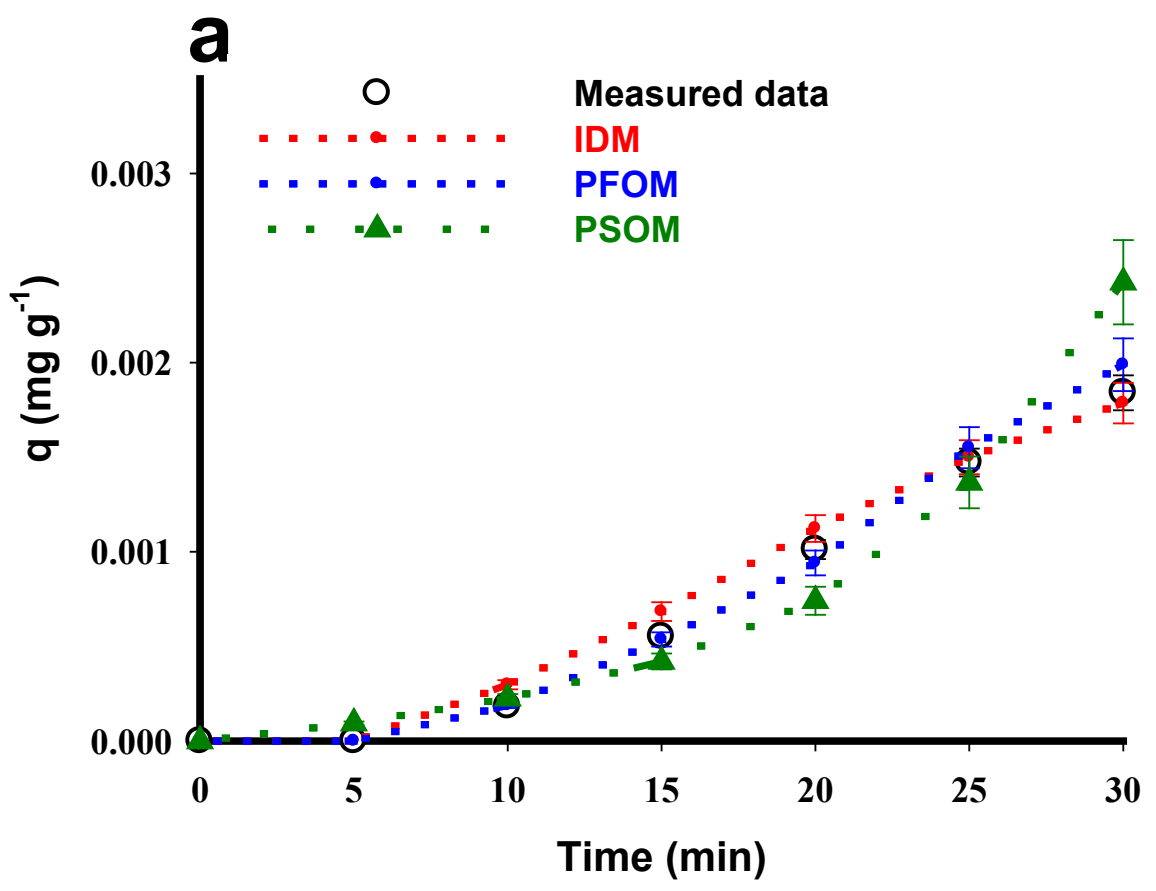

778

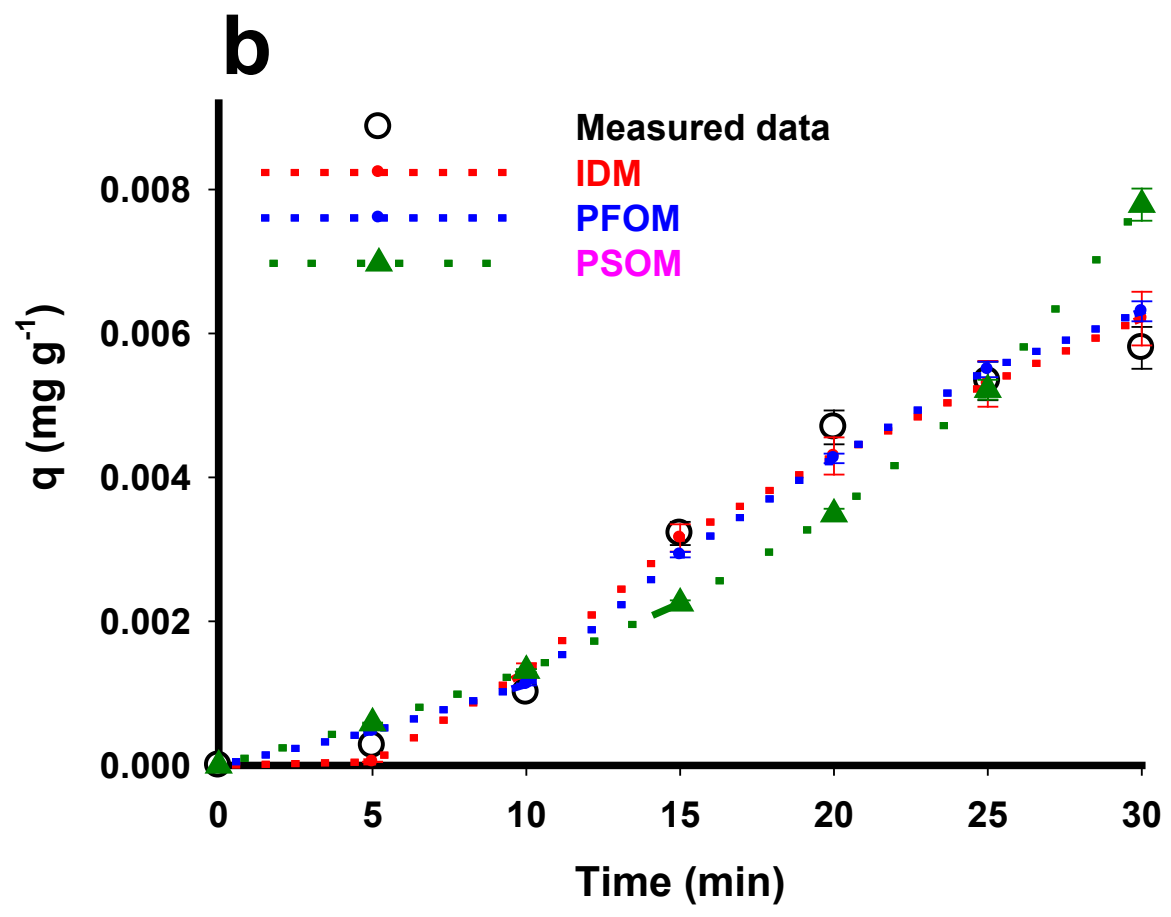

780

781 


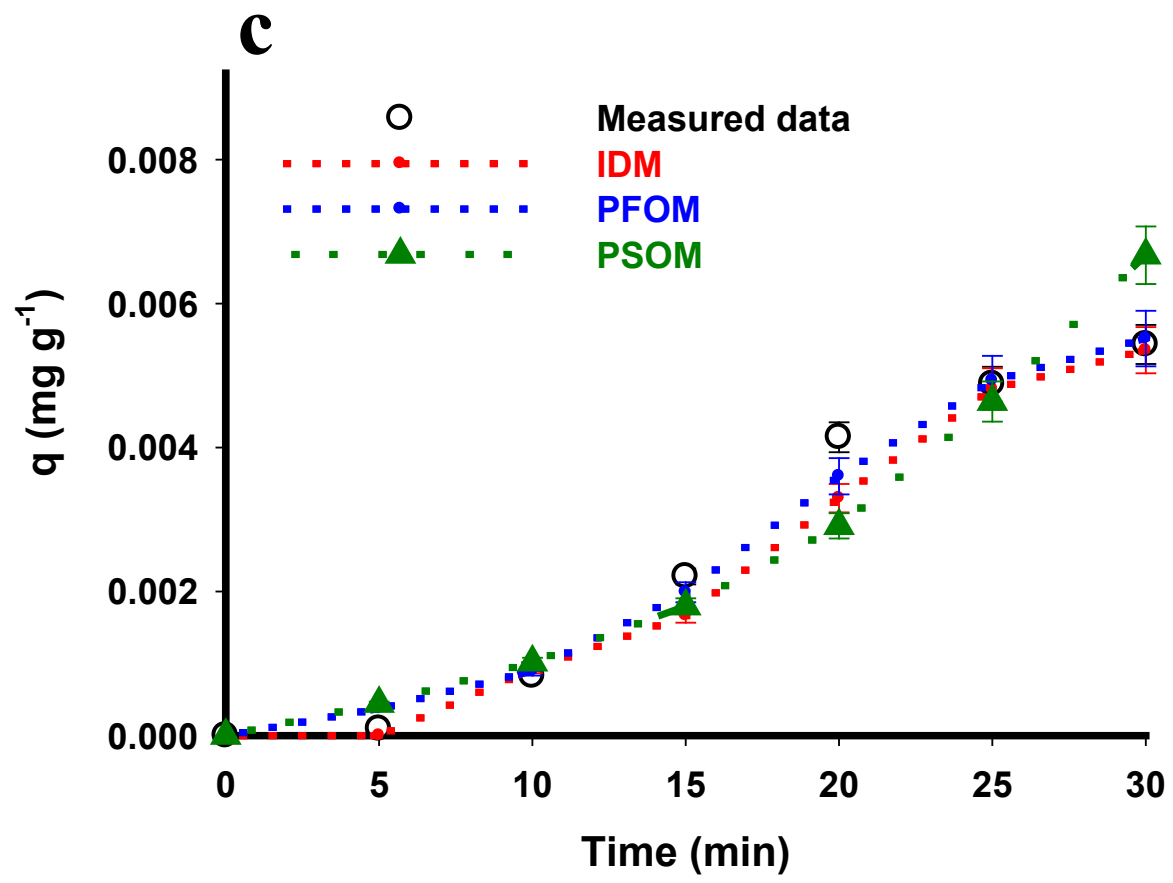

782

783

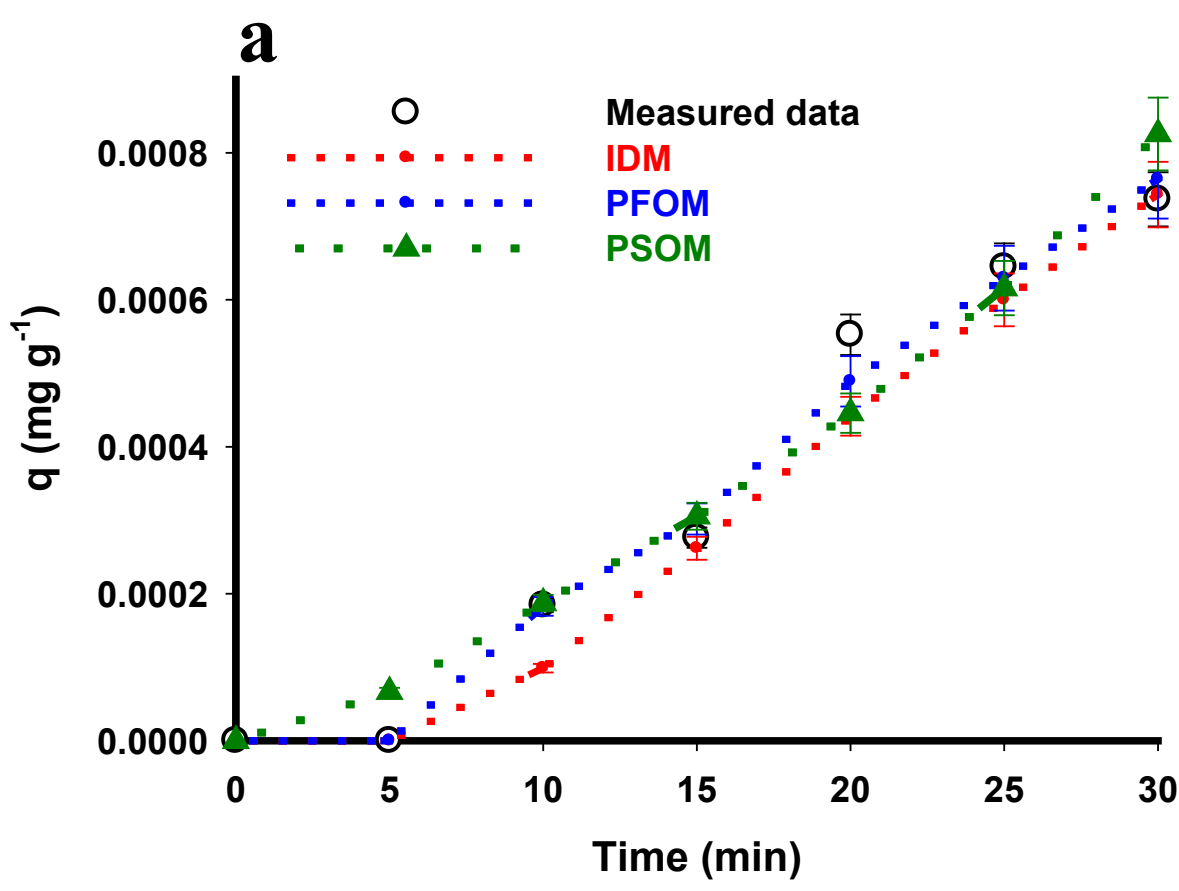

784

Figure 2.

785

786

787 

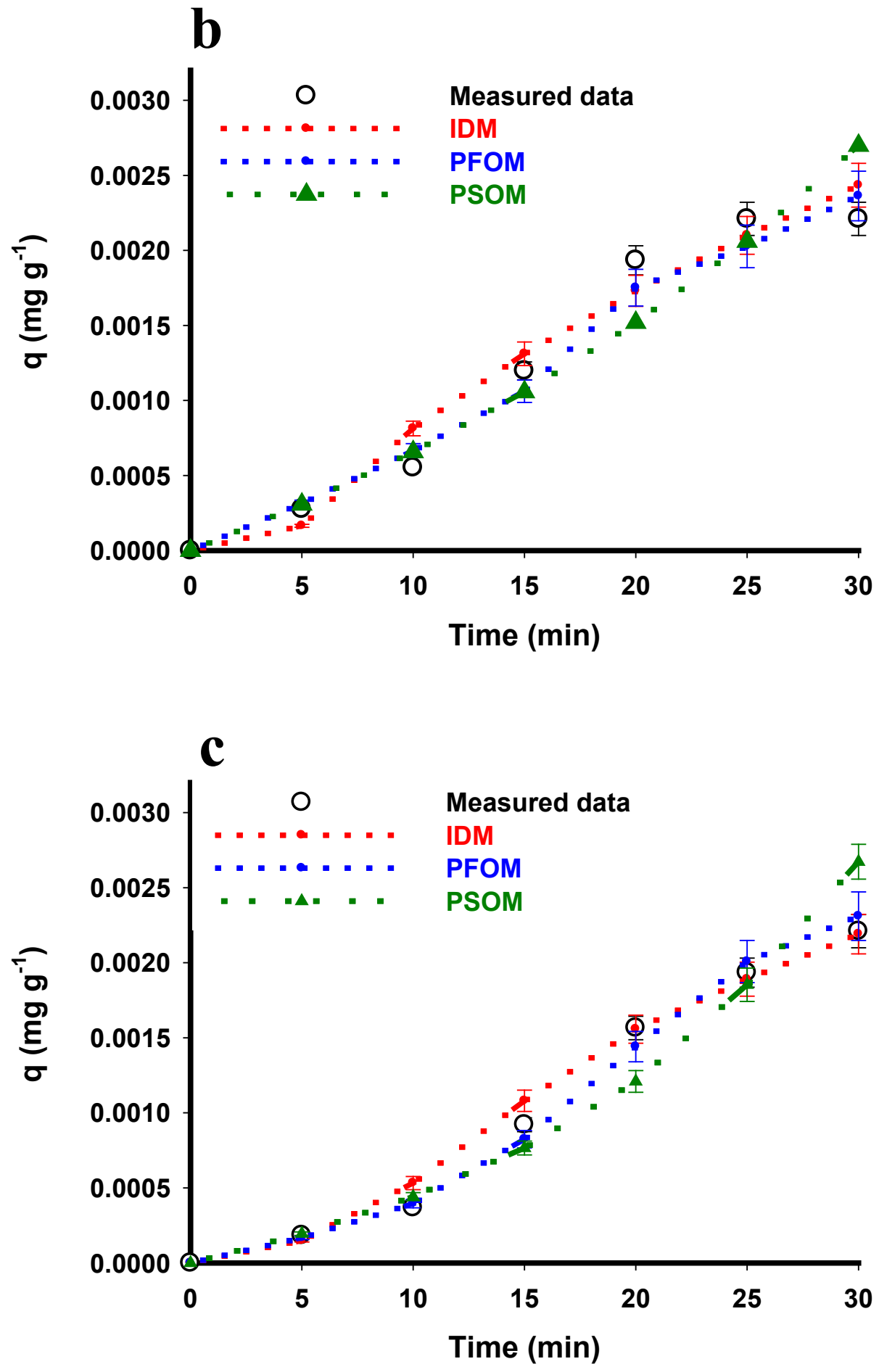

792

793
Figure 3. 


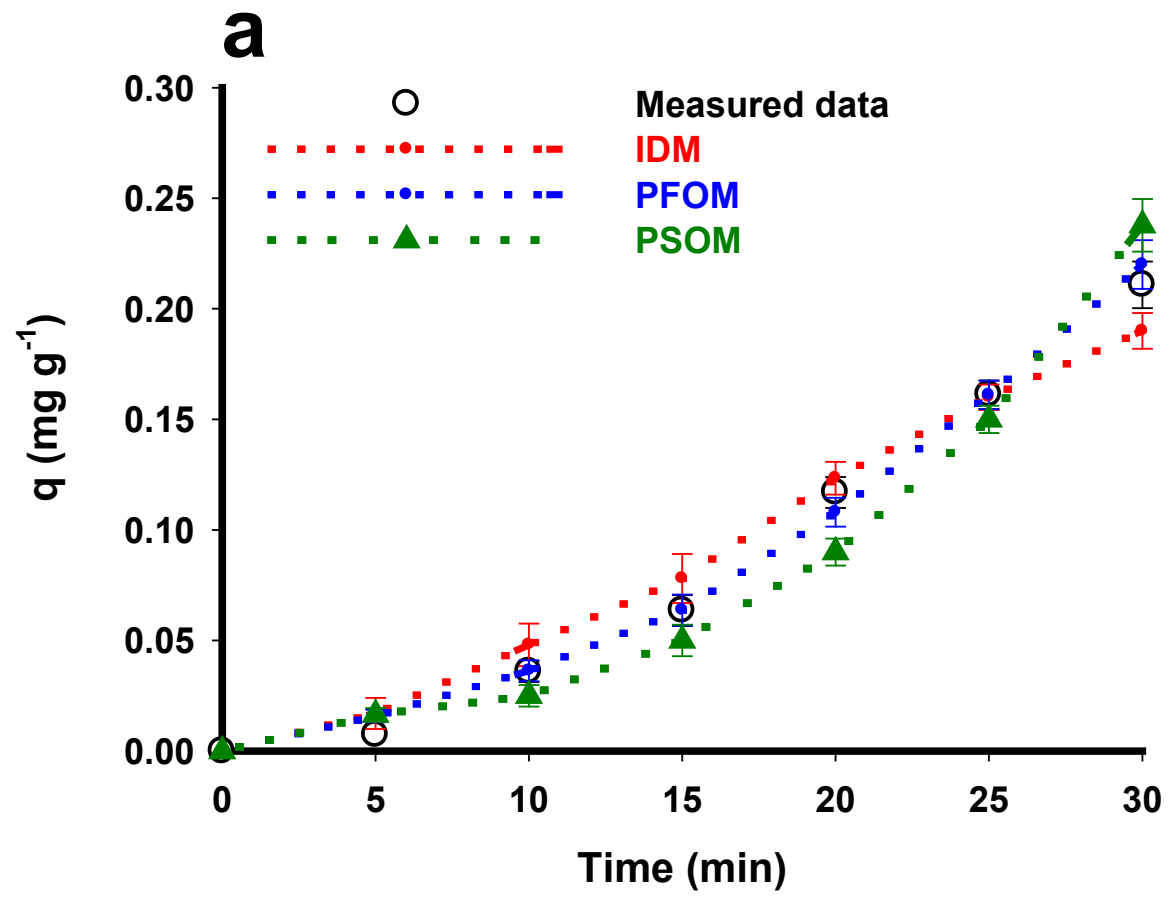

794

795

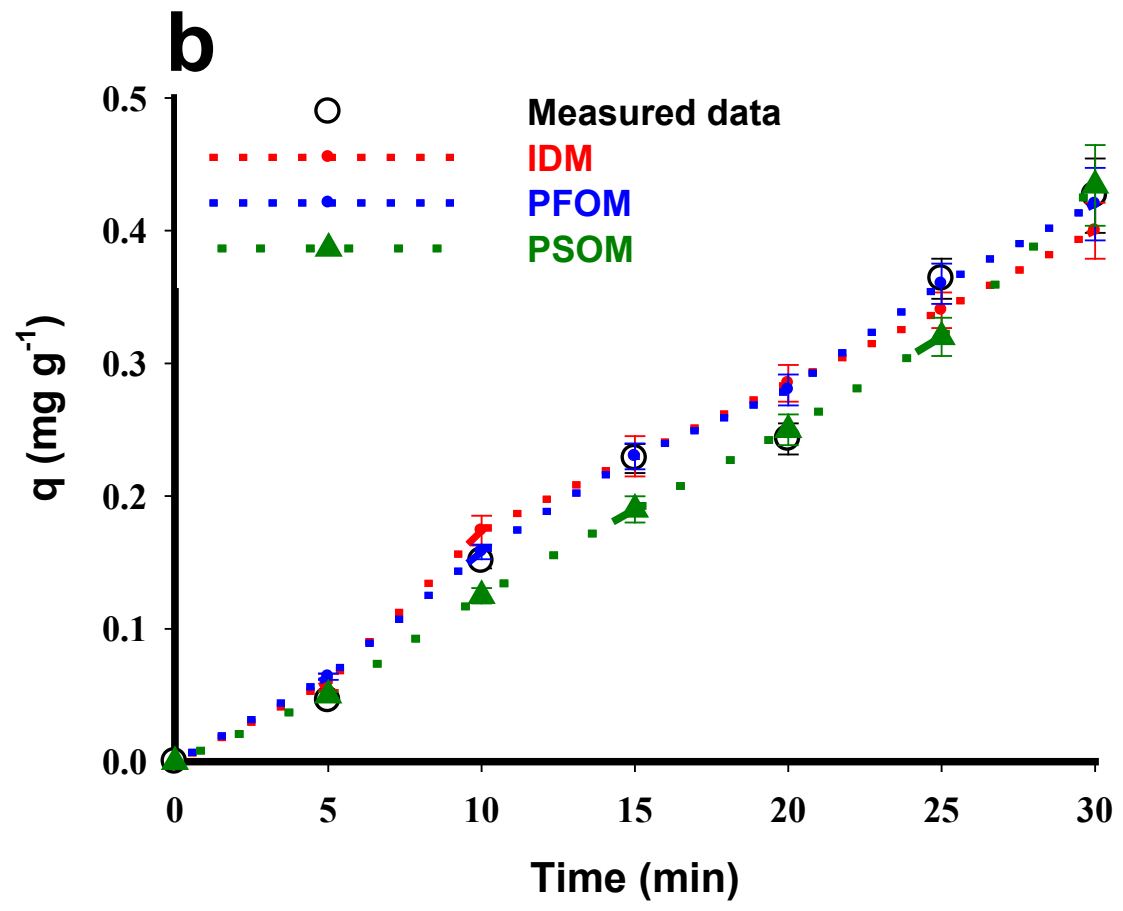

797

798 


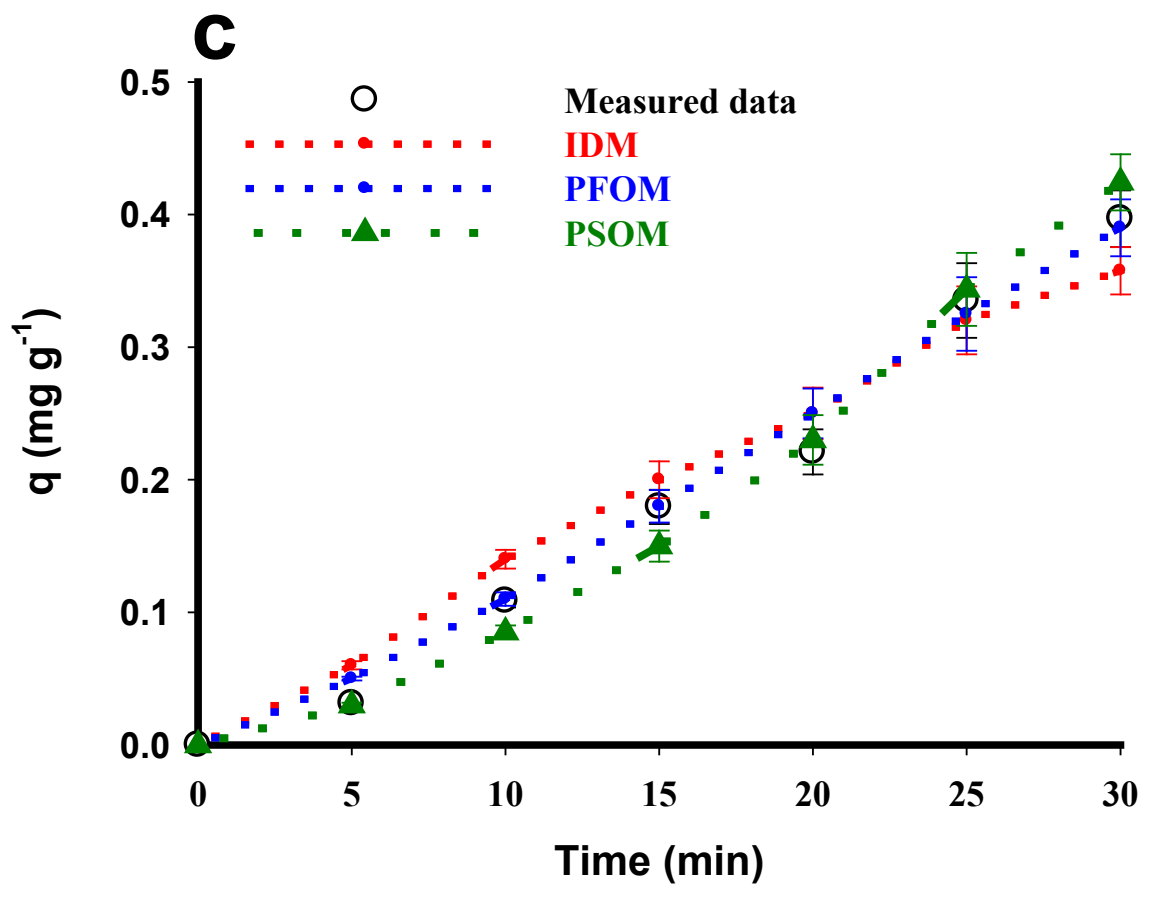

800

Figure 4.

801

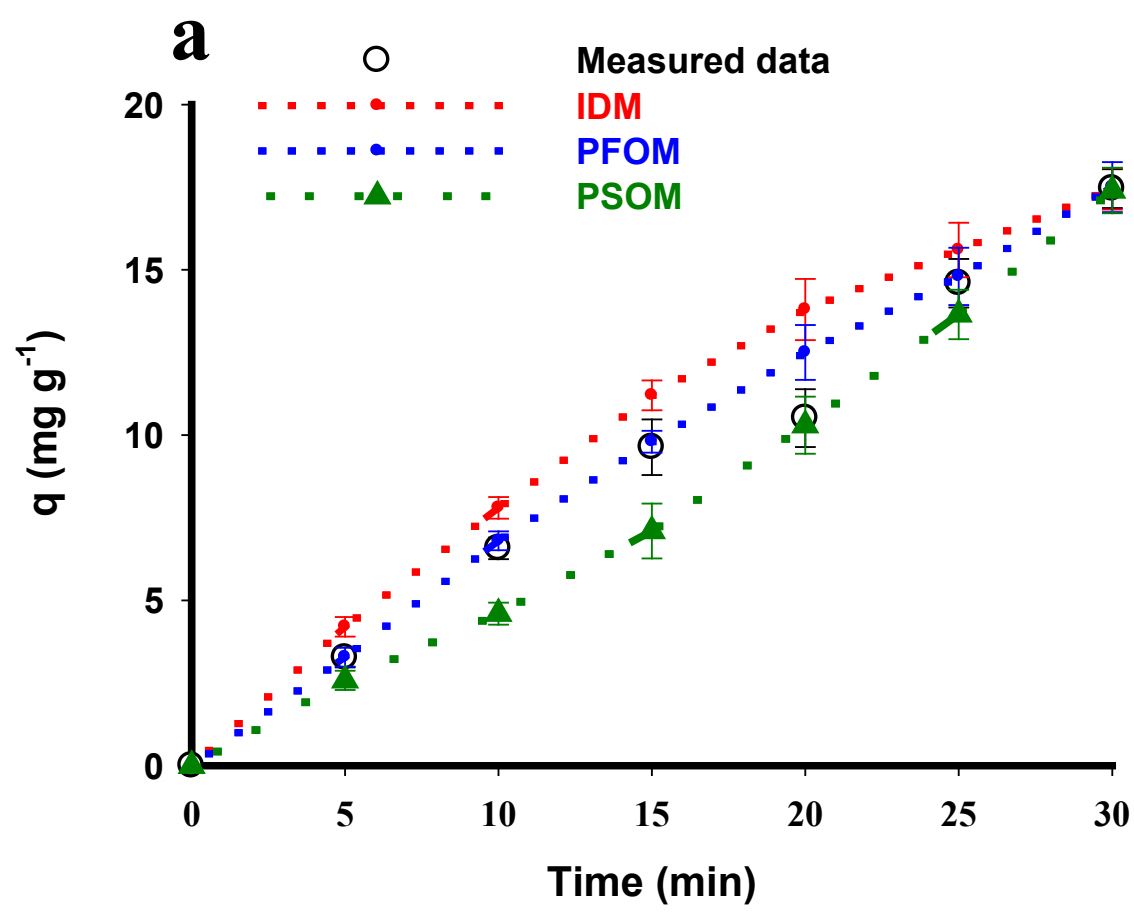

802

803 


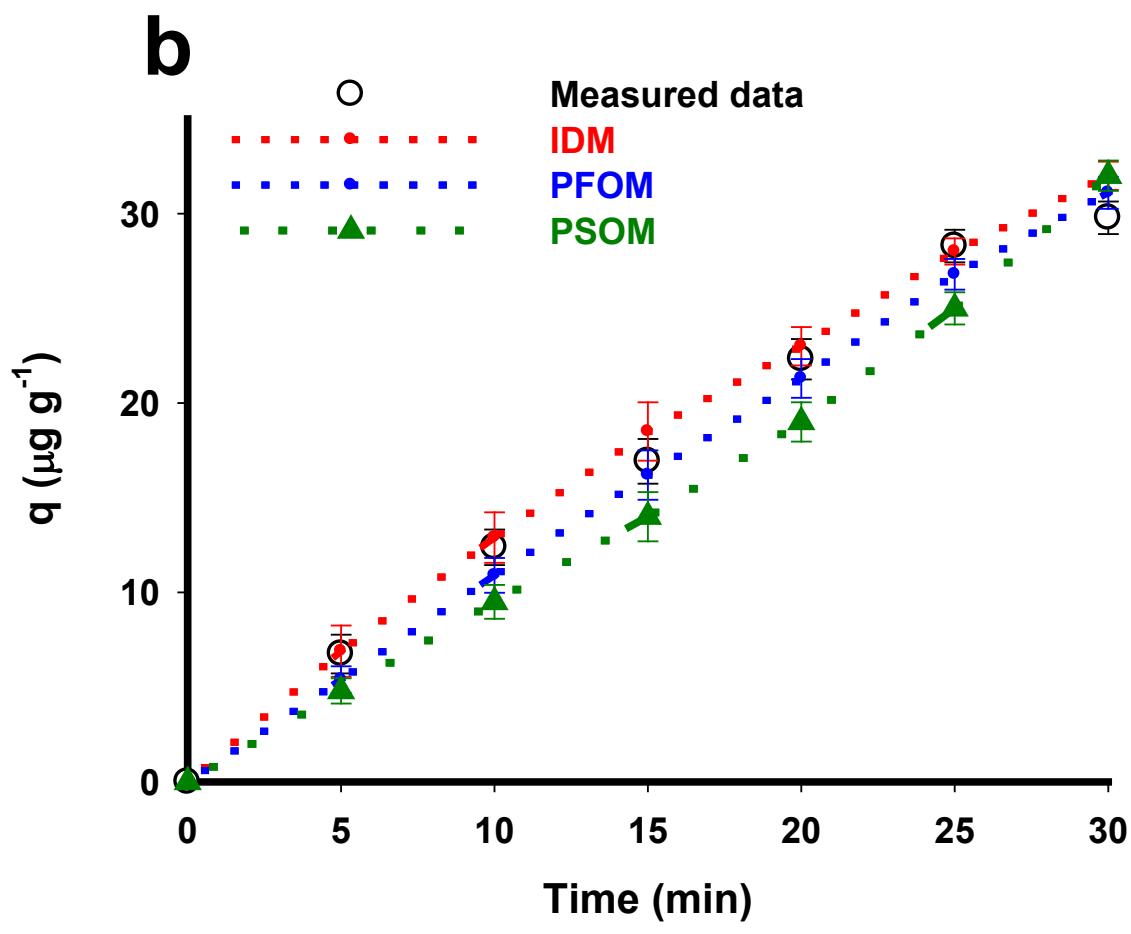

804
805

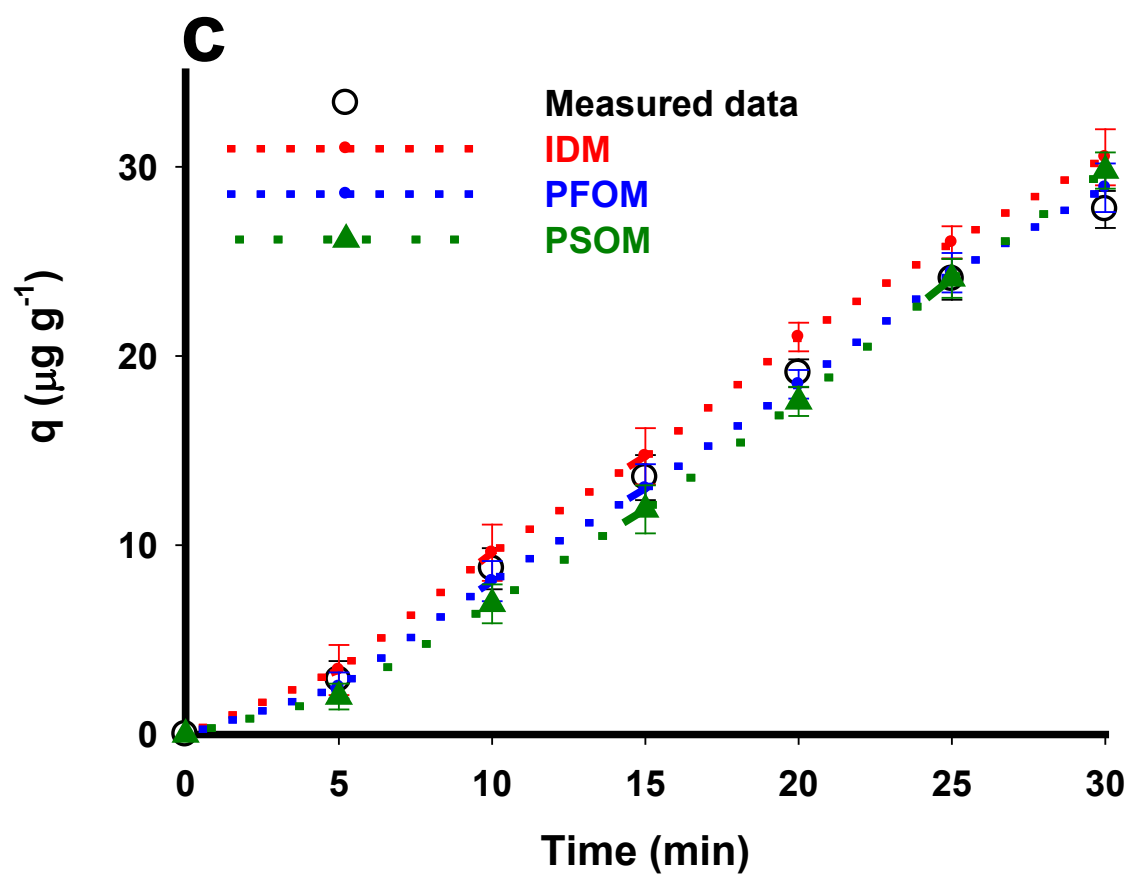

806

807

808

809

810
Figure 5. 

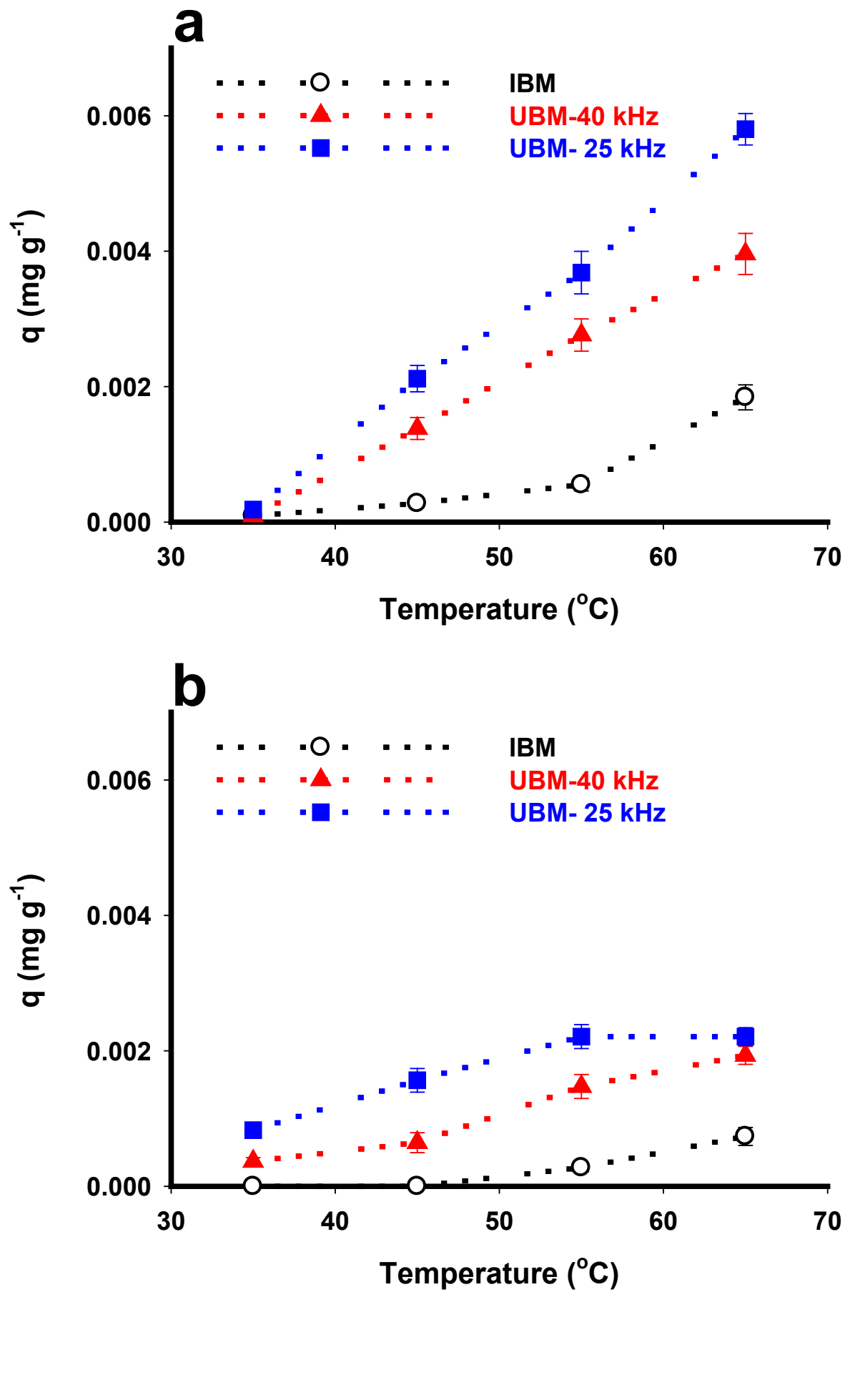


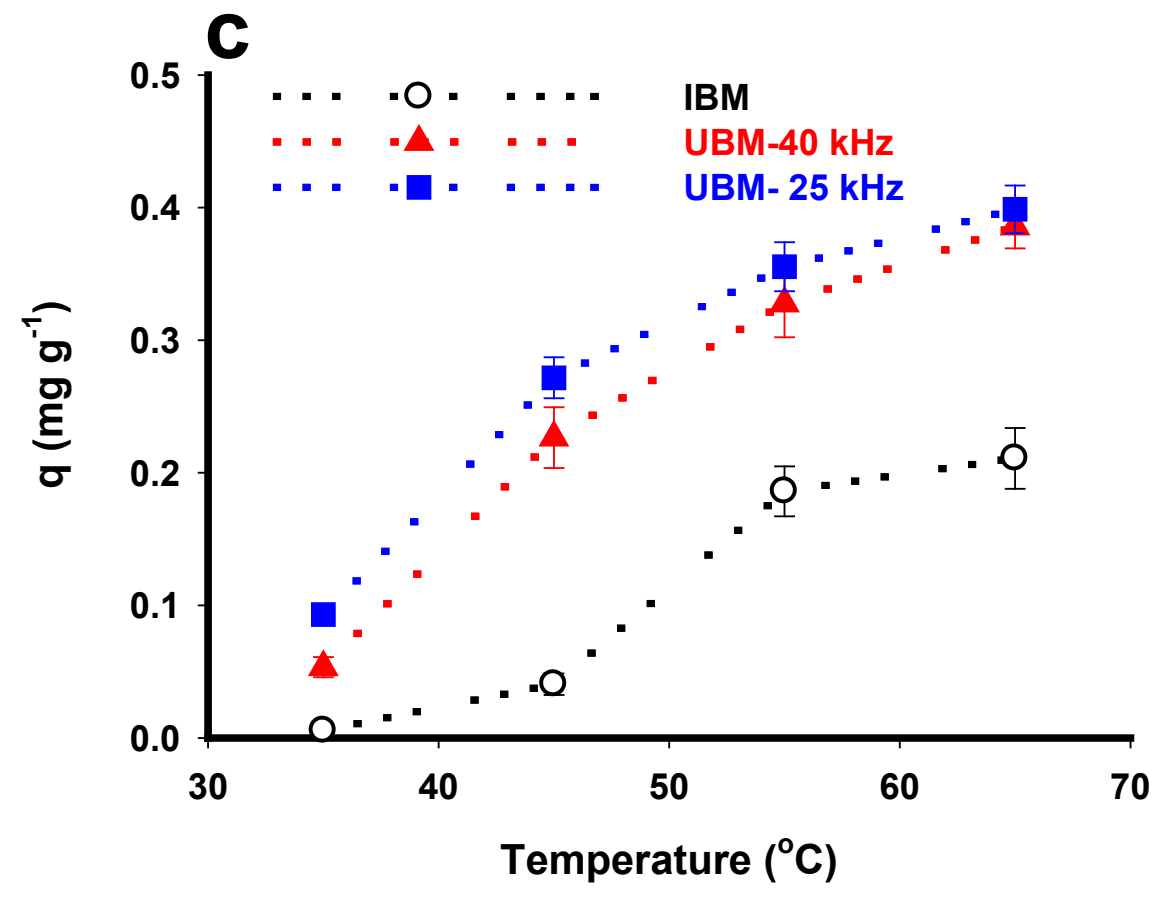

815

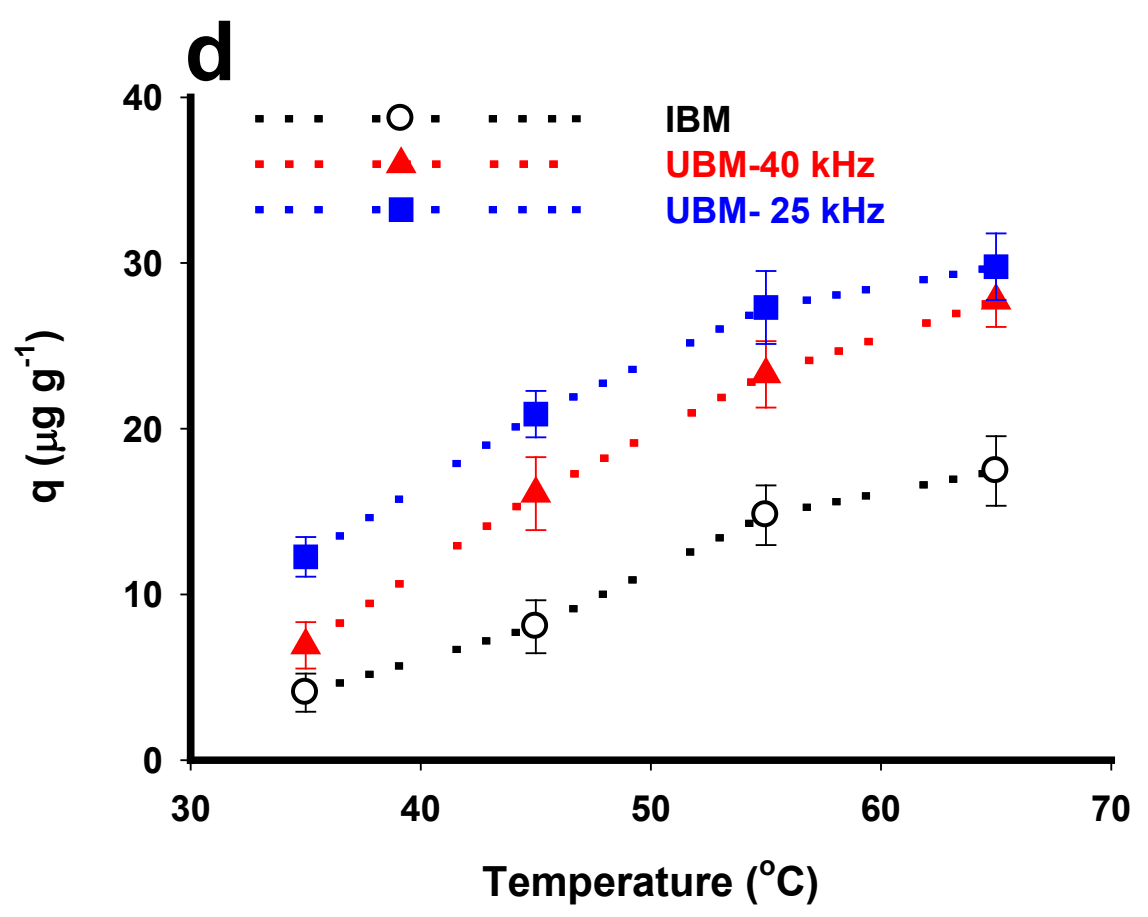

816

Fig 6. 


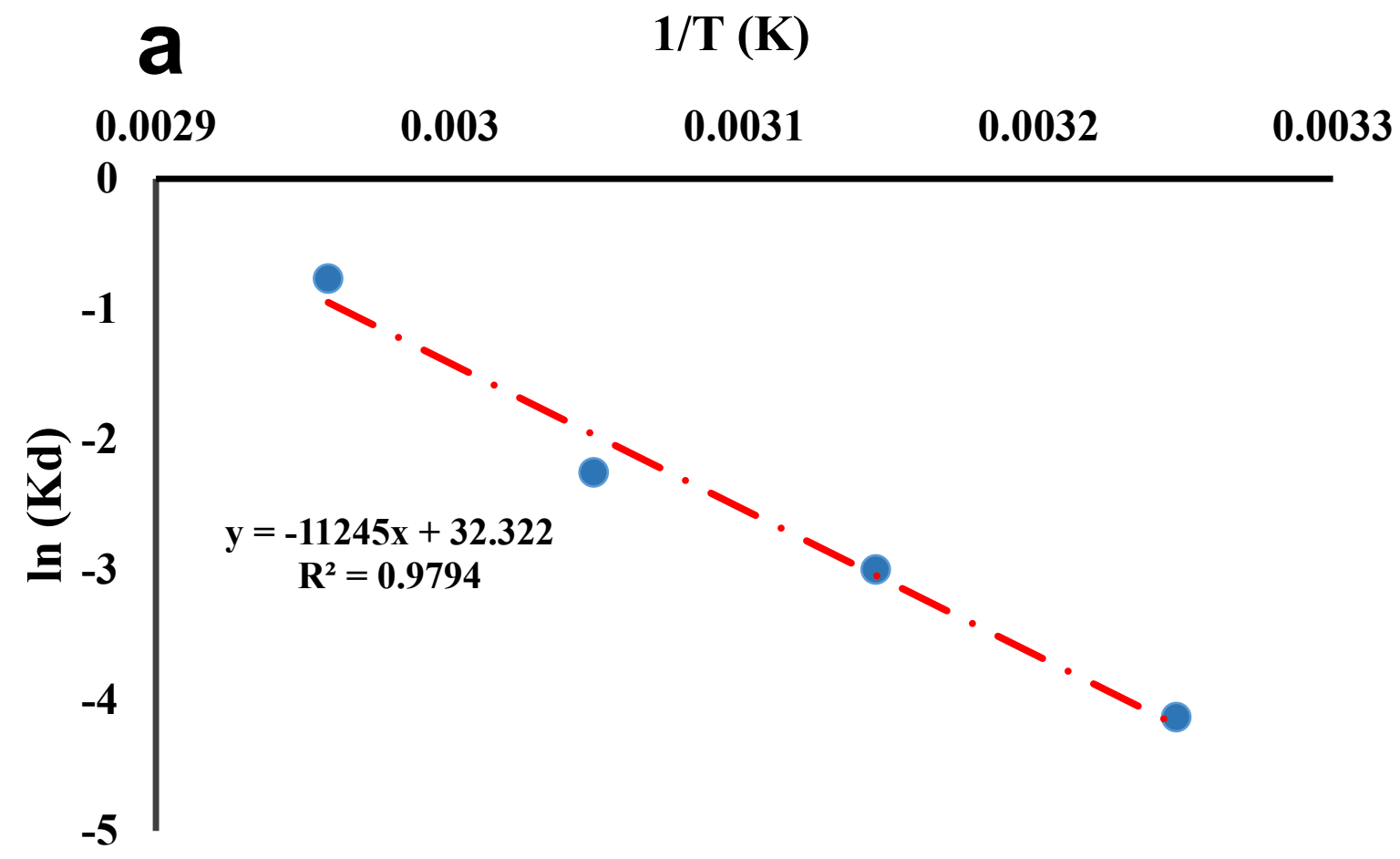

819

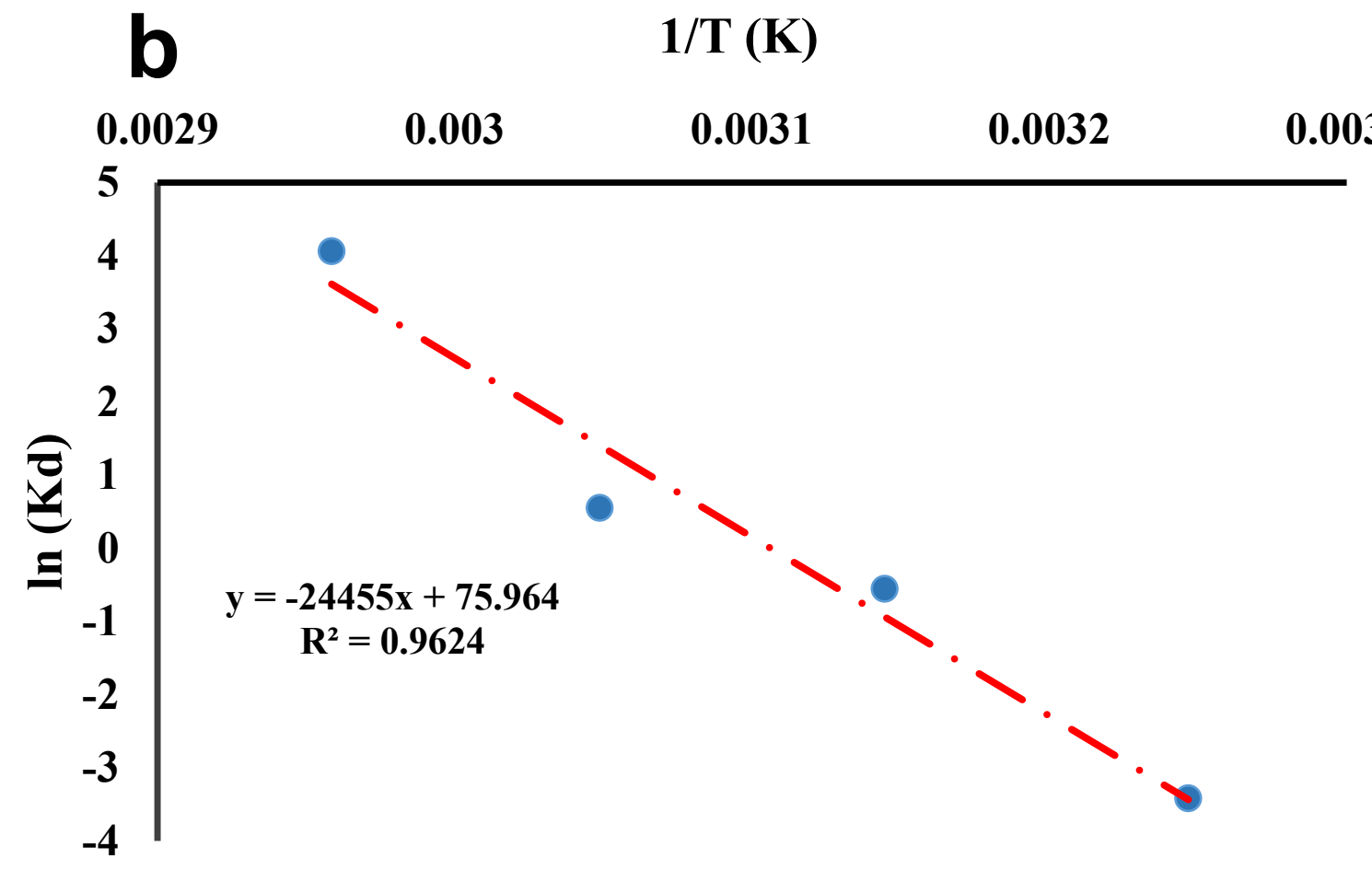

820

821 


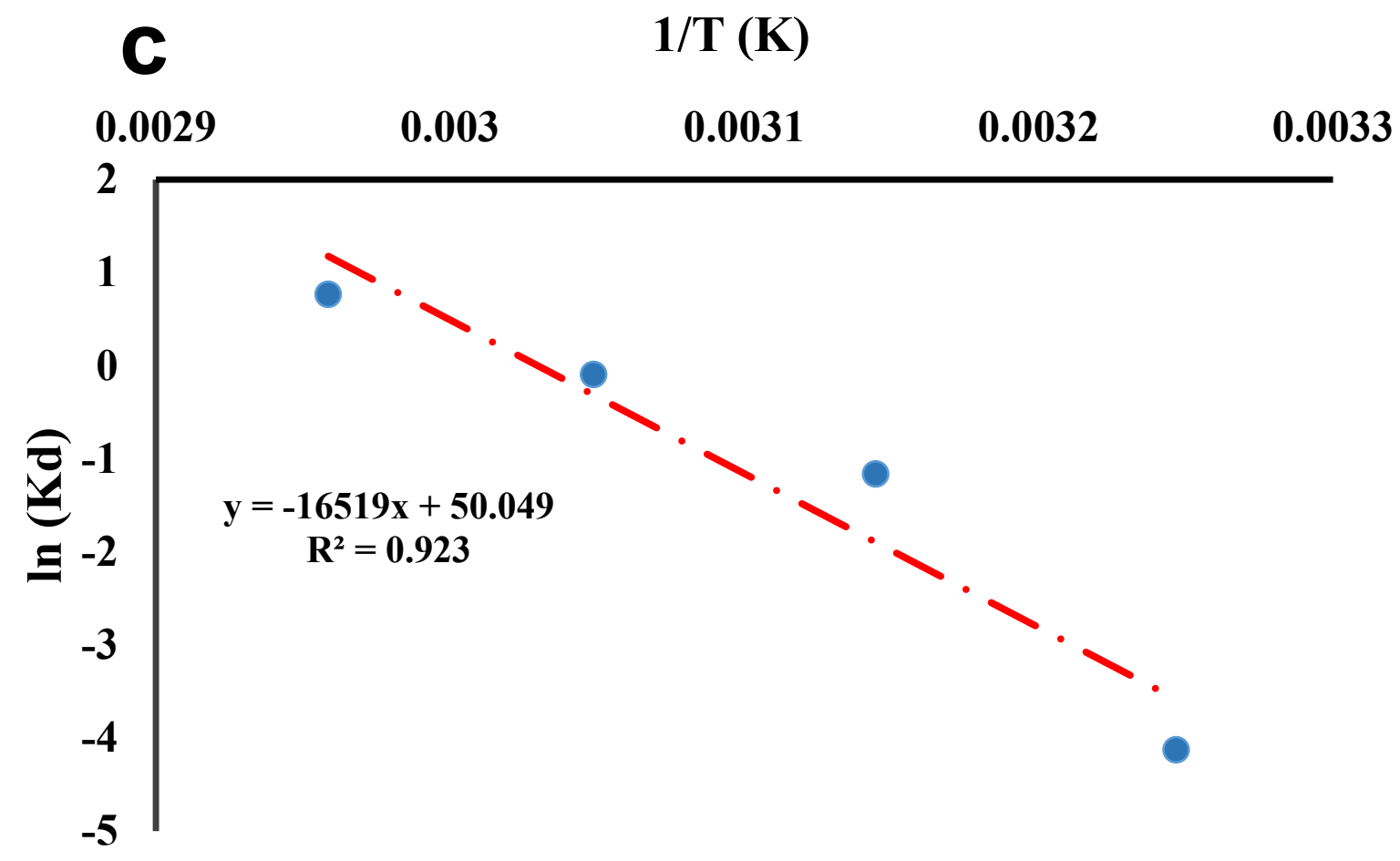

822

823

Figure 7.

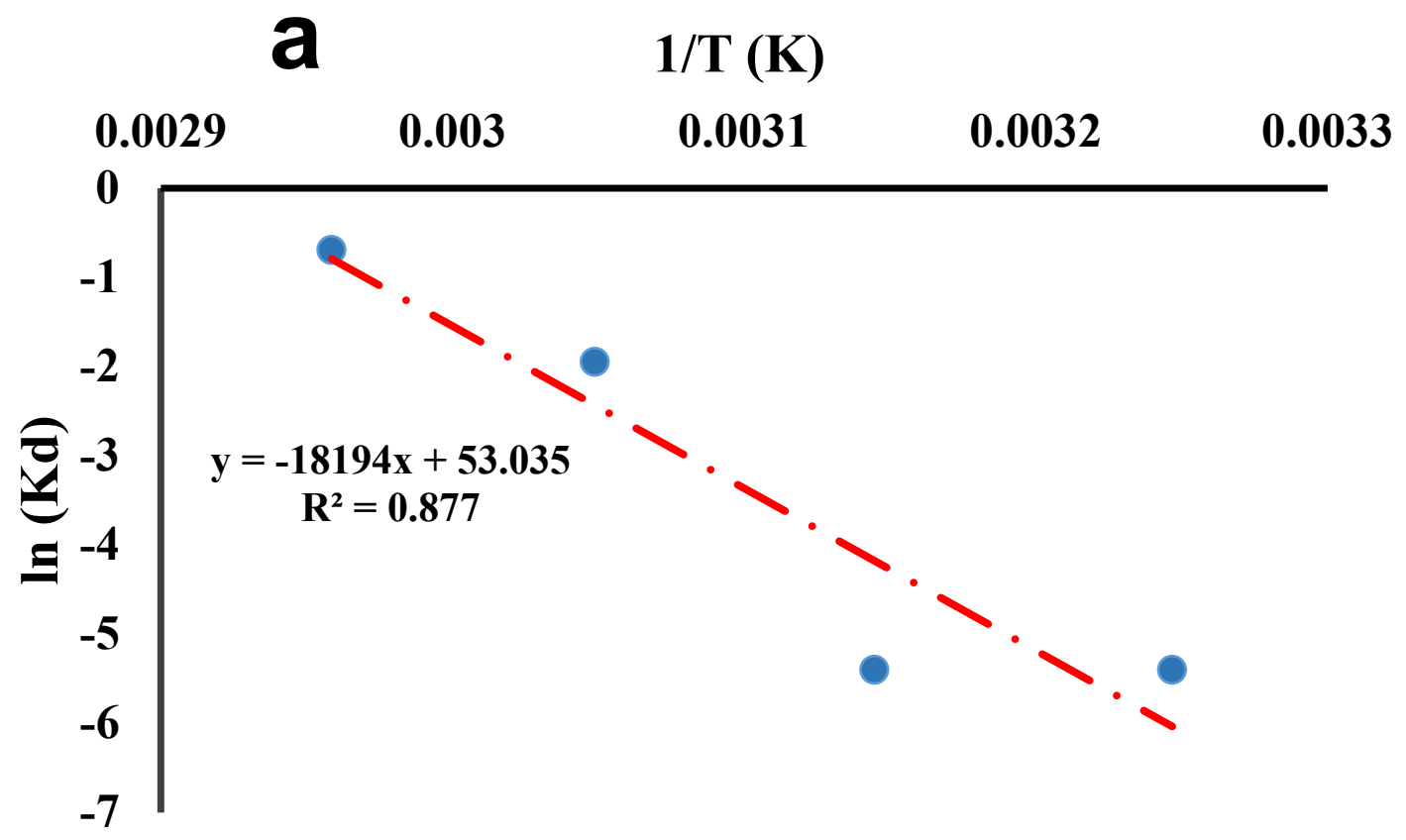

824

825 


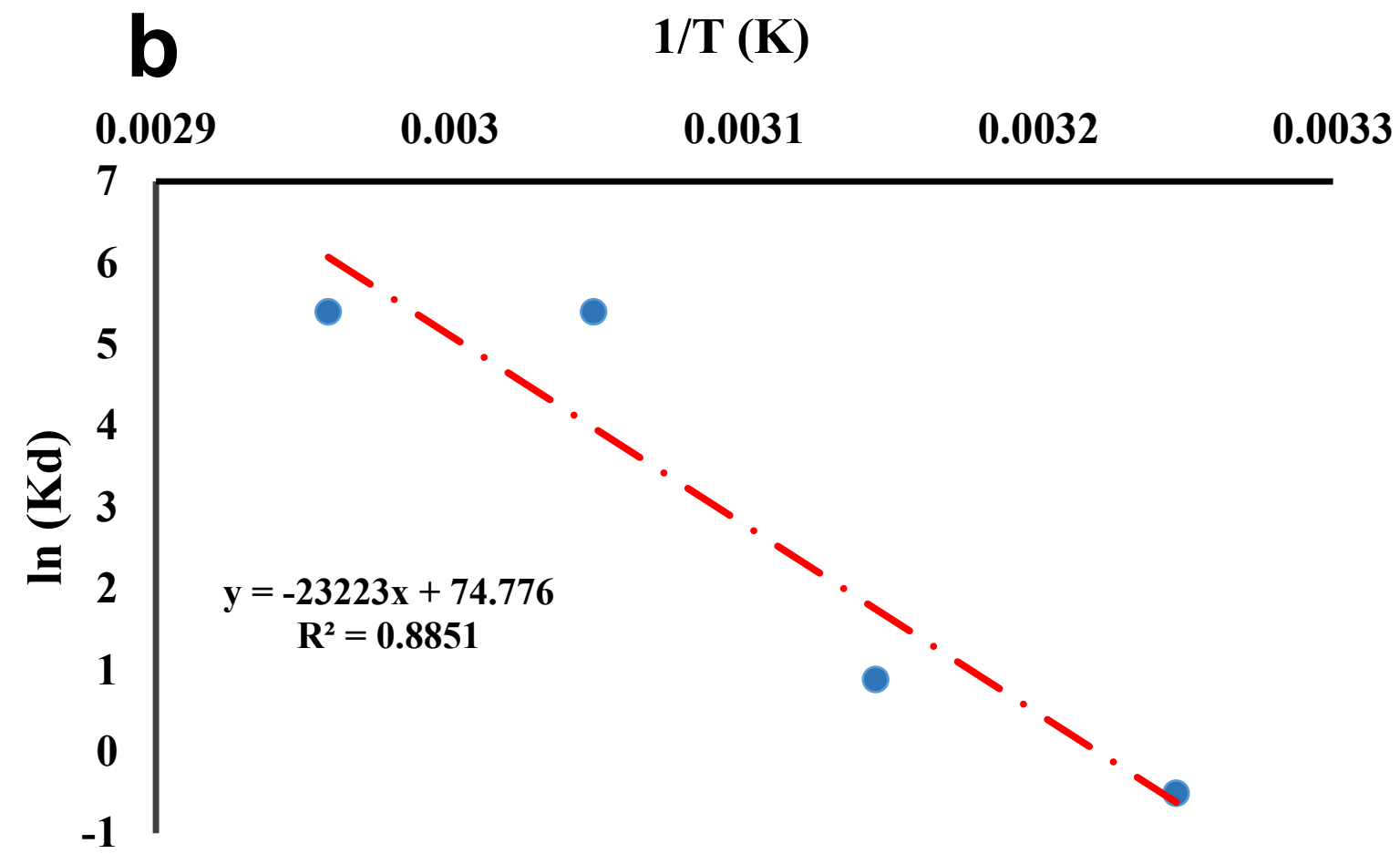

826

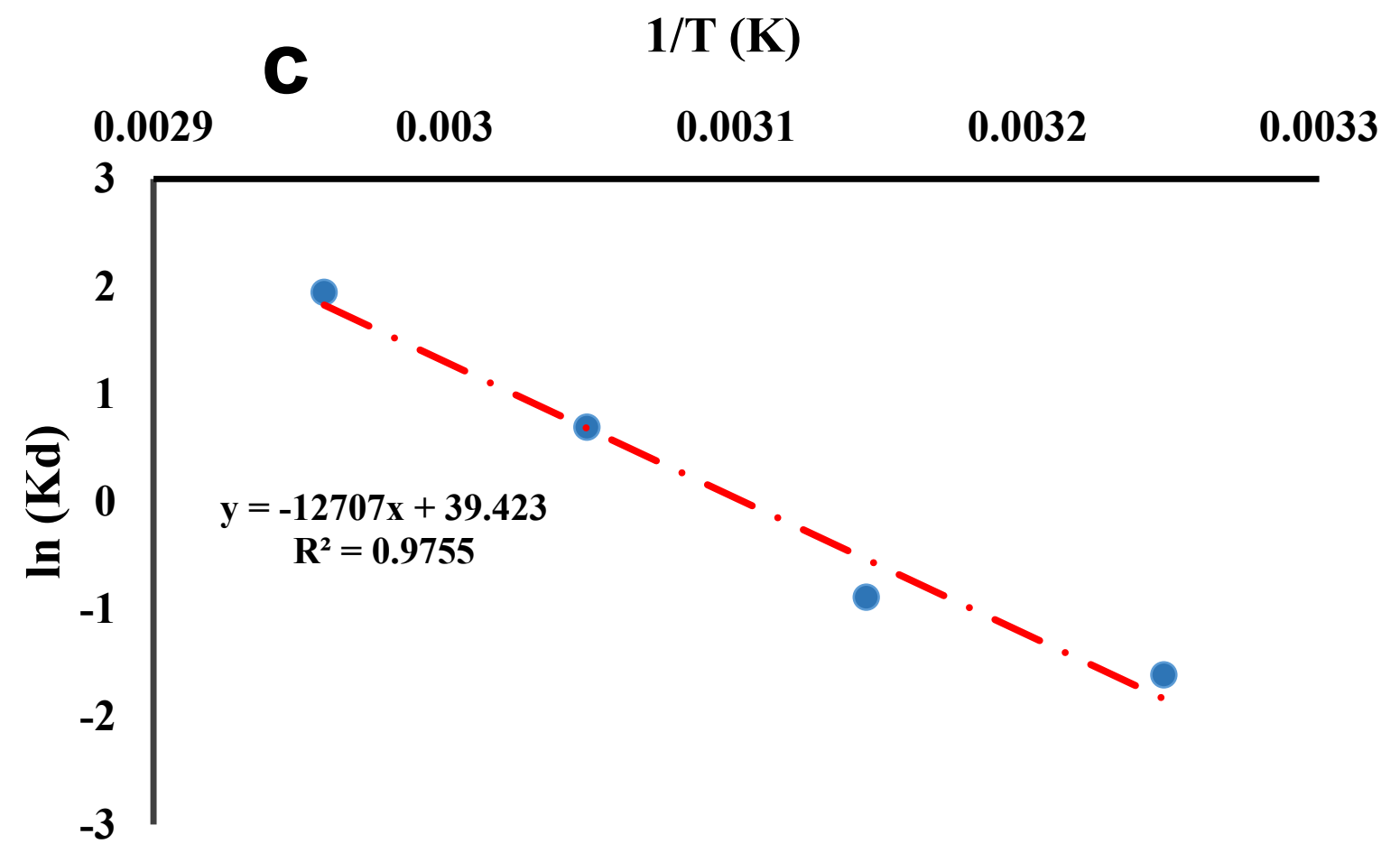

Figure 8. 


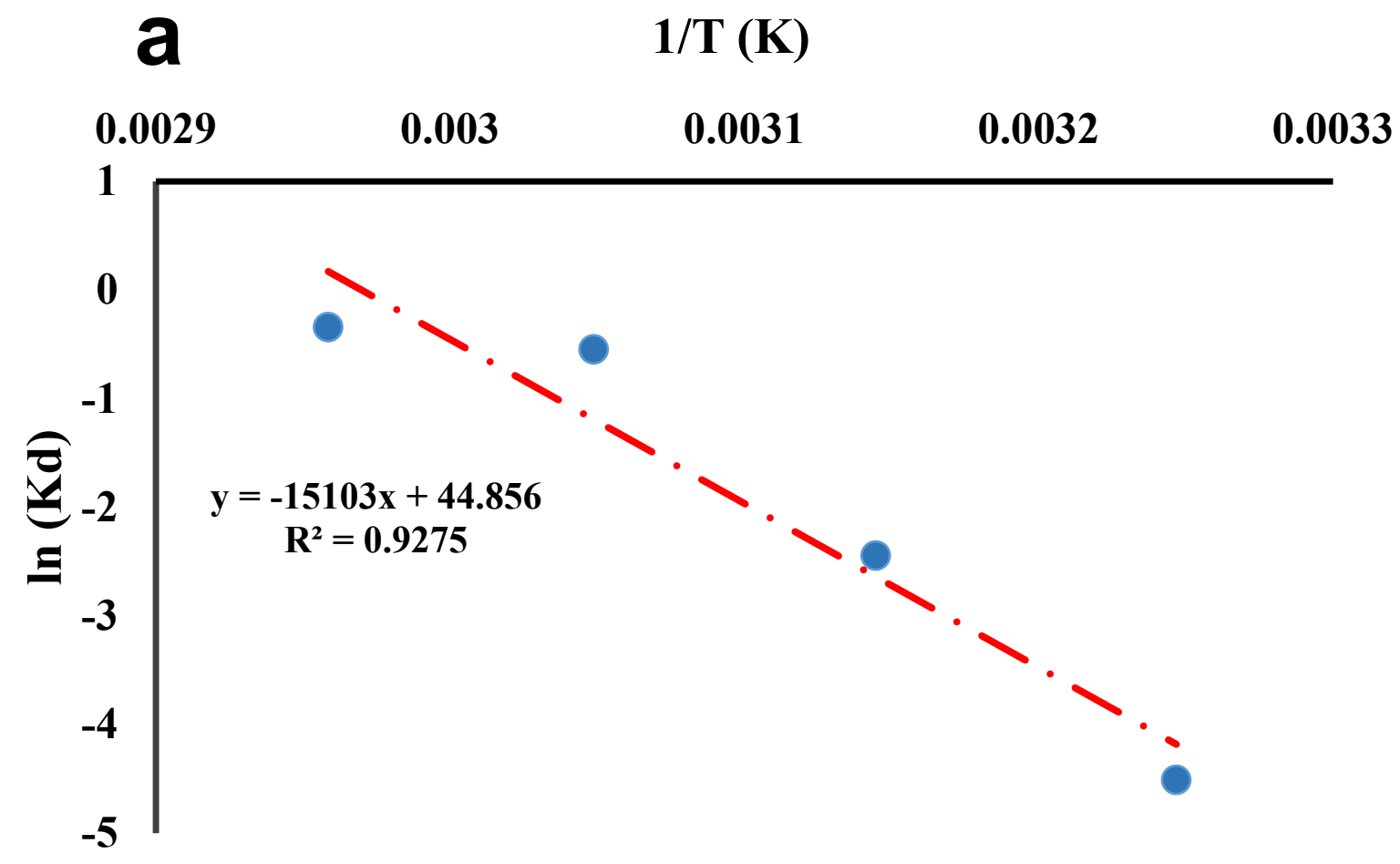

830

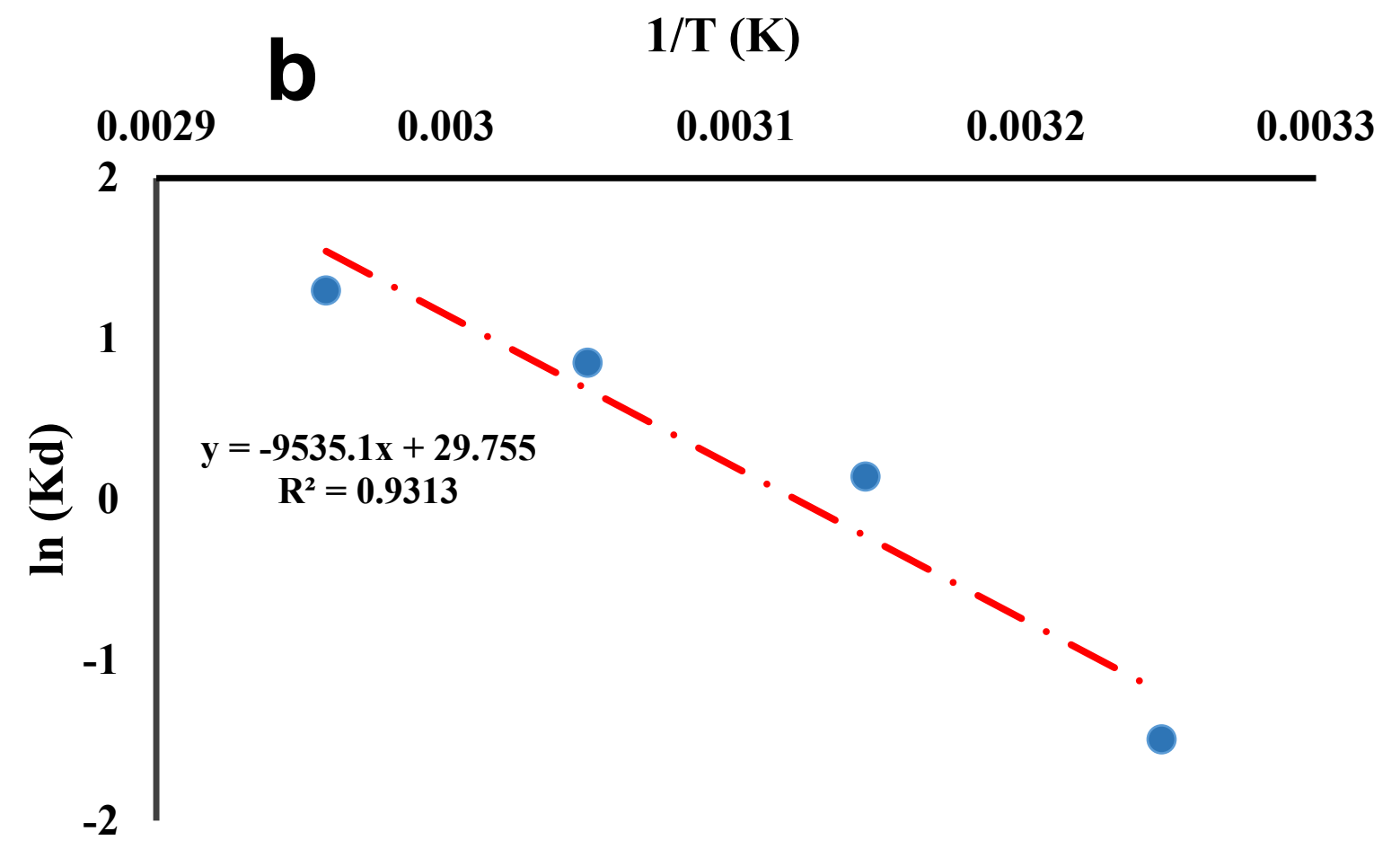

831 


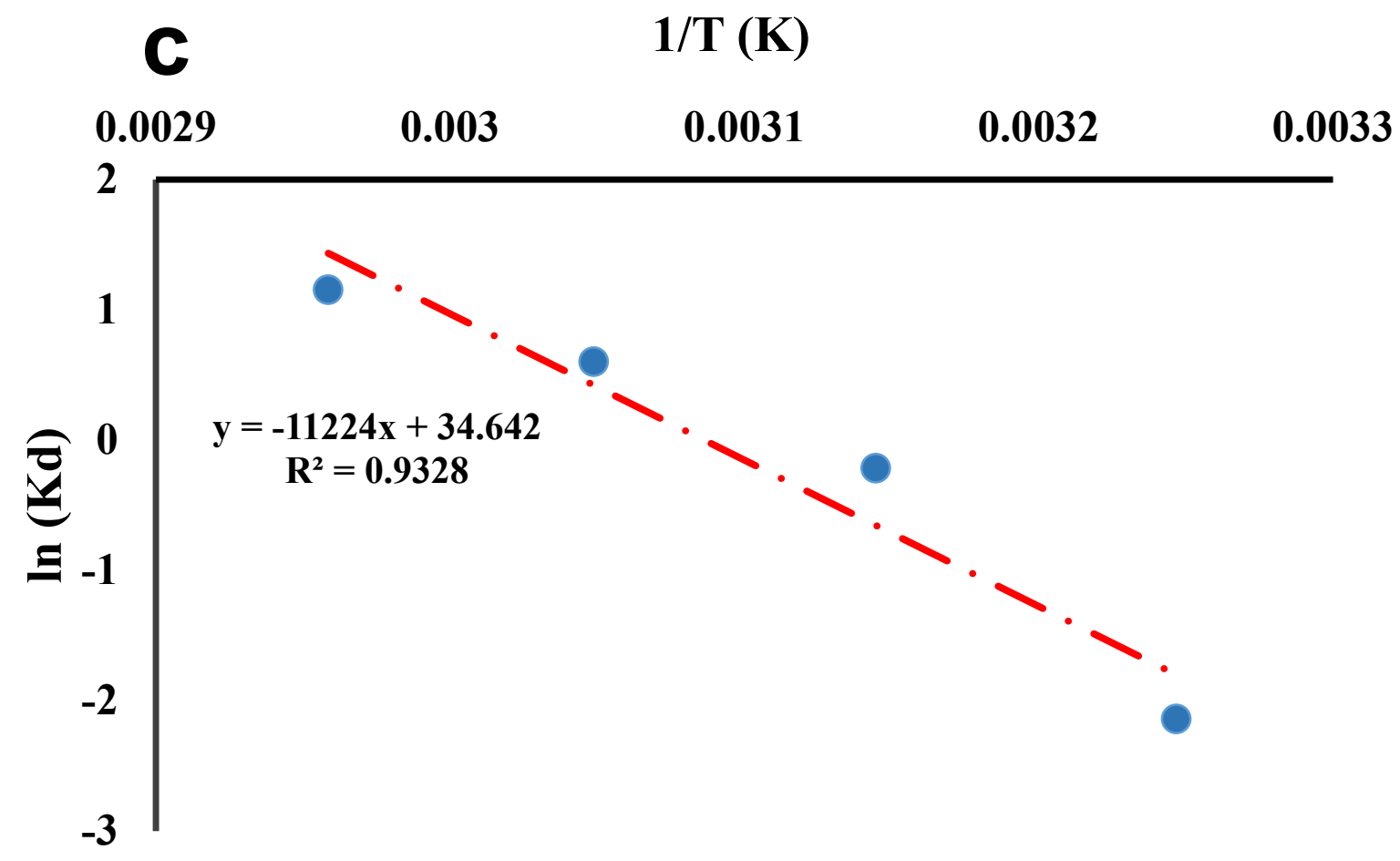

832

833

Figure 9.

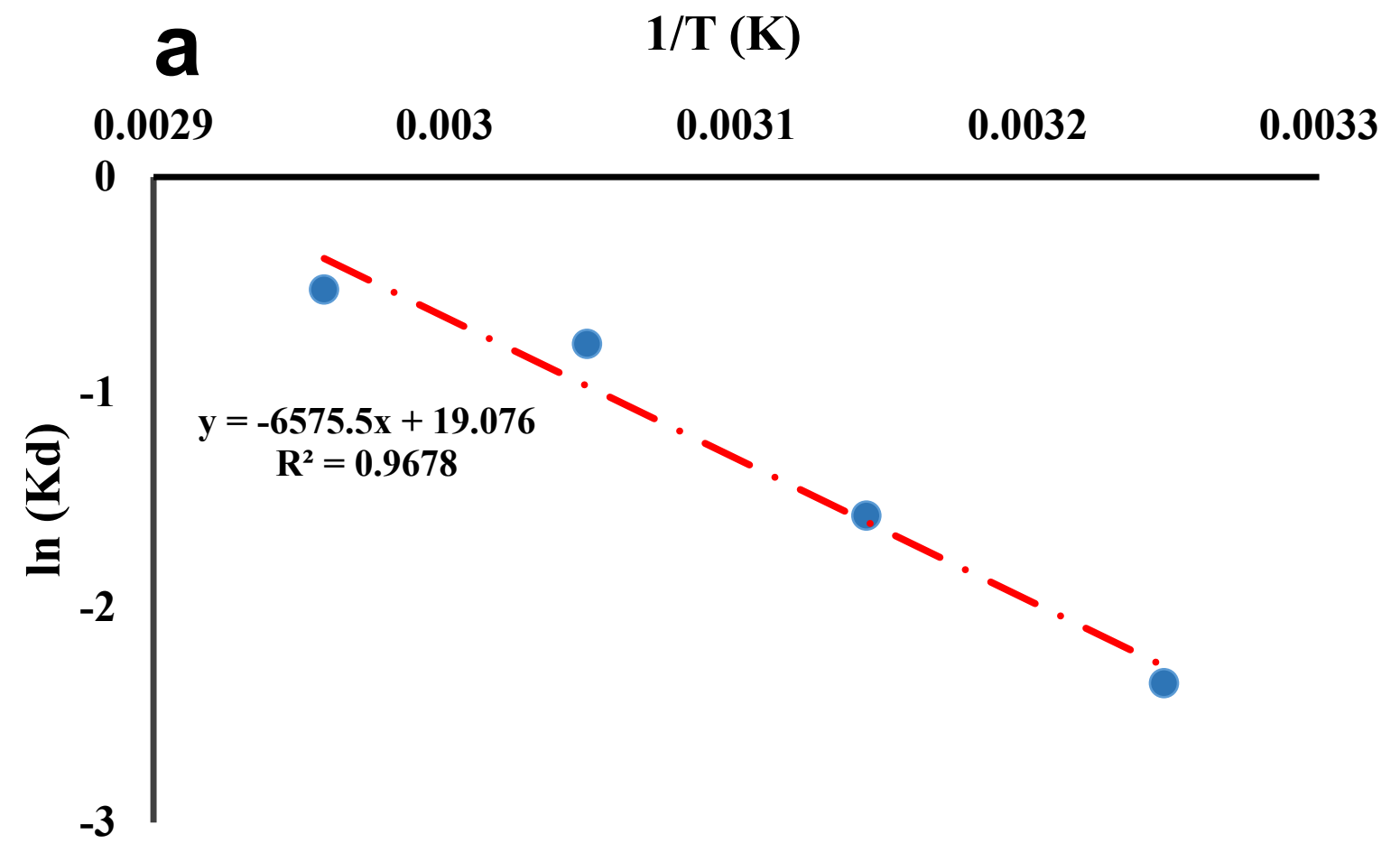

834 


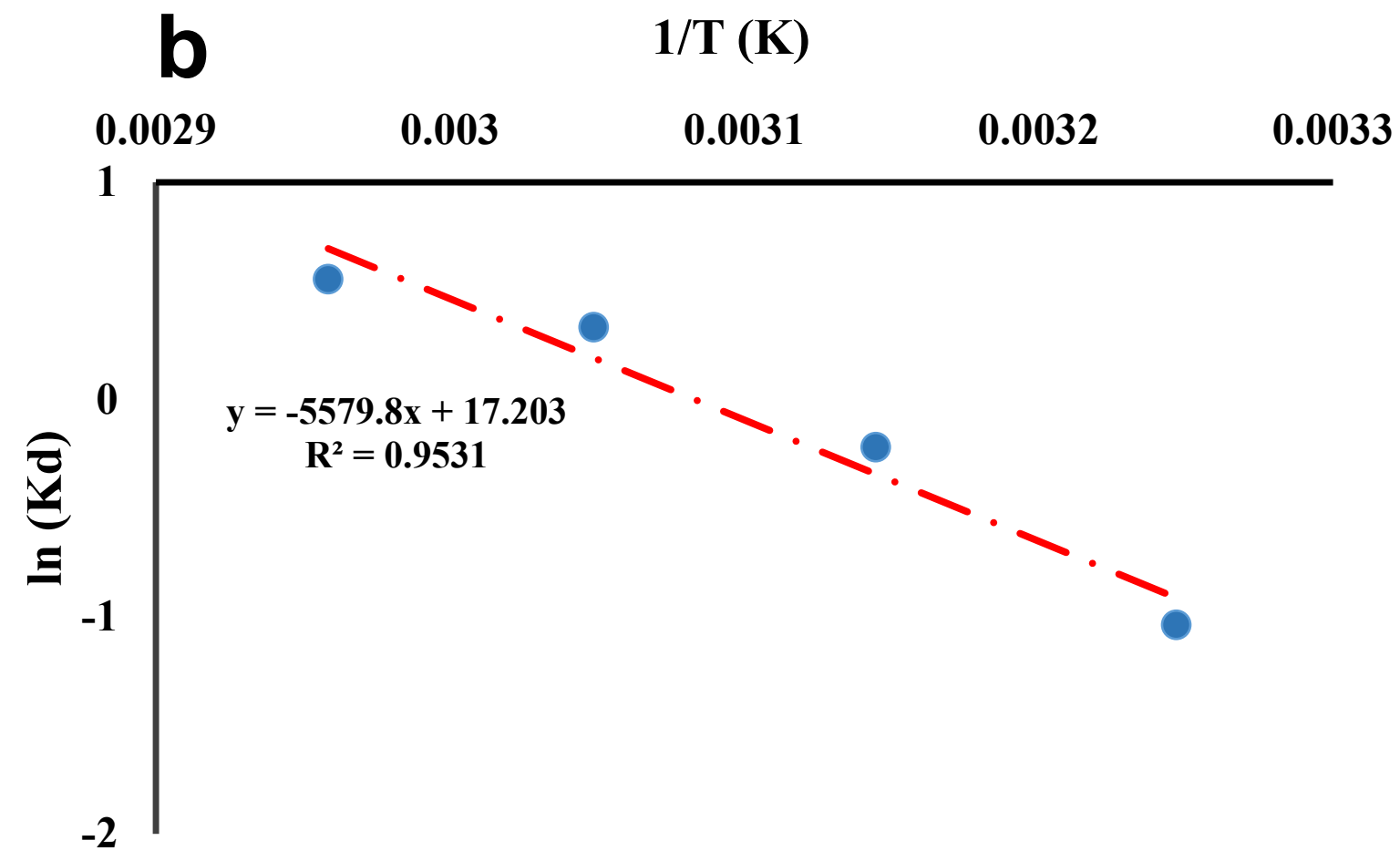

835

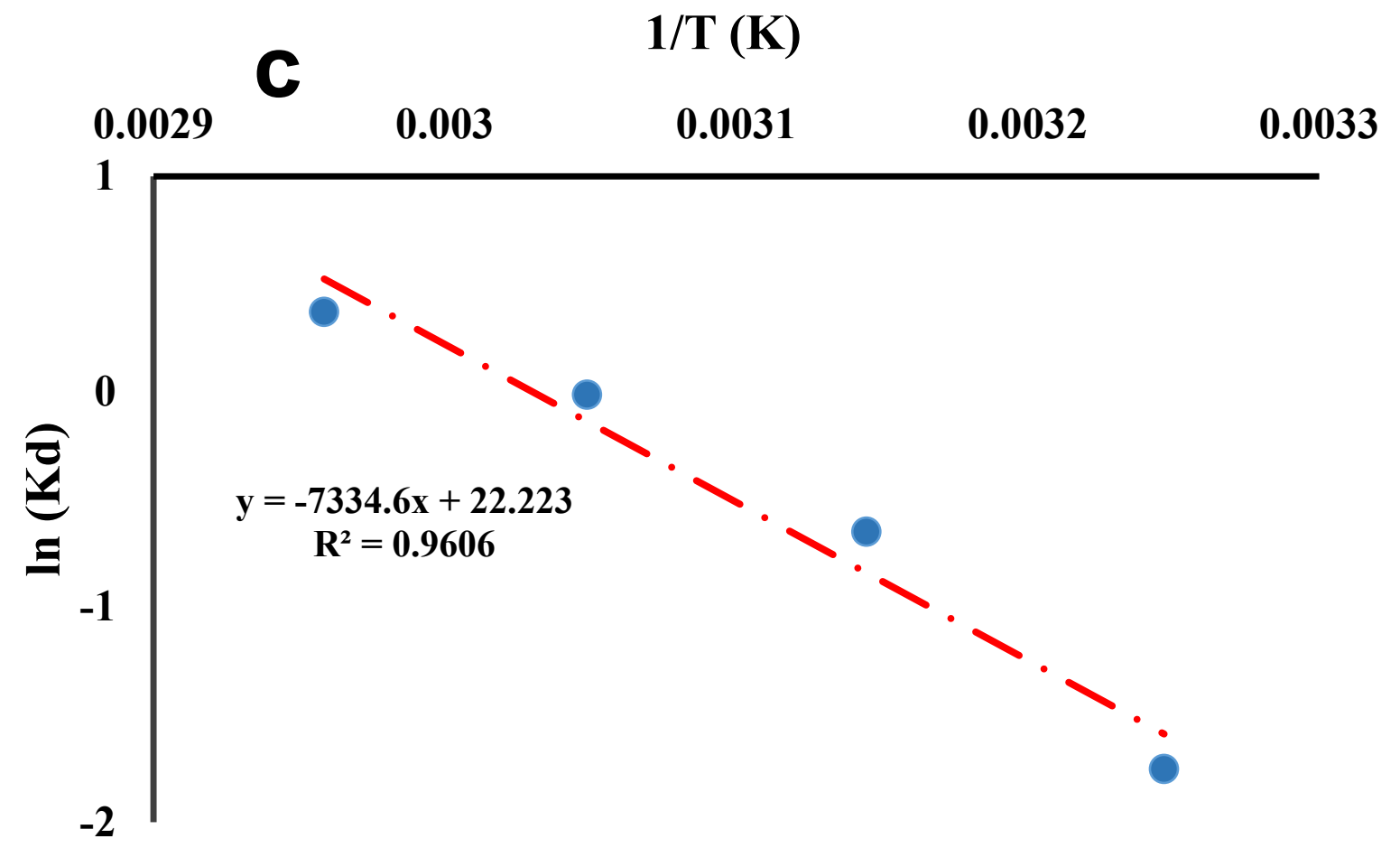

836

837

838

839

840

841

842

843

844

Figure 10. 
Table 1. The $\mathrm{Fe}(\mathrm{II})$ and $\mathrm{Cu}$ (II) content $\left(\mathrm{mg} \mathrm{kg}^{-1}\right)$ at $65^{\circ} \mathrm{C}$

\begin{tabular}{|c|c|c|c|c|c|c|}
\hline \multirow{3}{*}{ Time (min) } & \multicolumn{2}{|c|}{$\begin{array}{c}\text { Industrial bleaching } \\
\text { method (IBM) }\end{array}$} & \multicolumn{4}{|c|}{ Ultrasonic bleaching method (UBM) } \\
\hline & \multirow[t]{2}{*}{$\mathrm{Fe}(\mathrm{II}) *$} & \multirow[t]{2}{*}{$\mathrm{Cu}(\mathrm{II})$} & \multicolumn{2}{|c|}{ UBM-25 kHz } & \multicolumn{2}{|c|}{ UBM-40 kHz } \\
\hline & & & $\mathrm{Fe}(\mathrm{II})$ & $\mathrm{Cu}(\mathrm{II})$ & $\mathrm{Fe}(\mathrm{II})$ & $\mathrm{Cu}(\mathrm{II})$ \\
\hline $\mathbf{0}$ & $0.063^{\text {aA }}$ & $0.024^{\mathrm{aA}}$ & $0.063^{\mathrm{aA}}$ & $0.024^{\mathrm{aA}}$ & $0.063^{\mathrm{aA}}$ & $0.024^{\text {aA }}$ \\
\hline 5 & $0.063^{\text {aA }}$ & $0.024^{\mathrm{aA}}$ & $0.060^{\mathrm{bB}}$ & $0.021^{\mathbf{b B}}$ & $0.062^{\mathrm{aA}}$ & $0.022^{\text {abAB }}$ \\
\hline 10 & $0.058^{\mathbf{b A}}$ & $0.022^{\mathrm{abA}}$ & $0.051^{\mathrm{cBC}}$ & $0.018^{\mathrm{cC}}$ & $0.054^{\mathrm{bB}}$ & $0.020^{\mathrm{bB}}$ \\
\hline 15 & $0.051^{\mathrm{cA}}$ & $0.021^{\mathrm{bA}}$ & $0.028^{\mathrm{dC}}$ & $0.011^{\mathrm{dC}}$ & $0.039^{\mathbf{c B}}$ & $0.014^{\mathrm{cB}}$ \\
\hline 20 & $0.049^{\mathrm{cA}}$ & $0.018^{\mathrm{cA}}$ & $0.012^{\mathrm{eC}}$ & $0.03^{\mathrm{eC}}$ & $0.018^{\mathrm{dB}}$ & $0.007^{\mathrm{dB}}$ \\
\hline 25 & $0.045^{\mathrm{dA}}$ & $0.017^{\mathrm{cA}}$ & $0.005^{\mathrm{fC}}$ & $\mathrm{ND}^{\mathrm{fC}}$ & $0.010^{\mathrm{eB}}$ & $0.003^{\mathrm{eB}}$ \\
\hline 30 & $0.042^{\mathrm{eA}}$ & $0.016^{\mathrm{cA}}$ & $\mathrm{ND}^{\mathrm{gC}}$ & $\mathrm{ND}^{\mathrm{fB}}$ & $0.004^{\mathrm{fB}}$ & $\mathrm{ND}^{\mathrm{fB}}$ \\
\hline
\end{tabular}

* Each data represents the mean value from three replicates and values with similar letters are not

$849 * *$ Different lowercase letters in each column and capital letters in each row indicate significant 850 statistical difference in iron and cupper $(\mathrm{p} \leq 0.05)$. 
Table 2. The $\mathrm{Fe}(\mathrm{II})$ and $\mathrm{Cu}(\mathrm{II})$ content $\left(\mathrm{mg} \mathrm{kg}^{-1}\right)$ at $30 \mathrm{~min}$

\begin{tabular}{|c|c|c|c|c|c|c|}
\hline \multirow{3}{*}{ Temperature $\left({ }^{\circ} \mathrm{C}\right)$} & \multicolumn{2}{|c|}{$\begin{array}{c}\text { Industrial bleaching } \\
\text { method (IBM) }\end{array}$} & \multicolumn{4}{|c|}{ Ultrasonic bleaching method (UBM) } \\
\hline & \multirow[t]{2}{*}{$\mathrm{Fe}(\mathrm{II})$} & \multirow[t]{2}{*}{$\mathrm{Cu}(\mathrm{II})$} & \multicolumn{2}{|c|}{ UBM-25 kHz } & \multicolumn{2}{|c|}{ UBM-40 kHz } \\
\hline & & & $\mathrm{Fe}(\mathrm{II})$ & $\mathrm{Cu}(\mathrm{II})$ & $\mathrm{Fe}(\mathrm{II})$ & $\mathrm{Cu}(\mathrm{II})$ \\
\hline 35 & $0.062^{\mathrm{aA}}$ & $0.024^{\text {aA }}$ & $0.061^{\text {aA }}$ & $0.015^{\mathrm{bC}}$ & $0.062^{\text {aA }}$ & $0.020^{\mathrm{aB}}$ \\
\hline 45 & $0.060^{\mathrm{aA}}$ & $0.024^{\mathrm{aA}}$ & $0.040^{\mathrm{bC}}$ & $0.007^{\mathrm{bC}}$ & $0.048^{\mathbf{b B}}$ & $0.017^{\mathbf{b B}}$ \\
\hline 55 & $0.057^{\mathbf{b A}}$ & $0.021^{\mathbf{b A}}$ & $0.023^{\mathrm{cC}}$ & $\mathrm{ND}^{\mathrm{bC}}$ & $0.033^{\mathbf{c B}}$ & $0.008^{\mathbf{c B}}$ \\
\hline 65 & $0.043^{\mathbf{c A}}$ & $0.016^{\mathrm{cA}}$ & $\mathrm{ND}^{\mathrm{dC}}$ & $\mathrm{ND}^{\mathrm{bC}}$ & $0.020^{\mathrm{dB}}$ & $0.003^{\mathrm{dB}}$ \\
\hline
\end{tabular}

$853 *$ Each data represents the mean value from three replicates and values with similar letters are not 854 significantly different in each row $(\mathrm{P}<0.05)$. ND means not detected.

$855 * *$ Different lowercase letters in each column and capital letters in each row indicate significant

856 statistical difference in iron and cupper $(\mathrm{p} \leq 0.05)$. 
Table 3. The Carotenoid ( $\left.\mathrm{mg} \mathrm{kg}^{-1}\right)$ and Chlorophyll $\left(\mu \mathrm{g} \mathrm{kg}^{-1}\right)$ content at $65^{\circ} \mathrm{C}$

\begin{tabular}{|c|c|c|c|c|c|c|}
\hline \multirow{3}{*}{ Time (min) } & \multicolumn{2}{|c|}{$\begin{array}{c}\text { Industrial bleaching method } \\
\text { (IBM) }\end{array}$} & \multicolumn{4}{|c|}{ Ultrasonic bleaching method (UBM) } \\
\hline & \multirow[t]{2}{*}{ Carotenoid* } & \multirow[t]{2}{*}{ Chlorophyll } & \multicolumn{2}{|c|}{ UBM-25 kHz } & \multicolumn{2}{|c|}{ UBM-40 kHz } \\
\hline & & & Carotenoid* & Chlorophyll & Carotenoid* & Chlorophyll \\
\hline $\mathbf{0}$ & $5.51^{\text {aA }}$ & $509.9^{\text {aA }}$ & $5.51^{\mathrm{aA}}$ & $509.9^{\text {aA }}$ & $5.5^{\mathrm{aA}}$ & $509.9^{\text {aA }}$ \\
\hline 5 & $5.43^{\mathrm{aA}}$ & $473.8^{\mathrm{aA}}$ & $5.01^{\mathrm{bB}}$ & $436.1^{\mathbf{b B}}$ & $5.1^{\text {aA }}$ & $478.0^{\mathbf{a b A B}}$ \\
\hline 10 & $5.12^{\mathrm{bA}}$ & $437.3^{\mathbf{a b A}}$ & $3.87 \mathrm{cBC}$ & $374.8^{\mathrm{cC}}$ & $4.3^{\mathbf{b B}}$ & $414.2^{\text {bB }}$ \\
\hline 15 & $4.82^{\mathrm{cA}}$ & $404.7^{\text {bA }}$ & $3.03 \mathrm{dC}$ & $325.5^{\mathrm{dC}}$ & $3.5^{\mathrm{cB}}$ & $361.8^{\text {cB }}$ \\
\hline 20 & $4.24^{\mathrm{cA}}$ & $395.1^{\mathbf{c A}}$ & $2.78^{\mathrm{eC}}$ & $267.0^{\mathrm{eC}}$ & $3.1^{\mathrm{dB}}$ & $302.3^{\mathrm{dB}}$ \\
\hline 25 & $3.76^{\mathrm{dA}}$ & $350.7^{\mathrm{eA}}$ & $1.56^{\mathrm{fC}}$ & $202.5^{\mathrm{fC}}$ & $1.8^{\mathrm{eB}}$ & $248.6^{\mathrm{eB}}$ \\
\hline 30 & $2.83^{\mathrm{eA}}$ & $284.4^{\mathrm{cA}}$ & $0.48^{\mathrm{gC}}$ & $125.9^{\mathrm{fB}}$ & $0.82^{\mathrm{fB}}$ & $160.7^{\mathrm{fB}}$ \\
\hline
\end{tabular}

$859 *$ Each data represents the mean value from three replicates and values with similar letters are not 860 significantly different in each row $(\mathrm{P}<0.05)$. ND means not detected.

$861 * *$ Different lowercase letters in each column and capital letters in each row indicate significant 862 statistical difference in iron and cupper $(\mathrm{p} \leq 0.05)$. 
Table 4. The Carotenoid $\left(\mathrm{mg} \mathrm{kg}^{-1}\right)$ and Chlorophyll content $\left(\mu \mathrm{g} \mathrm{kg}^{-1}\right)$ at $30 \mathrm{~min}$

\begin{tabular}{|c|c|c|c|c|c|c|}
\hline \multirow{3}{*}{ Temperature $\left({ }^{\circ} \mathrm{C}\right)$} & \multicolumn{2}{|c|}{$\begin{array}{c}\text { Industrial bleaching } \\
\text { method (IBM) }\end{array}$} & \multicolumn{4}{|c|}{ Ultrasonic bleaching method (UBM) } \\
\hline & \multirow[t]{2}{*}{ Carotenoid* } & \multirow[t]{2}{*}{ Chlorophyll } & \multicolumn{2}{|c|}{ UBM-25 kHz } & \multicolumn{2}{|c|}{ UBM-40 kHz } \\
\hline & & & Carotenoid* & Chlorophyll & Carotenoid* & Chlorophyll \\
\hline 35 & $5.45^{\text {aA }}$ & $465.7^{\text {aA }}$ & $4.5^{\mathrm{aA}}$ & $376.8^{\text {bC }}$ & $4.9^{\mathrm{aA}}$ & $434.7^{\mathrm{aB}}$ \\
\hline 45 & $5.12^{\mathrm{aA}}$ & $421.8^{\text {aA }}$ & $3.5^{\mathrm{bC}}$ & $282.6^{\mathrm{bC}}$ & $3.0^{\mathrm{bB}}$ & $334.6^{\text {bB }}$ \\
\hline 55 & $3.79^{\mathbf{b A}}$ & $348.8^{\text {bA }}$ & $1.0^{\mathrm{cC}}$ & $202.6^{\text {bC }}$ & $1.6^{\mathrm{cB}}$ & $236.4^{\mathrm{cB}}$ \\
\hline 65 & $2.83^{\mathrm{eA}}$ & $284.4^{\mathrm{cA}}$ & $0.48 \mathrm{gC}$ & $125.9^{\mathrm{fB}}$ & $0.82^{\mathrm{fB}}$ & $160.7^{\mathrm{fB}}$ \\
\hline
\end{tabular}

$865 *$ Each data represents the mean value from three replicates and values with similar letters are not 866 significantly different in each row $(\mathrm{P}<0.05)$. ND means not detected.

$867 * *$ Different lowercase letters in each column and capital letters in each row indicate significant

868 statistical difference in iron and cupper $(\mathrm{p} \leq 0.05)$. 
871 Table 5. Fitting parameters of adsorption kinetics for Fe(II) ions under IBM and UBM

\begin{tabular}{|c|c|c|c|c|c|c|c|c|}
\hline \multirow[t]{2}{*}{ System } & \multirow[t]{2}{*}{ Model } & \multirow[t]{2}{*}{$\begin{array}{l}\text { Kinetics } \\
\text { parameters }\end{array}$} & \multicolumn{2}{|c|}{ Value } & \multicolumn{2}{|r|}{$\mathrm{R}^{2}$} & \multicolumn{2}{|c|}{$\chi^{2}$} \\
\hline & & & Linear & Nonlinear & Linear & Nonlinear & Linear & Nonlinear \\
\hline \multirow{6}{*}{ IBM } & \multirow{2}{*}{$\begin{array}{l}\text { Pseudo-first- } \\
\text { order }\end{array}$} & $k_{l}\left(\min ^{-I}\right)$ & 0.077 & 0.053 & \multirow[t]{2}{*}{0.912} & \multirow[t]{2}{*}{0.938} & \multirow[t]{2}{*}{0.0008} & \multirow[t]{2}{*}{0.0002} \\
\hline & & $q_{1}\left(m g g^{-1}\right)$ & 0.0026 & 0.0019 & & & & \\
\hline & \multirow[t]{2}{*}{$\begin{array}{l}\text { Pseudo-second- } \\
\text { order }\end{array}$} & $\begin{array}{l}k_{2}(g(m g \\
\left.(m i n)^{-1}\right)\end{array}$ & 0.0058 & 0.0066 & \multirow[t]{2}{*}{0.693} & \multirow[t]{2}{*}{0.752} & \multirow[t]{2}{*}{0.004} & \multirow[t]{2}{*}{0.0032} \\
\hline & & $q_{2}\left(m g g^{-1}\right)$ & 0.0034 & 0.0029 & & & & \\
\hline & \multirow[t]{2}{*}{$\begin{array}{l}\text { Intraparticle } \\
\text { diffusion }\end{array}$} & $\begin{array}{l}k_{i}(m g(g \\
\left.\left.m i n^{1 / 2}\right)^{-1}\right)\end{array}$ & - & 0.0004 & \multirow[t]{2}{*}{0.937} & \multirow[t]{2}{*}{0.844} & \multirow[t]{2}{*}{0.0014} & \multirow[t]{2}{*}{0.0028} \\
\hline & & $\mathrm{kiC} / \mathrm{C}$ & 0.011 & -0.0004 & & & & \\
\hline \multirow[t]{2}{*}{ System } & \multirow[t]{2}{*}{ Model } & \multirow{2}{*}{$\begin{array}{c}\text { Kinetics } \\
\text { parameters }\end{array}$} & \multicolumn{2}{|c|}{ Value } & \multicolumn{2}{|r|}{$\mathrm{R}^{2}$} & \multicolumn{2}{|c|}{$\chi^{2}$} \\
\hline & & & Linear & Nonlinear & Linear & Nonlinear & Linear & Nonlinear \\
\hline \multirow{6}{*}{$\begin{array}{c}\text { UBM-25 } \\
\text { kHz }\end{array}$} & \multirow{2}{*}{$\begin{array}{l}\text { Pseudo-first- } \\
\text { order }\end{array}$} & $k_{1}\left(\min ^{-1}\right)$ & 0.104 & 0.059 & \multirow[t]{2}{*}{0.887} & \multirow[t]{2}{*}{0.962} & \multirow[t]{2}{*}{0.002} & 0.0011 \\
\hline & & $q_{1}\left(m g g^{-1}\right)$ & 0.0088 & 0.0058 & & & & \\
\hline & $\begin{array}{l}\text { Pseudo-second- } \\
\text { order }\end{array}$ & $\begin{array}{c}k_{2}(g(m g \\
\left.m i n)^{-1}\right)\end{array}$ & 0.0054 & 0.0068 & 0.619 & 0.687 & 0.0047 & 0.0039 \\
\hline & & $q_{2}\left(m g g^{-1}\right)$ & 0.0094 & 0.009 & & & & \\
\hline & $\begin{array}{l}\text { Intraparticle } \\
\text { diffusion }\end{array}$ & $\begin{array}{l}k_{i}(m g(g \\
\left.\left.m i n^{1 / 2}\right)^{-1}\right)\end{array}$ & - & 0.0012 & 0.961 & 0.831 & 0.0013 & 0.003 \\
\hline & & $\mathrm{kiC} / \mathrm{C}$ & 0.0035 & -0.0012 & & & & \\
\hline System & Model & $\begin{array}{c}\text { Kinetics } \\
\text { parameters }\end{array}$ & & & & $\mathrm{R}^{2}$ & & $x^{2}$ \\
\hline & & & Linear & Nonlinear & Linear & Nonlinear & Linear & Nonlinear \\
\hline & Pseudo-first- & $k_{1}\left(\min ^{-1}\right)$ & 0.091 & 0.056 & 0.851 & 0.964 & 0.0088 & 0.0011 \\
\hline & order & $q_{1}\left(m g g^{-1}\right)$ & 0.0082 & 0.0054 & & & & \\
\hline $\mathrm{kHz}$ & $\begin{array}{l}\text { Pseudo-second- } \\
\text { order }\end{array}$ & $\begin{array}{c}k_{2}(g(m g \\
\left.m i n)^{-1}\right)\end{array}$ & 0.0057 & 0.0069 & 0.594 & 0.634 & 0.0048 & 0.0045 \\
\hline & & $q_{2}\left(m g g^{-1}\right)$ & 0.0096 & 0.0089 & & & & \\
\hline & $\begin{array}{l}\text { Intraparticle } \\
\text { diffusion }\end{array}$ & $\begin{array}{l}k_{i}(\operatorname{mg}(g \\
\left.\left.\min ^{1 / 2}\right)^{-1}\right)\end{array}$ & - & 0.0011 & 0.956 & 0.797 & 0.0012 & 0.008 \\
\hline & & $\mathrm{kiC} / \mathrm{C}$ & 0.0014 & -0.0013 & & & & \\
\hline
\end{tabular}


Table 6. Fitting parameters of adsorption kinetics for $\mathrm{Cu}(\mathrm{II})$ ions under IBM and UBM

\begin{tabular}{|c|c|c|c|c|c|c|c|c|}
\hline \multirow[t]{2}{*}{ System } & \multirow[t]{2}{*}{ Model } & \multirow{2}{*}{$\begin{array}{l}\text { Kinetics } \\
\text { parameters }\end{array}$} & \multicolumn{2}{|c|}{ Value } & \multicolumn{2}{|r|}{$\mathrm{R}^{2}$} & \multicolumn{2}{|c|}{$\chi^{2}$} \\
\hline & & & Linear & Nonlinear & Linear & Nonlinear & Linear & Nonlinear \\
\hline \multirow{6}{*}{ IBM } & \multirow{2}{*}{$\begin{array}{l}\text { Pseudo-first- } \\
\text { order }\end{array}$} & $k_{1}\left(\min ^{-1}\right)$ & 0.202 & 0.051 & \multirow[t]{2}{*}{0.632} & \multirow[t]{2}{*}{0.967} & \multirow[t]{2}{*}{0.002} & \multirow[t]{2}{*}{0.001} \\
\hline & & $q_{1}\left(m g g^{-1}\right)$ & 0.0027 & 0.0007 & & & & \\
\hline & \multirow[t]{2}{*}{$\begin{array}{l}\text { Pseudo-second- } \\
\text { order }\end{array}$} & $k_{2}\left(\begin{array}{c}g(\operatorname{mg~min})^{-} \\
\mathrm{l})\end{array}\right.$ & 0.0052 & 0.0065 & \multirow[t]{2}{*}{0.682} & \multirow[t]{2}{*}{0.759} & \multirow[t]{2}{*}{0.0038} & \multirow[t]{2}{*}{0.0033} \\
\hline & & $q_{2}\left(m g g^{-1}\right)$ & 0.0039 & 0.0032 & & & & \\
\hline & \multirow[t]{2}{*}{$\begin{array}{l}\text { Intraparticle } \\
\text { diffusion }\end{array}$} & $\begin{array}{l}k_{i}(m g(g \\
\left.\left.m i n^{I / 2}\right)^{-1}\right)\end{array}$ & - & 0.0005 & \multirow[t]{2}{*}{0.966} & \multirow[t]{2}{*}{0.858} & \multirow[t]{2}{*}{0.0026} & \multirow[t]{2}{*}{0.0028} \\
\hline & & $\mathrm{kiC} / \mathrm{C}$ & 0.0063 & -0.0004 & & & & \\
\hline \multirow[t]{2}{*}{ System } & \multirow[t]{2}{*}{ Model } & \multirow[t]{2}{*}{$\begin{array}{l}\text { Kinetics } \\
\text { parameters }\end{array}$} & \multicolumn{2}{|c|}{ Value } & \multicolumn{2}{|r|}{$\mathrm{R}^{2}$} & \multicolumn{2}{|c|}{$\chi^{2}$} \\
\hline & & & Linear & Nonlinear & Linear & Nonlinear & Linear & Nonlinear \\
\hline \multirow{6}{*}{$\begin{array}{c}\text { UBM-25 } \\
\mathrm{kHz}\end{array}$} & \multirow{2}{*}{$\begin{array}{l}\text { Pseudo-first- } \\
\text { order }\end{array}$} & $k_{l}\left(\min ^{-1}\right)$ & 0.389 & 0.062 & \multirow[t]{2}{*}{0.737} & \multirow[t]{2}{*}{0.967} & \multirow[t]{2}{*}{0.021} & 0.001 \\
\hline & & $q_{1}\left(m g g^{-1}\right)$ & 0.023 & 0.0023 & & & & \\
\hline & $\begin{array}{l}\text { Pseudo-second- } \\
\text { order }\end{array}$ & 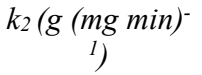 & 0.0045 & 0.0064 & 0.537 & 0.654 & 0.0046 & 0.0036 \\
\hline & & $q_{2}\left(m g g^{-1}\right)$ & 0.0036 & 0.0029 & & & & \\
\hline & $\begin{array}{l}\text { Intraparticle } \\
\text { diffusion }\end{array}$ & $\begin{array}{l}k_{i}(\operatorname{mg}(g \\
\left.\left.\min ^{1 / 2}\right)^{-1}\right)\end{array}$ & - & 0.0012 & 0.961 & 0.831 & 0.0003 & 0.002 \\
\hline & & $k_{i} C$ & 0.005 & -0.0012 & & & & \\
\hline System & Model & $\begin{array}{c}\text { Kinetics } \\
\text { parameters }\end{array}$ & & alue & & $\mathrm{R}^{2}$ & & $\chi^{2}$ \\
\hline & & & Linear & Nonlinear & Linear & Nonlinear & Linear & Nonlinear \\
\hline & Pseudo-first- & $k_{1}\left(\min ^{-1}\right)$ & 0.258 & 0.053 & 0.536 & 0.96 & 0.012 & 0.009 \\
\hline & order & $q_{1}\left(m g g^{-1}\right)$ & 0.0137 & 0.0022 & & & & \\
\hline $\mathrm{kHz}$ & $\begin{array}{l}\text { Pseudo-second- } \\
\text { order }\end{array}$ & 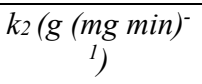 & 0.0036 & 0.0057 & 0.584 & 0.631 & 0.0042 & 0.0035 \\
\hline & & $q_{2}\left(m g g^{-1}\right)$ & 0.0034 & 0.0028 & & & & \\
\hline & $\begin{array}{c}\text { Intraparticle } \\
\text { diffusion }\end{array}$ & $\begin{array}{l}k_{i}(m g(g \\
\left.\left.\min ^{1 / 2}\right)^{-1}\right)\end{array}$ & - & 0.0011 & 0.958 & 0.797 & 0.009 & 0.01 \\
\hline & & $\mathrm{kiC} / \mathrm{C}$ & 0.0038 & -0.0013 & & & & \\
\hline
\end{tabular}


Table 7. Fitting parameters of adsorption kinetics for carotenoid under IBM and UBM

880

\begin{tabular}{|c|c|c|c|c|c|c|c|c|}
\hline \multirow[t]{2}{*}{ System } & \multirow[t]{2}{*}{ Model } & \multirow[t]{2}{*}{$\begin{array}{c}\text { Kinetics } \\
\text { parameters }\end{array}$} & \multicolumn{2}{|c|}{ Value } & \multicolumn{2}{|r|}{$\mathrm{R}^{2}$} & \multicolumn{2}{|c|}{$\chi^{2}$} \\
\hline & & & Linear & Nonlinear & Linear & Nonlinear & Linear & Nonlinear \\
\hline \multirow{6}{*}{ IBM } & \multirow{2}{*}{$\begin{array}{l}\text { Pseudo-first- } \\
\text { order }\end{array}$} & $k_{1}\left(\min ^{-1}\right)$ & 0.055 & 0.043 & \multirow[t]{2}{*}{0.861} & \multirow[t]{2}{*}{0.973} & \multirow[t]{2}{*}{0.012} & \multirow[t]{2}{*}{0.008} \\
\hline & & $q_{1}\left(m g g^{-1}\right)$ & 0.263 & 0.211 & & & & \\
\hline & \multirow[t]{2}{*}{$\begin{array}{l}\text { Pseudo-second- } \\
\text { order }\end{array}$} & 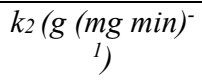 & 0.0068 & 0.0047 & \multirow[t]{2}{*}{0.746} & \multirow[t]{2}{*}{0.854} & \multirow[t]{2}{*}{0.069} & \multirow[t]{2}{*}{0.045} \\
\hline & & $q_{2}\left(m g g^{-1}\right)$ & 0.325 & 0.262 & & & & \\
\hline & \multirow[t]{2}{*}{$\begin{array}{l}\text { Intraparticle } \\
\text { diffusion }\end{array}$} & $\begin{array}{l}k_{i}(m g(g \\
\left.\left.\min ^{I / 2}\right)^{-1}\right)\end{array}$ & - & 0.037 & \multirow[t]{2}{*}{0.972} & \multirow[t]{2}{*}{0.775} & \multirow[t]{2}{*}{0.009} & \multirow[t]{2}{*}{0.032} \\
\hline & & $k i C / C$ & 0.02 & -0.045 & & & & \\
\hline \multirow[t]{2}{*}{ System } & \multirow[t]{2}{*}{ Model } & \multirow[t]{2}{*}{$\begin{array}{c}\text { Kinetics } \\
\text { parameters }\end{array}$} & \multicolumn{2}{|c|}{ Value } & \multicolumn{2}{|r|}{$\mathrm{R}^{2}$} & \multicolumn{2}{|c|}{$\chi^{2}$} \\
\hline & & & Linear & Nonlinear & Linear & Nonlinear & Linear & Nonlinear \\
\hline \multirow{6}{*}{$\begin{array}{c}\text { UBM-25 } \\
\text { kHz }\end{array}$} & \multirow{2}{*}{$\begin{array}{l}\text { Pseudo-first- } \\
\text { order }\end{array}$} & $k_{1}\left(\min ^{-1}\right)$ & 0.069 & 0.055 & \multirow[t]{2}{*}{0.869} & \multirow[t]{2}{*}{0.967} & \multirow[t]{2}{*}{0.054} & 0.035 \\
\hline & & $q_{1}\left(m g g^{-1}\right)$ & 0.513 & 0.426 & & & & \\
\hline & $\begin{array}{l}\text { Pseudo-second- } \\
\text { order }\end{array}$ & 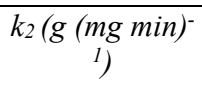 & 0.0078 & 0.0068 & 0.746 & 0.815 & 0.098 & 0.088 \\
\hline & & $q_{2}\left(m g g^{-1}\right)$ & 0.501 & 0.489 & & & & \\
\hline & $\begin{array}{l}\text { Intraparticle } \\
\text { diffusion }\end{array}$ & $\begin{array}{l}k_{i}(m g(g \\
\left.\left.m i n^{1 / 2}\right)^{-1}\right)\end{array}$ & - & 0.078 & 0.965 & 0.887 & 0.04 & 0.08 \\
\hline & & $\mathrm{kiC} / \mathrm{C}$ & 0.086 & -0.063 & & & & \\
\hline System & Model & $\begin{array}{c}\text { Kinetics } \\
\text { parameters }\end{array}$ & & alue & & $\mathrm{R}^{2}$ & & $y^{2}$ \\
\hline & & & Linear & Nonlinear & Linear & Nonlinear & Linear & Nonlinear \\
\hline & Pseudo-first- & $k_{1}\left(\min ^{-1}\right)$ & 0.067 & 0.05 & 0.847 & 0.989 & 0.06 & 0.04 \\
\hline & order & $q_{1}\left(m g g^{-1}\right)$ & 0.498 & 0.397 & & & & \\
\hline $\mathrm{kHz}$ & $\begin{array}{l}\text { Pseudo-second- } \\
\text { order }\end{array}$ & 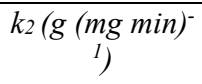 & 0.0088 & 0.0078 & 0.678 & 0.741 & 0.096 & 0.079 \\
\hline & & $q_{2}\left(m g g^{-1}\right)$ & 0.568 & 0.512 & & & & \\
\hline & $\begin{array}{l}\text { Intraparticle } \\
\text { diffusion }\end{array}$ & $\begin{array}{l}k_{i}(m g(g \\
\left.\left.m i n^{I / 2}\right)^{-1}\right)\end{array}$ & - & 0.073 & 0.985 & 0.849 & 0.05 & 0.07 \\
\hline & & $\mathrm{kiC} / \mathrm{C}$ & 0.058 & -0.07 & & & & \\
\hline
\end{tabular}

881 
884 Table 8. Fitting parameters of adsorption kinetics for chlorophyll under IBM and UBM

\begin{tabular}{|c|c|c|c|c|c|c|c|c|}
\hline \multirow[t]{2}{*}{ System } & \multirow[t]{2}{*}{ Model } & \multirow{2}{*}{$\begin{array}{c}\text { Kinetics } \\
\text { parameters }\end{array}$} & \multicolumn{2}{|c|}{ Value } & \multicolumn{2}{|r|}{$\mathrm{R}^{2}$} & \multicolumn{2}{|c|}{$\chi^{2}$} \\
\hline & & & Linear & Nonlinear & Linear & Nonlinear & Linear & Nonlinear \\
\hline \multirow{6}{*}{ IBM } & \multirow{2}{*}{$\begin{array}{l}\text { Pseudo-first- } \\
\text { order }\end{array}$} & $k_{1}\left(\min ^{-1}\right)$ & 0.065 & 0.056 & \multirow[b]{2}{*}{0.914} & \multirow[b]{2}{*}{0.967} & \multirow[b]{2}{*}{1.34} & \multirow[b]{2}{*}{0.22} \\
\hline & & $q_{1}\left(m g g^{-1}\right)$ & 19.67 & 17.45 & & & & \\
\hline & \multirow[t]{2}{*}{$\begin{array}{l}\text { Pseudo-second- } \\
\text { order }\end{array}$} & $k_{2}\left(\begin{array}{c}g(m g \text { min } \\
l)\end{array}\right.$ & 0.0088 & 0.0078 & \multirow[t]{2}{*}{0.817} & \multirow[t]{2}{*}{0.897} & \multirow[t]{2}{*}{1.78} & \multirow[t]{2}{*}{1.39} \\
\hline & & $q_{2}\left(m g g^{-1}\right)$ & 19.85 & 18.69 & & & & \\
\hline & \multirow[t]{2}{*}{$\begin{array}{l}\text { Intraparticle } \\
\text { diffusion }\end{array}$} & $\begin{array}{l}k_{i}(m g(g \\
\left.\left.m i n^{I / 2}\right)^{-1}\right)\end{array}$ & - & 3.13 & \multirow[t]{2}{*}{0.959} & \multirow[t]{2}{*}{0.922} & \multirow[t]{2}{*}{0.28} & \multirow[t]{2}{*}{0.5} \\
\hline & & $k i C / C$ & 0.882 & -1.97 & & & & \\
\hline \multirow[t]{2}{*}{ System } & \multirow[t]{2}{*}{ Model } & \multirow[t]{2}{*}{$\begin{array}{l}\text { Kinetics } \\
\text { parameters }\end{array}$} & \multicolumn{2}{|c|}{ Value } & \multicolumn{2}{|r|}{$\mathrm{R}^{2}$} & \multicolumn{2}{|c|}{$\chi^{2}$} \\
\hline & & & Linear & Nonlinear & Linear & Nonlinear & Linear & Nonlinear \\
\hline \multirow{6}{*}{$\begin{array}{l}\text { UBM-25 } \\
\text { kHz }\end{array}$} & \multirow{2}{*}{$\begin{array}{l}\text { Pseudo-first- } \\
\text { order }\end{array}$} & $k_{1}\left(\min ^{-1}\right)$ & 0.106 & 0.068 & \multirow{2}{*}{0.841} & \multirow{2}{*}{0.968} & \multirow{2}{*}{3.2} & \\
\hline & & $q_{1}\left(m g g^{-1}\right)$ & 41.39 & 29.77 & & & & 0.63 \\
\hline & $\begin{array}{l}\text { Pseudo-second- } \\
\text { order }\end{array}$ & $k_{2}\left(\begin{array}{c}g(\operatorname{mg} \min )^{-} \\
1)\end{array}\right.$ & 0.0028 & 0.0089 & 0.798 & 0.845 & 4.15 & 3.47 \\
\hline & & $q_{2}\left(m g g^{-1}\right)$ & 39.76 & 33.48 & & & & \\
\hline & $\begin{array}{l}\text { Intraparticle } \\
\text { diffusion }\end{array}$ & $\begin{array}{l}k_{i}(\operatorname{mg}(g \\
\left.\left.\min ^{1 / 2}\right)^{-1}\right)\end{array}$ & - & 5.72 & 0.957 & 0.945 & 0.71 & 1.84 \\
\hline & & $\mathrm{kiC} / \mathrm{C}$ & 1.27 & -3.16 & & & & \\
\hline System & Model & $\begin{array}{c}\text { Kinetics } \\
\text { parameters }\end{array}$ & & alue & & $\mathrm{R}^{2}$ & & $\chi^{2}$ \\
\hline & & & Linear & Nonlinear & Linear & Nonlinear & Linear & Nonlinear \\
\hline & Pseudo-first- & $k_{1}\left(\min ^{-1}\right)$ & 0.077 & 0.058 & & & & \\
\hline & order & $q_{1}\left(m g g^{-1}\right)$ & 35.41 & 27.74 & 0.91 & 0.962 & 7.7 & 5.7 \\
\hline $\mathrm{kHz}$ & $\begin{array}{l}\text { Pseudo-second- } \\
\text { order }\end{array}$ & 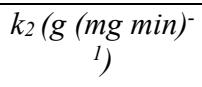 & 0.0088 & 0.0081 & 0.623 & 0.721 & 9.6 & 8.1 \\
\hline & & $q_{2}\left(m g g^{-1}\right)$ & 41.56 & 37.56 & & & & \\
\hline & $\begin{array}{l}\text { Intraparticle } \\
\text { diffusion }\end{array}$ & $\begin{array}{l}k_{i}(m g(g \\
\left.\left.\min ^{1 / 2}\right)^{-1}\right)\end{array}$ & - & 5.27 & 0.943 & 0.889 & 6.2 & 6.4 \\
\hline & & $\mathrm{kiC} / \mathrm{C}$ & 0.615 & -4.52 & & & & \\
\hline
\end{tabular}

885

886 
Table 9. Thermodynamic parameters for $\mathrm{Fe}(\mathrm{II})$ and $\mathrm{Cu}(\mathrm{II})$ adsorption by activated bentonite clay under IBM and UBM. IBM; industrial bleaching method, UBM; ultrasonic bleaching method, $\Delta \mathrm{H}^{\circ}$; standard enthalpy, $\Delta \mathrm{S}^{\circ}$; standard entropy, $\Delta \mathrm{G}^{\mathrm{o}}$, standard free energy.

\begin{tabular}{|c|c|c|c|c|}
\hline System & $\Delta \mathbf{H}^{\mathbf{0}}\left(\mathrm{kJ} \mathrm{mol}^{-1}\right)$ & $\Delta \mathbf{S}^{\mathbf{0}}\left(\mathrm{J} \mathrm{mol}^{-1} \mathrm{~K}^{-1}\right)$ & $\mathbf{T}(\mathrm{K})$ & $\Delta \mathbf{G}^{\mathbf{0}}\left(\mathrm{kJ} \mathrm{mol}^{-1}\right)$ \\
\hline \multirow[t]{2}{*}{ IBM } & & & 308 & 10.72 \\
\hline & & & 318 & 8.03 \\
\hline \multirow[t]{3}{*}{$\mathrm{Fe}(\mathrm{II})$} & 93.49 & 268.72 & 328 & 5.35 \\
\hline & & & 338 & 2.66 \\
\hline & & & 308 & 15.44 \\
\hline \multirow[t]{3}{*}{$\mathrm{Cu}(\mathrm{II})$} & 151.26 & 440.93 & 318 & 11.04 \\
\hline & & & 328 & 6.63 \\
\hline & & & 338 & 2.22 \\
\hline \multicolumn{5}{|l|}{ UBM-25 kHz } \\
\hline & & & 308 & 8.79 \\
\hline \multirow{4}{*}{$\mathrm{Fe}(\mathrm{II})$} & & & 318 & 2.48 \\
\hline & 203.32 & 631.56 & 328 & -3.83 \\
\hline & & & 338 & -10.14 \\
\hline & & & 308 & 1.61 \\
\hline \multirow[t]{3}{*}{$\mathrm{Cu}(\mathrm{II})$} & 193.1 & 621.63 & 318 & -4.61 \\
\hline & & & 328 & -10.82 \\
\hline & & & 338 & -17.04 \\
\hline UBM-40 kHz & & & 308 & 9.16 \\
\hline \multirow[t]{3}{*}{$\mathrm{Fe}(\mathrm{II})$} & 137.33 & 416.12 & 318 & 5.00 \\
\hline & & & 328 & 0.84 \\
\hline & & & 338 & -3.32 \\
\hline \multirow[t]{4}{*}{$\mathrm{Cu}(\mathrm{II})$} & 105.64 & 517.73 & 308 & 4.69 \\
\hline & & & 318 & 1.42 \\
\hline & & & 328 & -1.85 \\
\hline & & & 338 & -5.13 \\
\hline
\end{tabular}


Table 10. Thermodynamic parameters for carotenoid and chlorophyll adsorption by activated bentonite clay under IBM and UBM. IBM; industrial bleaching method, UBM; ultrasonic bleaching method, $\Delta \mathrm{H}^{\circ}$; standard enthalpy, $\Delta \mathrm{S}^{\circ}$; standard entropy, $\Delta \mathrm{G}^{\mathrm{o}}$, standard free energy.

\begin{tabular}{|c|c|c|c|c|}
\hline System & $\Delta \mathbf{H}^{\mathbf{0}}\left(\mathrm{kJ} \mathrm{mol}^{-1}\right)$ & $\boldsymbol{\Delta} \mathbf{S}^{\mathbf{0}}\left(\mathrm{J} \mathrm{mol}^{-1} \mathrm{~K}^{-1}\right)$ & $\mathbf{T}(\mathrm{K})$ & $\Delta \mathbf{G}^{\mathbf{0}}\left(\mathrm{kJ} \mathrm{mol}^{-1}\right)$ \\
\hline \multirow[t]{2}{*}{ IBM } & & & 308 & 10.69 \\
\hline & & & 318 & 6.96 \\
\hline \multirow[t]{3}{*}{ Carotenoid } & 125.56 & 372.93 & 328 & 3.23 \\
\hline & & & 338 & -0.49 \\
\hline & & & 308 & 5.82 \\
\hline \multirow[t]{3}{*}{ Chlorophyll } & 54.67 & 158.59 & 318 & 4.23 \\
\hline & & & 328 & 2.65 \\
\hline & & & 338 & 1.066 \\
\hline \multicolumn{5}{|l|}{ UBM-25 kHz } \\
\hline & & & 308 & 3.03 \\
\hline & & & 318 & 0.55 \\
\hline \multirow[t]{3}{*}{ Carotenoid } & 79.27 & 247.54 & 328 & -1.92 \\
\hline & & & 338 & -4.39 \\
\hline & & & 308 & 2.33 \\
\hline \multirow[t]{3}{*}{ Chlorophyll } & 46.39 & 143.02 & 318 & 0.908 \\
\hline & & & 328 & -0.52 \\
\hline & & & 338 & -1.95 \\
\hline UBM-40 kHz & & & 308 & 4.61 \\
\hline \multirow[t]{3}{*}{ Carotenoid } & 93.32 & 288.01 & 318 & 1.73 \\
\hline & & & 328 & -1.15 \\
\hline & & & 338 & -4.03 \\
\hline \multirow[t]{4}{*}{ Chlorophyll } & 60.98 & 184.73 & 308 & 4.08 \\
\hline & & & 318 & 2.23 \\
\hline & & & 328 & 0.388 \\
\hline & & & 338 & -1.46 \\
\hline
\end{tabular}




\begin{tabular}{|c|c|c|c|c|c|c|c|c|}
\hline \multirow[t]{2}{*}{ System } & \multirow[t]{2}{*}{ Model } & \multirow[t]{2}{*}{$\begin{array}{l}\text { Kinetics } \\
\text { parameters }\end{array}$} & \multicolumn{2}{|c|}{ Value } & \multicolumn{2}{|c|}{$\mathrm{R}^{2}$} & \multicolumn{2}{|c|}{$\chi^{2}$} \\
\hline & & & Linear & Nonlinear & Linear & Nonlinear & Linear & Nonlinear \\
\hline \multirow{6}{*}{ IBM } & \multirow{2}{*}{ Langmuir } & $K_{L}\left(L m g^{-1}\right)$ & 0.151 & 0.134 & \multirow{2}{*}{0.763} & \multirow{2}{*}{0.857} & \multirow{2}{*}{0.065} & \multirow{2}{*}{0.044} \\
\hline & & $q_{m}\left(m g g^{-1}\right)$ & 0.0032 & 0.0023 & & & & \\
\hline & \multirow[t]{2}{*}{ Freundlich } & $\begin{array}{c}K_{F} \\
\left(\left(m g g^{-1}\right)\left(L m g^{-1}\right)^{1 / n}\right.\end{array}$ & 0.376 & 0.345 & \multirow[t]{2}{*}{0.851} & \multirow[t]{2}{*}{0.938} & \multirow[t]{2}{*}{0.043} & \multirow[t]{2}{*}{0.037} \\
\hline & & $n$ & 1.33 & 1.26 & & & & \\
\hline & \multirow[t]{2}{*}{ Tempkin } & $A_{T}\left(L m g^{-1}\right)$ & 1.42 & 1.36 & \multirow[t]{2}{*}{0.799} & \multirow[t]{2}{*}{0.888} & \multirow[t]{2}{*}{0.063} & \multirow[t]{2}{*}{0.041} \\
\hline & & $b_{T}\left(\mathrm{Jmol}^{-1}\right)$ & 7.14 & 5.22 & & & & \\
\hline \multirow[t]{2}{*}{ System } & \multirow[t]{2}{*}{ Model } & $\begin{array}{c}\text { Kinetics } \\
\text { parameters }\end{array}$ & \multicolumn{2}{|c|}{ Value } & \multicolumn{2}{|c|}{$\mathrm{R}^{2}$} & \multicolumn{2}{|c|}{$\chi^{2}$} \\
\hline & & & Linear & Nonlinear & Linear & Nonlinear & Linear & Nonlinear \\
\hline \multirow{6}{*}{$\begin{array}{c}\text { UBM-25 } \\
\mathrm{kHz}\end{array}$} & \multirow{2}{*}{ Langmuir } & $K_{L}\left(L m g^{-1}\right)$ & 0.164 & 0.141 & \multirow{2}{*}{0.777} & \multirow{2}{*}{0.889} & \multirow{2}{*}{0.063} & \multirow{2}{*}{0.042} \\
\hline & & $q_{m}\left(m g g^{-1}\right)$ & 0.0077 & 0.0066 & & & & \\
\hline & Freundlich & $\begin{array}{c}K_{F} \\
\left(\left(m g g^{-1}\right)\left(L m g^{-1}\right)^{1 / n}\right.\end{array}$ & 0.467 & 0.436 & 0.898 & 0.937 & 0.041 & 0.036 \\
\hline & & $n$ & 3.01 & 2.86 & & & & \\
\hline & Tempkin & $A_{T}\left(L m g^{-1}\right)$ & 4.11 & 3.41 & 0.871 & 0.899 & 0.043 & 0.04 \\
\hline & & $b_{T}\left(\mathrm{Jmol}^{-1}\right)$ & 11.56 & 9.91 & & & & \\
\hline System & Model & $\begin{array}{c}\text { Kinetics } \\
\text { parameters }\end{array}$ & & alue & & 2 & & $x^{2}$ \\
\hline & & & Linear & Nonlinear & Linear & Nonlinear & Linear & Nonlinear \\
\hline & I anomuir & $K_{L}\left(L m g^{-1}\right)$ & 0.157 & 0.138 & 0746 & 0889 & 0057 & 0030 \\
\hline UBM-40 & & $q_{m}\left(m g g^{-1}\right)$ & 0.0072 & 0.0062 & 0.140 & 0.007 & 0.051 & 0.039 \\
\hline & Freundlich & $\begin{array}{c}K_{F} \\
\left(\left(m g g^{-1}\right)\left(L m g^{-1}\right)^{1 / n}\right.\end{array}$ & 0.436 & 0.412 & 0.886 & 0.964 & 0.042 & 0.031 \\
\hline & & $n$ & 2.89 & 2.46 & & & & \\
\hline & Tempkin & $A_{T}\left(L m g^{-1}\right)$ & 3.65 & 3.26 & 0.854 & 0.921 & 0.046 & 0.034 \\
\hline & & $b_{T}\left(\right.$ Jmol $\left.^{-1}\right)$ & 8.19 & 7.56 & & & & \\
\hline
\end{tabular}

Table 11. Fitting parameters of adsorption isotherms for Fe(II) ions under IBM and UBM 
Table 12. Fitting parameters of adsorption isotherms for $\mathrm{Cu}(\mathrm{II})$ ions under IBM and

\begin{tabular}{|c|c|c|c|c|c|c|c|c|}
\hline \multirow[t]{2}{*}{ System } & \multirow[t]{2}{*}{ Model } & \multirow{2}{*}{$\begin{array}{l}\text { Kinetics } \\
\text { parameters }\end{array}$} & \multicolumn{2}{|c|}{ Value } & \multicolumn{2}{|c|}{$\mathrm{R}^{2}$} & \multicolumn{2}{|c|}{$\chi^{2}$} \\
\hline & & & Linear & Nonlinear & Linear & Nonlinear & Linear & Nonlinear \\
\hline \multirow{6}{*}{ IBM } & \multirow{2}{*}{ Langmuir } & $K_{L}\left(L m g^{-1}\right)$ & 0.151 & 0.139 & \multirow{2}{*}{0.754} & \multirow{2}{*}{0.834} & \multirow{2}{*}{0.064} & \multirow{2}{*}{0.046} \\
\hline & & $q_{m}\left(m g g^{-1}\right)$ & 0.0033 & 0.0013 & & & & \\
\hline & \multirow[t]{2}{*}{ Freundlich } & $\begin{array}{c}K_{F} \\
\left(\left(m g g^{-1}\right)\left(L m g^{-1}\right)^{1 / n}\right.\end{array}$ & 0.364 & 0.338 & \multirow[t]{2}{*}{0.843} & \multirow[t]{2}{*}{0.901} & \multirow[t]{2}{*}{0.047} & \multirow[t]{2}{*}{0.039} \\
\hline & & $n$ & 1.33 & 1.21 & & & & \\
\hline & \multirow[t]{2}{*}{ Tempkin } & $A_{T}\left(L m g^{-1}\right)$ & 1.48 & 1.39 & \multirow[t]{2}{*}{0.791} & \multirow[t]{2}{*}{0.867} & \multirow[t]{2}{*}{0.061} & \multirow[t]{2}{*}{0.043} \\
\hline & & $b_{T}\left(\mathrm{Jmol}^{-1}\right)$ & 8.63 & 6.1 & & & & \\
\hline \multirow[t]{2}{*}{ System } & \multirow[t]{2}{*}{ Model } & $\begin{array}{c}\text { Kinetics } \\
\text { parameters }\end{array}$ & \multicolumn{2}{|c|}{ Value } & \multicolumn{2}{|c|}{$\overline{\mathrm{R}^{2}}$} & \multicolumn{2}{|c|}{$\chi^{2}$} \\
\hline & & & Linear & Nonlinear & Linear & Nonlinear & Linear & Nonlinear \\
\hline \multirow{6}{*}{$\begin{array}{c}\text { UBM-25 } \\
\mathrm{kHz}\end{array}$} & \multirow{2}{*}{ Langmuir } & $K_{L}\left(L m g^{-1}\right)$ & 0.159 & 0.144 & \multirow{2}{*}{0.765} & \multirow{2}{*}{0.876} & \multirow{2}{*}{0.057} & \multirow{2}{*}{0.043} \\
\hline & & $q_{m}\left(m g g^{-1}\right)$ & 0.0052 & 0.0043 & & & & \\
\hline & Freundlich & $\begin{array}{c}K_{F} \\
\left(\left(m g g^{-1}\right)\left(L m g^{-1}\right)^{1 / n}\right.\end{array}$ & 0.453 & 0.429 & 0.894 & 0.921 & 0.039 & 0.037 \\
\hline & & $n$ & 2.83 & 2.79 & & & & \\
\hline & Tempkin & $A_{T}\left(L m g^{-1}\right)$ & 3.76 & 3.87 & 0.864 & 0.898 & 0.051 & 0.04 \\
\hline & & $b_{T}\left(\mathrm{Jmol}^{-1}\right)$ & 11.89 & 10.7 & & & & \\
\hline System & Model & $\begin{array}{c}\text { Kinetics } \\
\text { parameters }\end{array}$ & & alue & & 2 & & $\chi^{2}$ \\
\hline & & & Linear & Nonlinear & Linear & Nonlinear & Linear & Nonlinear \\
\hline & Lanomuir & $K_{L}\left(L m g^{-1}\right)$ & 0.155 & 0.141 & 0.741 & 0869 & 0.054 & 0.041 \\
\hline UBM-40 & & $q_{m}\left(m g g^{-1}\right)$ & 0.0044 & 0.0036 & & & & \\
\hline & Freundlich & $\begin{array}{c}K_{F} \\
\left(\left(m g g^{-1}\right)\left(L m g^{-1}\right)^{1 / n}\right.\end{array}$ & 0.427 & 0.406 & 0.867 & 0.934 & 0.04 & 0.034 \\
\hline & & $n$ & 2.66 & 2.46 & & & & \\
\hline & Tempkin & $A_{T}\left(L m g^{-1}\right)$ & 3.74 & 3.65 & 0.834 & 0.901 & 0.048 & 0.038 \\
\hline & & $b_{T}\left(\mathrm{Jmol}^{-1}\right)$ & 9.3 & 7.6 & & & & \\
\hline
\end{tabular}


Table 13. Fitting parameters of adsorption isotherms for carotenoid under IBM and

UBM

\begin{tabular}{|c|c|c|c|c|c|c|c|c|}
\hline \multirow[t]{2}{*}{ System } & \multirow[t]{2}{*}{ Model } & \multirow[t]{2}{*}{$\begin{array}{c}\text { Kinetics } \\
\text { parameters }\end{array}$} & \multicolumn{2}{|c|}{ Value } & \multicolumn{2}{|c|}{$\mathrm{R}^{2}$} & \multicolumn{2}{|c|}{$\chi^{2}$} \\
\hline & & & Linear & Nonlinear & Linear & Nonlinear & Linear & Nonlinear \\
\hline \multirow{6}{*}{ IBM } & \multirow{2}{*}{ Langmuir } & $K_{L}\left(L m g^{-1}\right)$ & 0.192 & 0.174 & \multirow{2}{*}{0.785} & \multirow{2}{*}{0.926} & \multirow{2}{*}{0.061} & \multirow{2}{*}{0.036} \\
\hline & & $q_{m}\left(m g g^{-1}\right)$ & 0.257 & 0.231 & & & & \\
\hline & \multirow[t]{2}{*}{ Freundlich } & $\begin{array}{c}K_{F} \\
\left(\left(m g g^{-1}\right)\left(L m g^{-1}\right)^{1 / n}\right.\end{array}$ & 0.634 & 0.589 & \multirow[t]{2}{*}{0.917} & \multirow[t]{2}{*}{0.987} & \multirow[t]{2}{*}{0.037} & \multirow[t]{2}{*}{0.028} \\
\hline & & $n$ & 1.46 & 1.34 & & & & \\
\hline & \multirow[t]{2}{*}{ Tempkin } & $A_{T}\left(L m g^{-1}\right)$ & 2.36 & 2.22 & \multirow[t]{2}{*}{0.887} & \multirow[t]{2}{*}{0.945} & \multirow[t]{2}{*}{0.039} & \multirow[t]{2}{*}{0.033} \\
\hline & & $b_{T}\left(\mathrm{Jmol}^{-1}\right)$ & 8.15 & 5.79 & & & & \\
\hline \multirow[t]{2}{*}{ System } & \multirow[t]{2}{*}{ Model } & $\begin{array}{l}\text { Kinetics } \\
\text { parameters }\end{array}$ & \multicolumn{2}{|c|}{ Value } & \multicolumn{2}{|c|}{$\mathrm{R}^{2}$} & \multicolumn{2}{|c|}{$\chi^{2}$} \\
\hline & & & Linear & Nonlinear & Linear & Nonlinear & Linear & Nonlinear \\
\hline \multirow{6}{*}{$\begin{array}{c}\text { UBM-25 } \\
\text { kHz }\end{array}$} & \multirow{2}{*}{ Langmuir } & $K_{L}\left(L m g^{-1}\right)$ & 0.224 & 0.186 & \multirow{2}{*}{0.882} & \multirow{2}{*}{0.946} & \multirow{2}{*}{0.054} & \multirow{2}{*}{0.033} \\
\hline & & $q_{m}\left(m g g^{-1}\right)$ & 0.479 & 0.448 & & & & \\
\hline & Freundlich & $\begin{array}{c}K_{F} \\
\left(\left(m g g^{-1}\right)\left(L m g^{-1}\right)^{1 / n}\right.\end{array}$ & 0.778 & 0.765 & 0.921 & 0.991 & 0.034 & 0.025 \\
\hline & & $n$ & 3.46 & 3.23 & & & & \\
\hline & Tempkin & $A_{T}\left(L m g^{-1}\right)$ & 4.87 & 4.63 & 0.906 & 0.974 & 0.036 & 0.029 \\
\hline & & $b_{T}\left(\mathrm{Jmol}^{-1}\right)$ & 15.89 & 11.86 & & & & \\
\hline System & Model & $\begin{array}{c}\text { Kinetics } \\
\text { parameters }\end{array}$ & & alue & & 2 & & $x^{2}$ \\
\hline & & & Linear & Nonlinear & Linear & Nonlinear & Linear & Nonlinear \\
\hline & I anomuir & $K_{L}\left(L m g^{-1}\right)$ & 0.211 & 0.181 & 700 & 0001 & 0050 & 0036 \\
\hline UBM-40 & & $q_{m}\left(m g g^{-1}\right)$ & 0.436 & 0.419 & & & & \\
\hline & Freundlich & $\begin{array}{c}K_{F} \\
\left(\left(m g g^{-1}\right)\left(L^{\prime} m g^{-1}\right)^{1 / n}\right.\end{array}$ & 0.684 & 0.649 & 0.891 & 0.978 & 0.039 & 0.031 \\
\hline & & $n$ & 2.74 & 2.65 & & & & \\
\hline & Tempkin & $A_{T}\left(L m g^{-1}\right)$ & 3.65 & 3.49 & 0.876 & 0.931 & 0.046 & 0.033 \\
\hline & & $b_{T}\left(\mathrm{Jmol}^{-1}\right)$ & 12.49 & 8.59 & & & & \\
\hline
\end{tabular}




\begin{tabular}{|c|c|c|c|c|c|c|c|c|}
\hline \multirow[t]{2}{*}{ System } & \multirow[t]{2}{*}{ Model } & \multirow{2}{*}{$\begin{array}{c}\text { Kinetics } \\
\text { parameters }\end{array}$} & \multicolumn{2}{|c|}{ Value } & \multicolumn{2}{|c|}{$\mathrm{R}^{2}$} & \multicolumn{2}{|c|}{$\chi^{2}$} \\
\hline & & & Linear & Nonlinear & Linear & Nonlinear & Linear & Nonlinear \\
\hline \multirow{6}{*}{ IBM } & \multirow{2}{*}{ Langmuir } & $K_{L}\left(L m g^{-1}\right)$ & 0.295 & 0.251 & \multirow{2}{*}{0.786} & \multirow{2}{*}{0.889} & \multirow{2}{*}{0.065} & \multirow{2}{*}{0.045} \\
\hline & & $q_{m}\left(m g g^{-1}\right)$ & 23.87 & 21.48 & & & & \\
\hline & \multirow[t]{2}{*}{ Freundlich } & $\begin{array}{c}K_{F} \\
\left(\left(m g g^{-1}\right)\left(L^{-1} g^{-1}\right)^{1 / n}\right.\end{array}$ & 18.65 & 17.41 & \multirow[t]{2}{*}{0.899} & \multirow[t]{2}{*}{0.981} & \multirow[t]{2}{*}{0.042} & \multirow[t]{2}{*}{0.033} \\
\hline & & $n$ & 1.78 & 1.45 & & & & \\
\hline & \multirow[t]{2}{*}{ Tempkin } & $A_{T}\left(L m g^{-1}\right)$ & 2.87 & 2.74 & \multirow[t]{2}{*}{0.887} & \multirow[t]{2}{*}{0.965} & \multirow[t]{2}{*}{0.044} & \multirow[t]{2}{*}{0.038} \\
\hline & & $b_{T}\left(\mathrm{Jmol}^{-1}\right)$ & 39.67 & 33.58 & & & & \\
\hline \multirow[t]{2}{*}{ System } & \multirow[t]{2}{*}{ Model } & Kinetics & \multicolumn{2}{|c|}{ Value } & \multicolumn{2}{|c|}{$\mathrm{R}^{2}$} & \multicolumn{2}{|c|}{$\chi^{2}$} \\
\hline & & & Linear & Nonlinear & Linear & Nonlinear & Linear & Nonlinear \\
\hline \multirow{6}{*}{$\begin{array}{l}\text { UBM-25 } \\
\text { kHz }\end{array}$} & \multirow{2}{*}{ Langmuir } & $K_{L}\left(L m g^{-1}\right)$ & 0.322 & 0.274 & \multirow{2}{*}{0.787} & \multirow{2}{*}{0.901} & \multirow{2}{*}{0.063} & \multirow{2}{*}{0.043} \\
\hline & & $q_{m}\left(m g g^{-1}\right)$ & 36.89 & 32.85 & & & & \\
\hline & Freundlich & $\begin{array}{c}K_{F} \\
\left(\left(m g g^{-1}\right)\left(\mathrm{Lmg}^{-1}\right)^{1 / n}\right.\end{array}$ & 31.45 & 29.91 & 0.891 & 0.981 & 0.047 & 0.035 \\
\hline & & $n$ & 3.96 & 3.79 & & & & \\
\hline & Tempkin & $A_{T}\left(L m g^{-1}\right)$ & 4.58 & 4.36 & 0.868 & 0.937 & 0.05 & 0.039 \\
\hline & & $b_{T}\left(\mathrm{Jmol}^{-1}\right)$ & 70.31 & 65.85 & & & & \\
\hline System & Model & Kinetics & & alue & & & & $\chi^{2}$ \\
\hline & & & Linear & Nonlinear & Linear & Nonlinear & Linear & Nonlinear \\
\hline & J nnomuir & $K_{L}\left(L m g^{-1}\right)$ & 0.301 & 0.259 & 0785 & 0871 & 0066 & 0044 \\
\hline UBM-40 & Langmuit & $q_{m}\left(m g g^{-1}\right)$ & 34.89 & 29.78 & $0.10 \mathrm{~J}$ & 0.071 & 0.000 & S.0.074 \\
\hline $\mathrm{KHz}$ & Freundlich & $\begin{array}{c}K_{F} \\
\left(\left(m g g^{-1}\right)\left(L m g^{-1}\right)^{1 / n}\right.\end{array}$ & 29.42 & 27.41 & 0.851 & 0.946 & 0.048 & 0.039 \\
\hline & & $n$ & 2.91 & 2.79 & & & & \\
\hline & Tempkin & $A_{T}\left(L m g^{-1}\right)$ & 3.74 & 3.65 & 0.846 & 0.901 & 0.051 & 0.042 \\
\hline & & $b_{T}\left(\mathrm{Jmol}^{-1}\right)$ & 45.68 & 41.36 & & & & \\
\hline
\end{tabular}

Table 14. Fitting parameters of adsorption isotherms for chlorophyll under IBM and 
973 
Figures
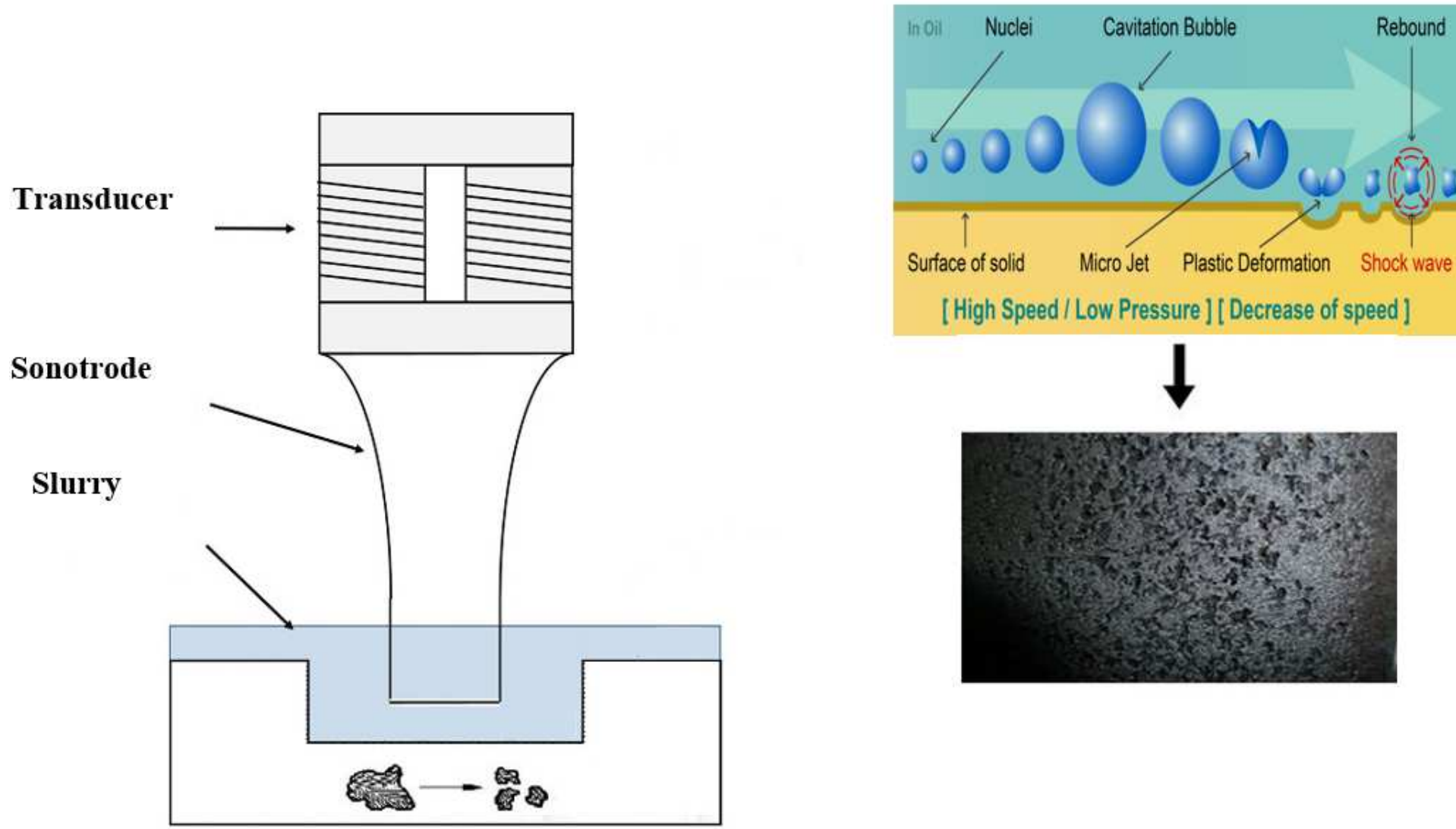

[ High Speed / Low Pressure ] [ Decrease of speed]

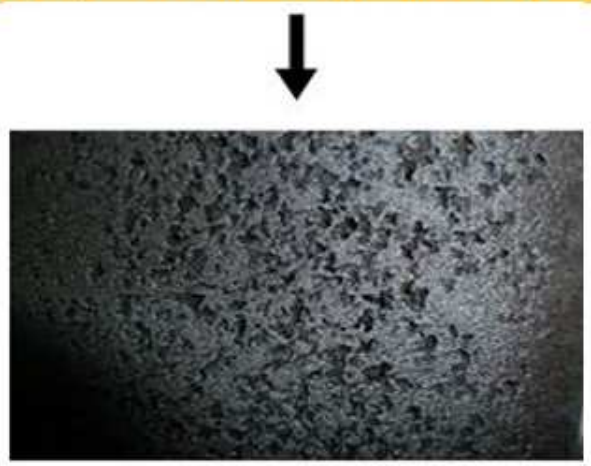

Figure 1

The effect of ultrasonication on the reduction of particle size and cleaning of surface. 

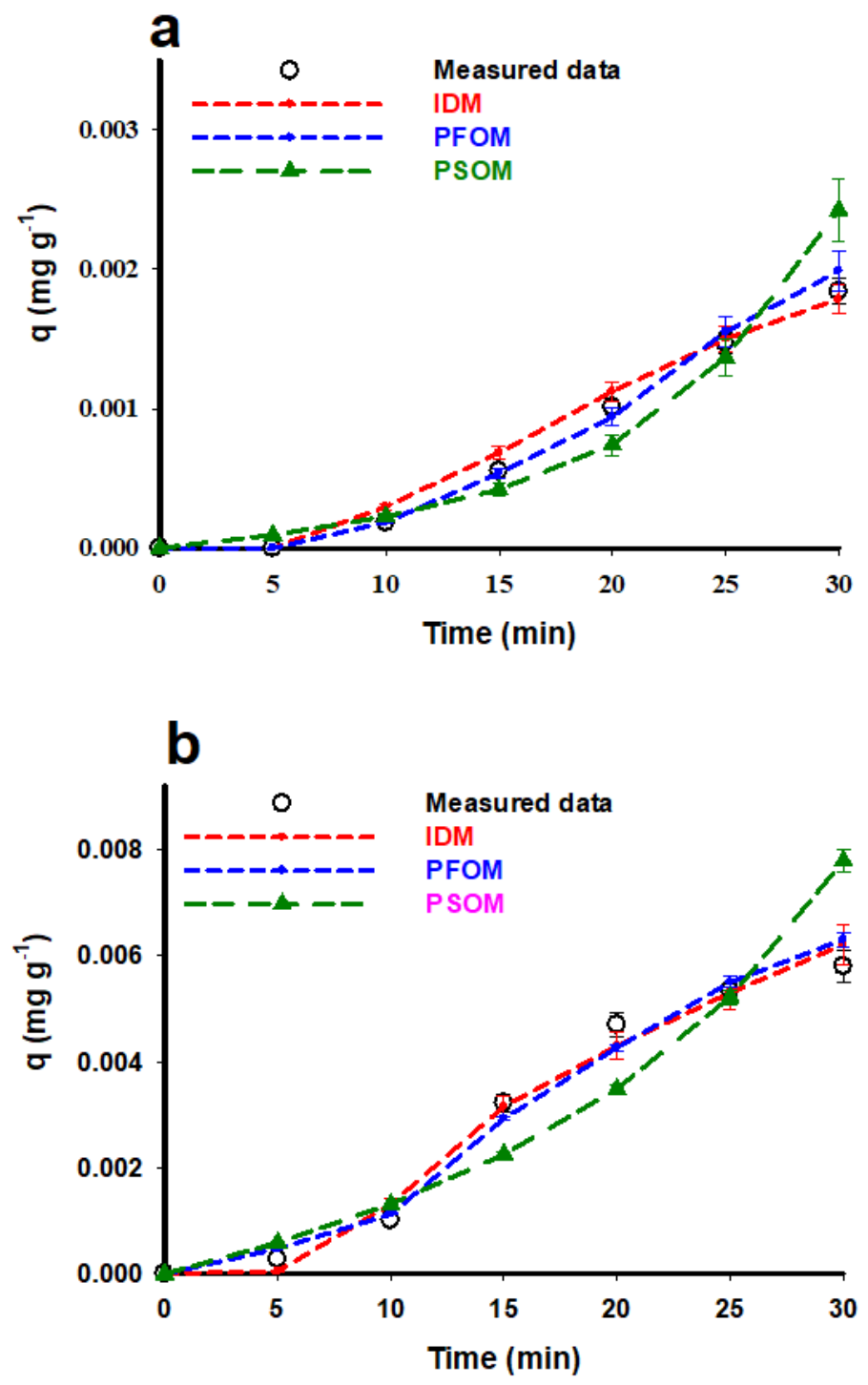

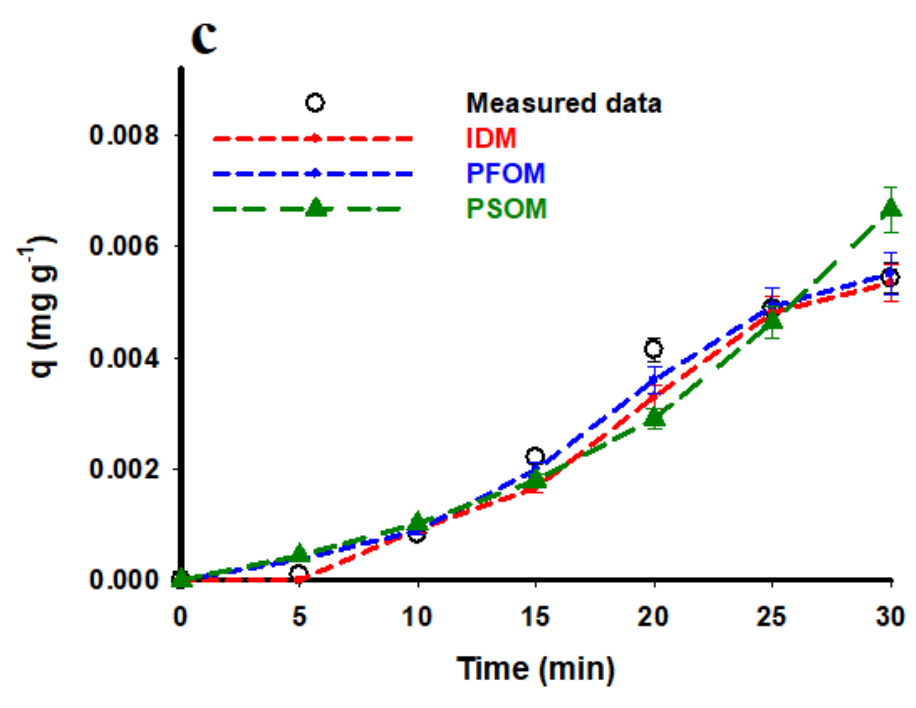

Figure 2

The experimental kinetic data and predicted values of $\mathrm{Fe}(\mathrm{II})$ ions on bentonite clay under IBM (a), UBM-25 $\mathrm{kHz}$ (b) and UBM-40 kHz (c) for soybean oil. 

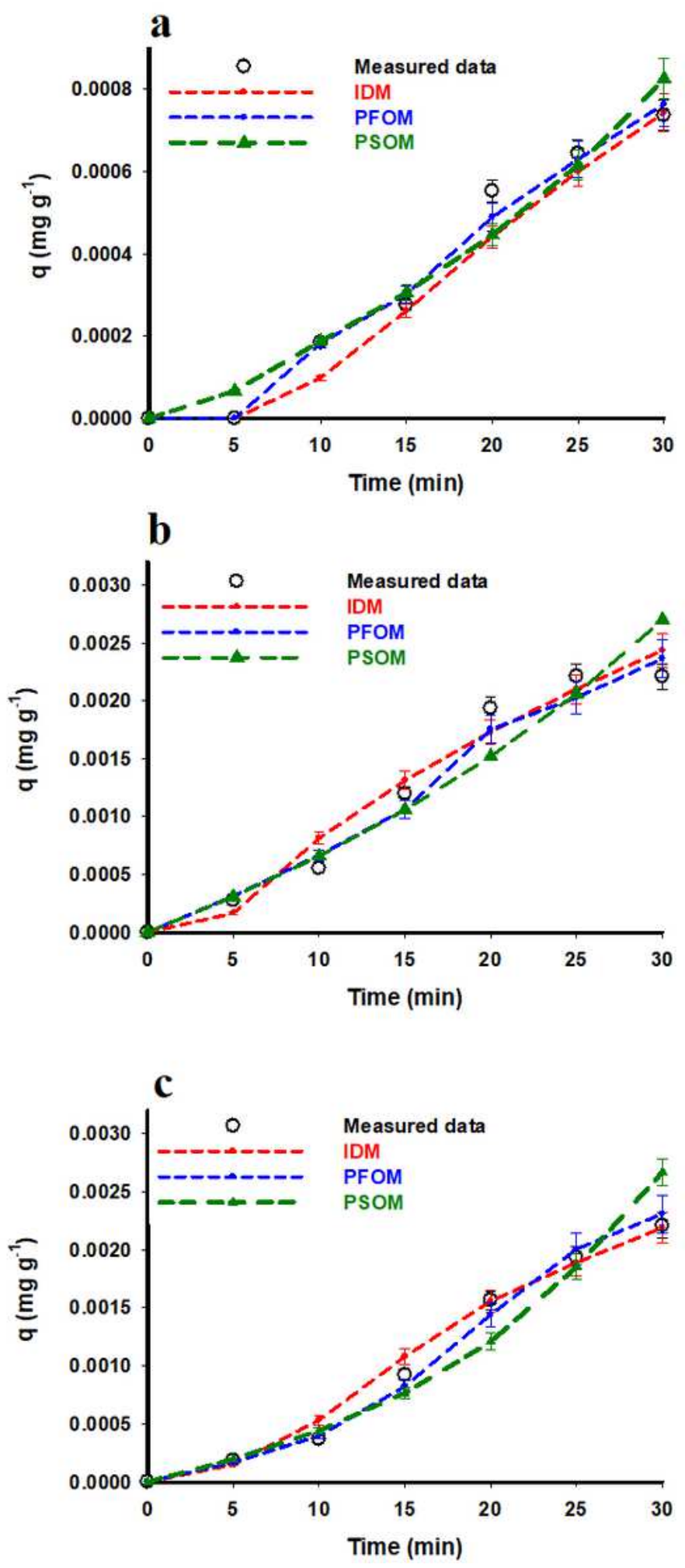

\section{Figure 3}

The experimental kinetic data and predicted values of $\mathrm{Cu}$ (II) ions on bentonite clay under IBM (a), UBM$25 \mathrm{kHz}(\mathrm{b})$ and UBM-40 kHz (c) for soybean oil. 

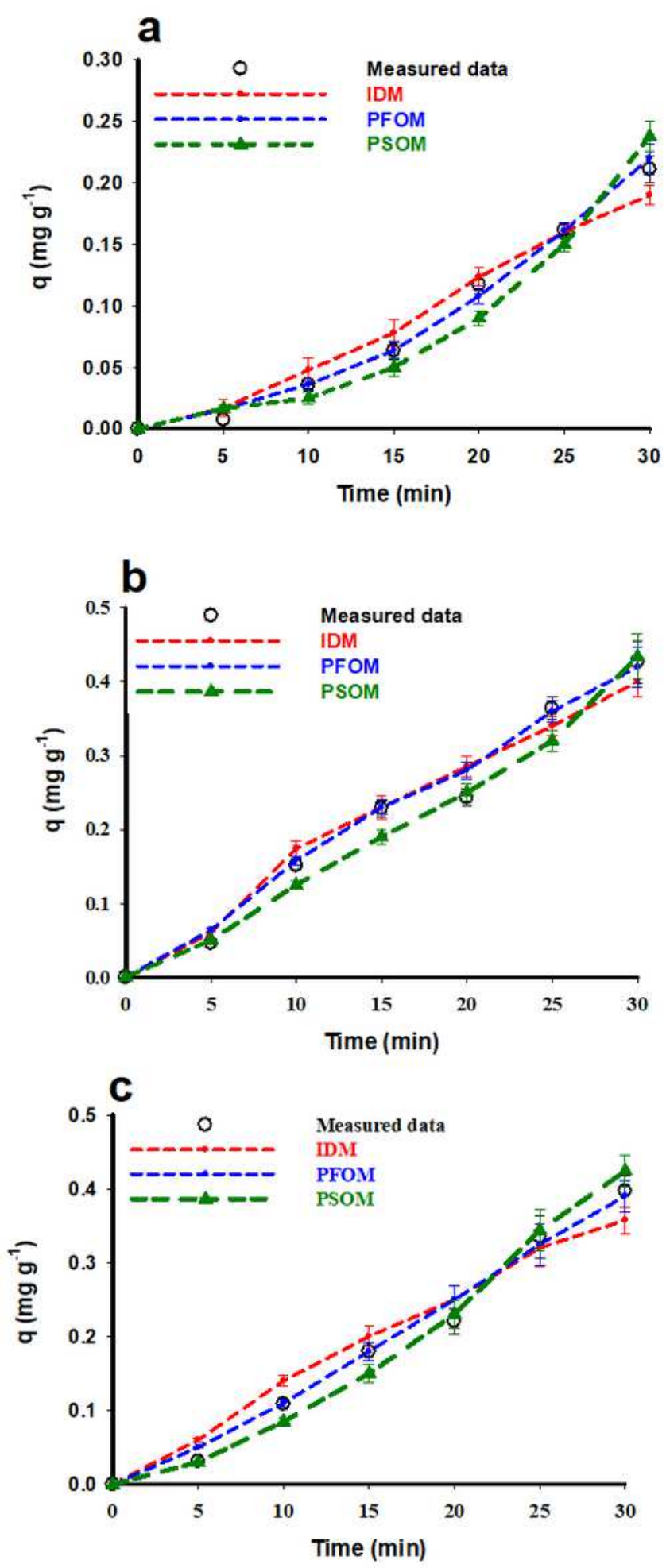

\section{Figure 4}

The experimental kinetic data and predicted values of Carotenoid on bentonite clay under IBM (a), UBM$25 \mathrm{kHz}$ (b) and UBM-40 kHz (c) for soybean oil. 

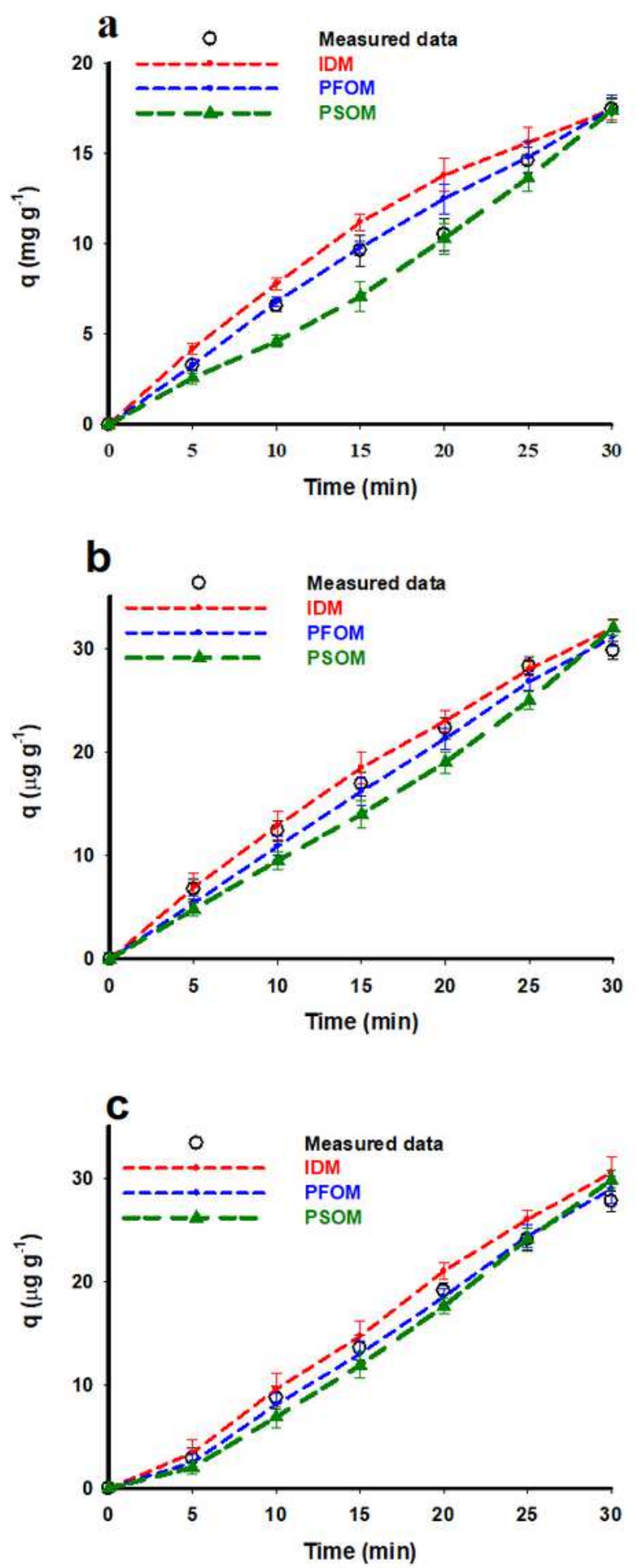

\section{Figure 5}

The experimental kinetic data and predicted values of Chlrophyl on bentonite clay under IBM (a), UBM-25 $\mathrm{kHz}$ (b) and UBM-40 kHz (c) for soybean oil. 

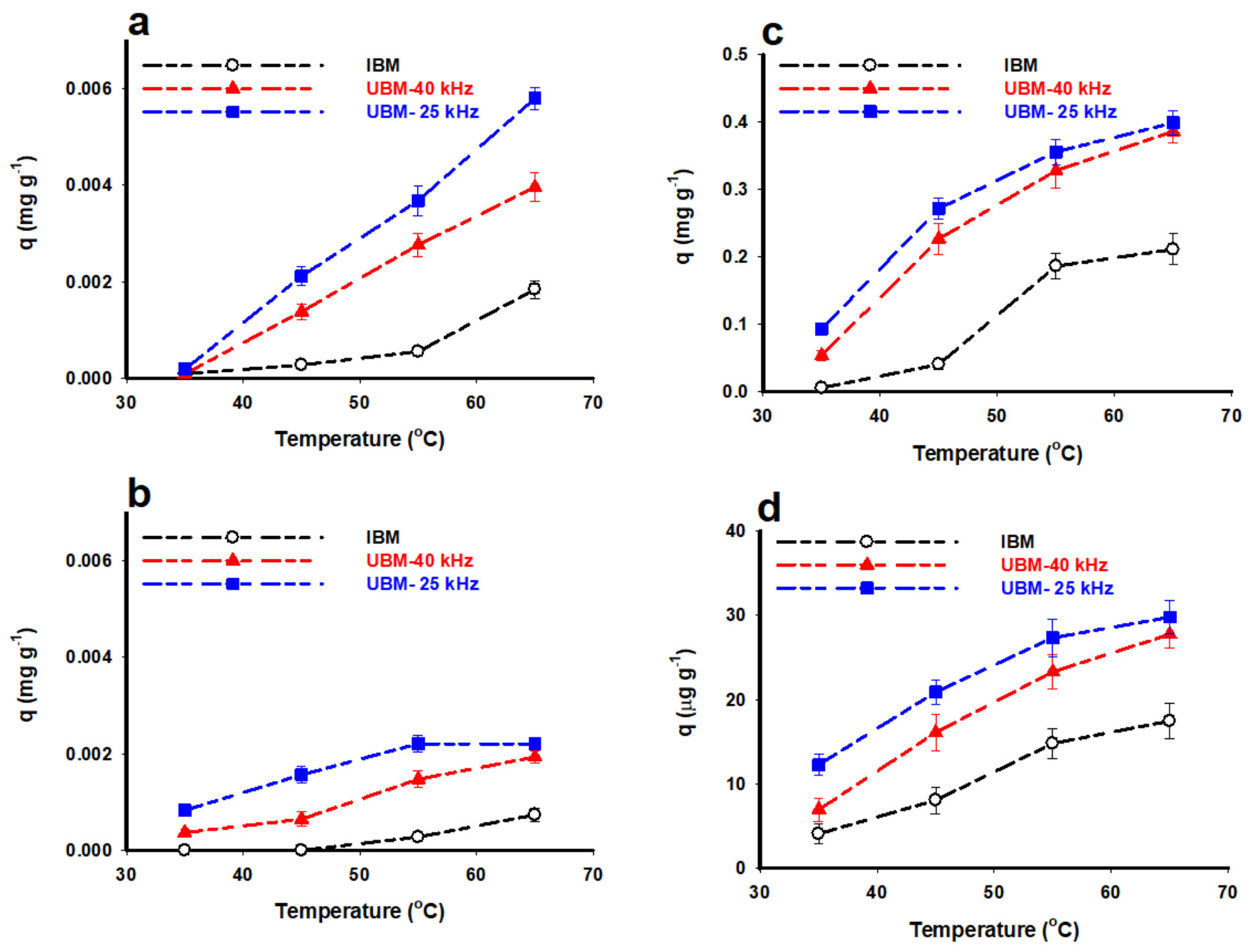

Figure 6

The influence of temperature for the adsorption of (a) Fe(II); (b) $\mathrm{Cu}(\mathrm{II})$; (c) carotenoid; and (d) chlorophyll onto activated bentonite clay under IBM and UBM. Industrial bleaching method (IBM), Ultrasonic bleaching method (UBM). 


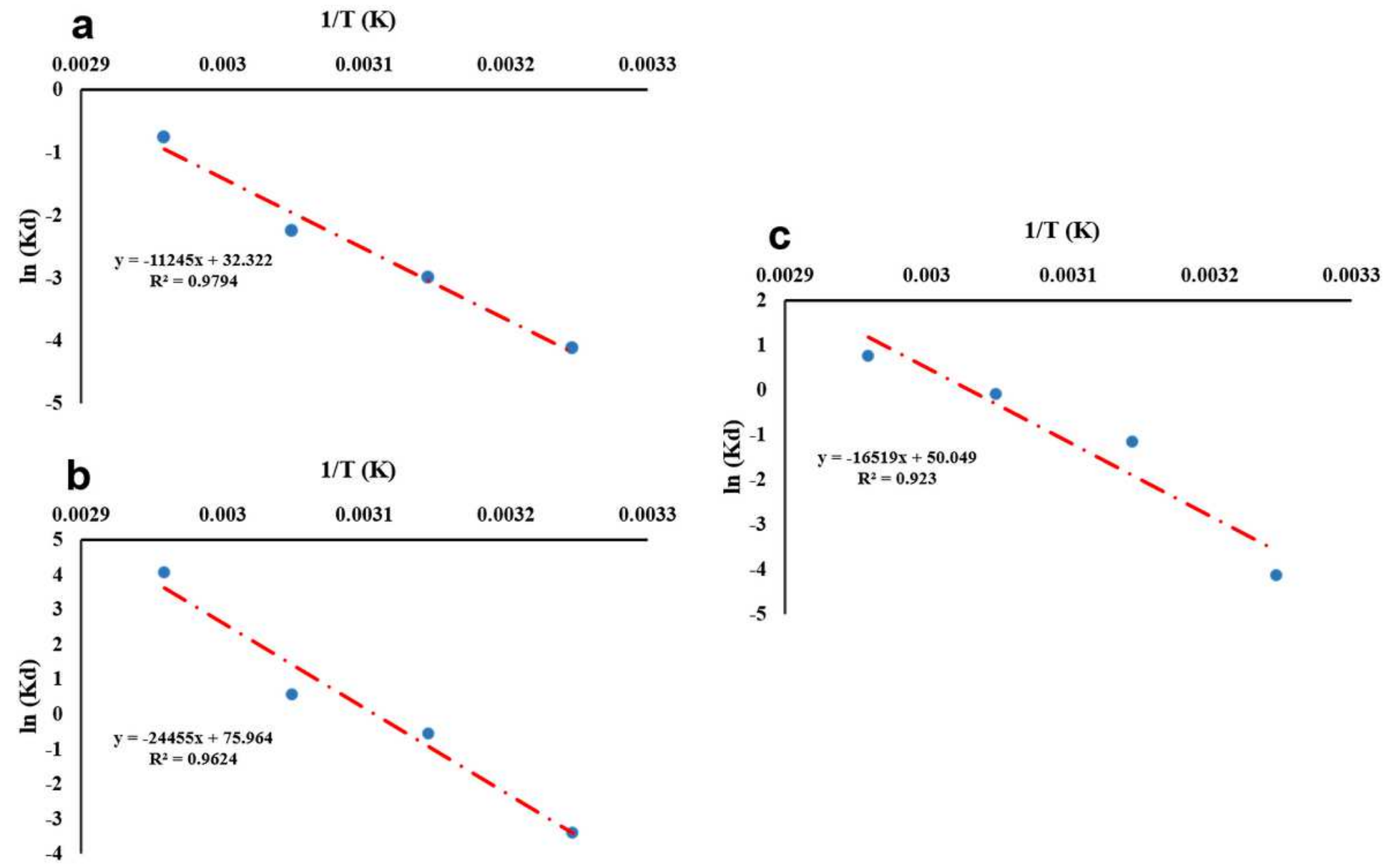

\section{Figure 7}

Plot of $\ln (\mathrm{Kd})$ versus $1 / \mathrm{T}$ for the adsorption of $\mathrm{Fe}(\mathrm{II})$ on activated bentonite clay under (a) IBM, (b) UBM$25 \mathrm{kHz}$, and (c) UBM-40 kHz. IBM; industrial bleaching method, UBM; ultrasonic bleaching method. 

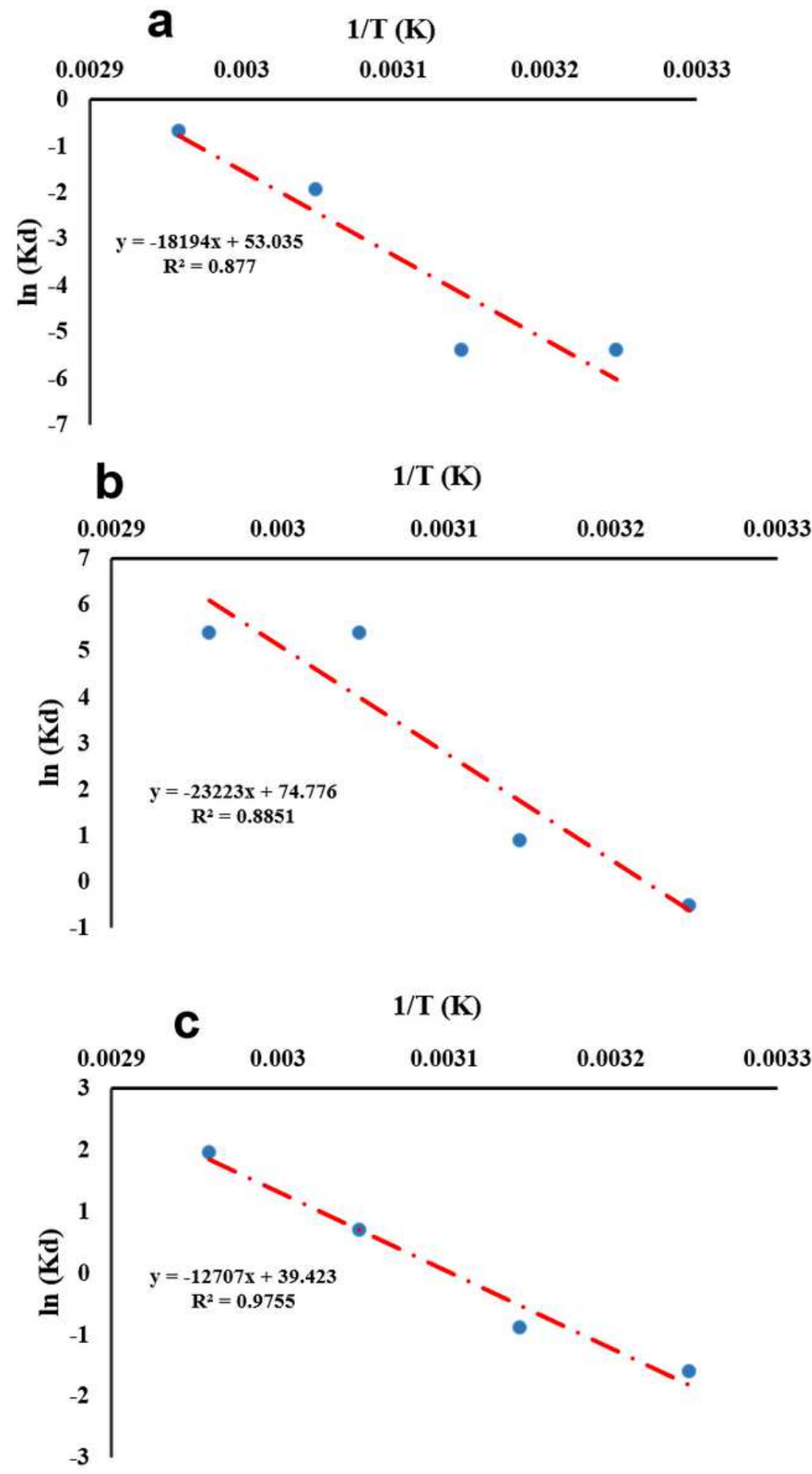

Figure 8

Plot of $\ln (\mathrm{Kd})$ versus $1 / T$ for the adsorption of $\mathrm{Cu}$ (II) on activated bentonite clay under (a) IBM, (b) UBM$25 \mathrm{kHz}$, and (c) UBM-40 kHz. IBM; industrial bleaching method, UBM; ultrasonic bleaching method. 


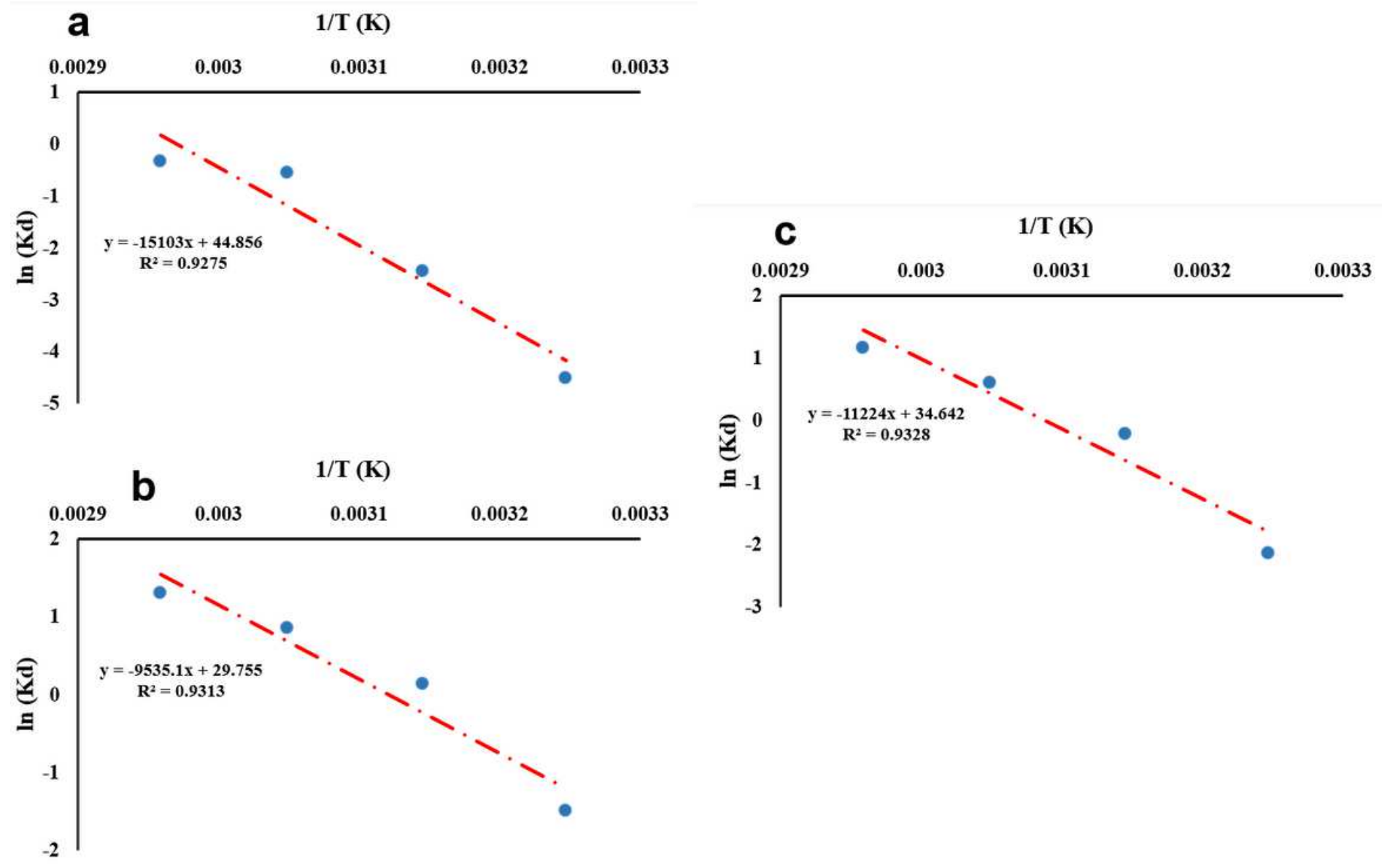

Figure 9

Plot of $\ln (K d)$ versus $1 / T$ for the adsorption of carotenoid on activated bentonite clay under (a) IBM, (b) UBM-25 kHz, and (c) UBM-40 kHz. IBM; industrial bleaching method, UBM; ultrasonic bleaching method. 

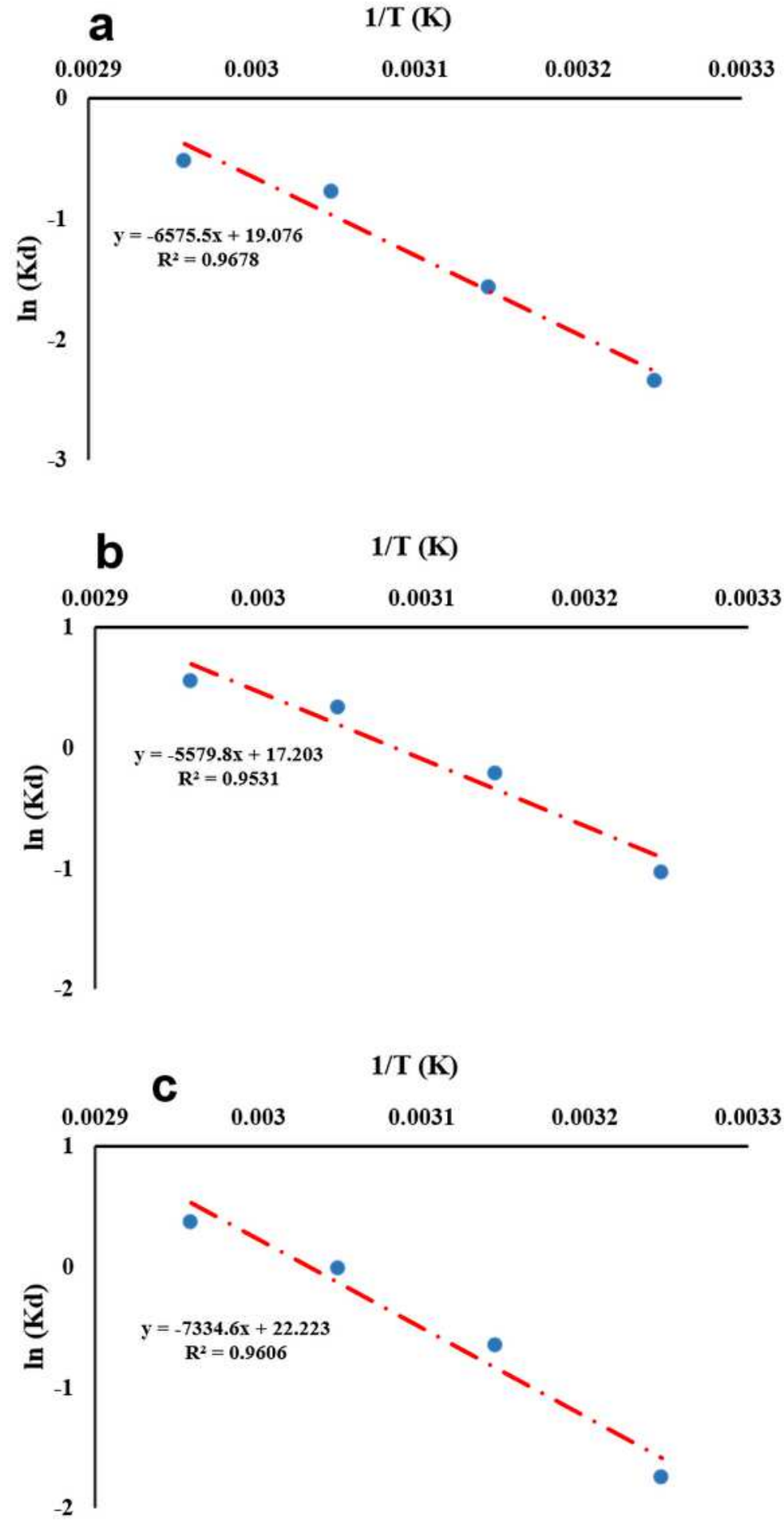

Figure 10

Plot of $\ln (\mathrm{Kd})$ versus $1 / T$ for the adsorption of chlorophyll on activated bentonite clay under (a) IBM, (b) UBM-25 kHz, and (c) UBM-40 kHz. IBM; industrial bleaching method, UBM; ultrasonic bleaching method. 